Relating deformation fabrics to multiple metamorphic events preserved in metapelites of the Belt-Purcell supergroup in the Snow Peak area of northern Idaho

\author{
Kacey Jo Largent \\ West Virginia University
}

Follow this and additional works at: https://researchrepository.wvu.edu/etd

\footnotetext{
Recommended Citation

Largent, Kacey Jo, "Relating deformation fabrics to multiple metamorphic events preserved in metapelites of the Belt-Purcell supergroup in the Snow Peak area of northern Idaho" (2014). Graduate Theses, Dissertations, and Problem Reports. 330.

https://researchrepository.wvu.edu/etd/330

This Thesis is protected by copyright and/or related rights. It has been brought to you by the The Research Repository @ WVU with permission from the rights-holder(s). You are free to use this Thesis in any way that is permitted by the copyright and related rights legislation that applies to your use. For other uses you must obtain permission from the rights-holder(s) directly, unless additional rights are indicated by a Creative Commons license in the record and/ or on the work itself. This Thesis has been accepted for inclusion in WVU Graduate Theses, Dissertations, and Problem Reports collection by an authorized administrator of The Research Repository @ WVU. For more information, please contact researchrepository@mail.wvu.edu.
} 


\title{
RELATING DEFORMATION FABRICS TO MULTIPLE METAMORPHIC EVENTS PRESERVED IN METAPELITES OF THE BELT-PURCELL SUPERGROUP IN THE SNOW PEAK AREA OF NORTHERN IDAHO
}

\author{
Kacey Jo Largent \\ Thesis submitted \\ to the Eberly College of Arts and Science \\ At West Virginia University
}

In partial fulfillment of the requirements for the degree of

Master of Science in

Geology

\author{
Helen Lang, Ph.D., Chair \\ Jaime Toro, Ph.D. \\ Shikha Sharma, Ph.D. \\ Department of Geology and Geography
}

Morgantown, West Virginia

2014

Keywords: metamorphic petrology, polymetamorphism, micro-structure, northern Idaho, garnet zoning

Copyright 2014 Kacey Largent 


\title{
Abstract \\ Relating deformation fabrics to multiple metamorphic events preserved in metapelites of the Belt-Purcell Supergroup in the Snow Peak area of northern Idaho.
}

\author{
Kacey Largent
}

Previous work has shown that two significant metamorphic/deformation events (M1/D1 and M2/D2) affected the metapelites of the upper Wallace Formation in the Snow Peak area of northern Idaho. This study's goal was to distinguish the effects of the two metamorphic and deformation events by studying garnet growth and structural fabrics preserved in the metapelites in the Snow Peak area. All the samples within the M1/D1 affected area have the earlier foliation (S1) as the dominant matrix foliation. S1 in these samples was overprinted by $\mathrm{S} 2$ which is defined by a crenulation cleavage and/or sheared strain shadows around porphyroblasts that did not transpose S1. Garnet zoning in these samples shows that an abrupt increase in Ca in garnet separates M1 and M2 growth and the majority of garnet growth occurred during the M1/D1 event. The high-Ca boundary is marked by a ring of coarse-grained quartz inclusions. The proportion of M2 garnet growth increases with metamorphic grade towards the southwest and garnet ages reflect this. Garnets with more M2 growth have younger ages and garnets with minimal M2 growth are the oldest. The oldest dated garnet in the area is located in the garnet zone in the far eastern portion of the study area and is dated at $~ 1314$ Ma. This is the best estimate of the age of the M1/D1 event. The youngest sample is located in the northwestern portion of the map, furthest from the M1 relict isograd and is dated at $\sim 1085 \mathrm{Ma}$. This sample shows no signs of polymetamorphism and has a different matrix foliation orientation than the other samples. It was determined that this sample's dominant foliation is S2 and that it was only affected by the M2/D2 event. Garnet growth for this sample occurred entirely during M2. 


\section{TABLE OF CONTENTS}

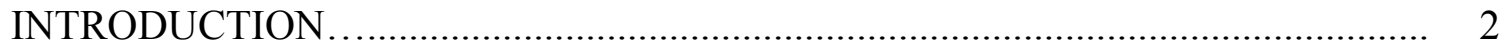

\section{REGIONAL SETTING}

Geologic Background......................................................... 3

Metamorphism and mineral assemblages.......................................... 5

Rock Deformation and textures.............................................. 7

METHODOLOGIES

Sample Selection ............................................................ 8

Electron Microprobe Analysis ...................................... 9

SAMPLE DESCRIPTIONS .............................................. 10

Snow Peak

08 TN-80a ................................................... 11

09 HL-09........................................................ 13

09 HL-10b....................................................... 15

08 TN-124B....................................................... 17

09 HL-01a........................................................ 20

09 HL-07 ......................................................... 22

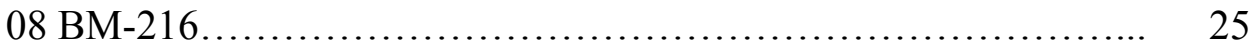

09 HL-22a ..................................................... 27

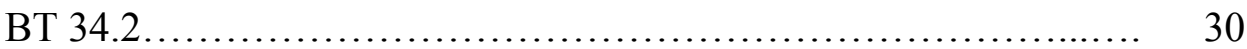

09 HL-04b.................................................... 32

Clarkia

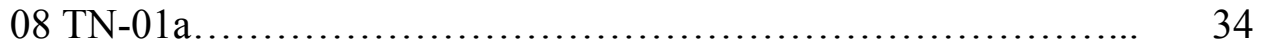

08 HL-04.................................................... 36

RESULTS

Structural Results.................................................................. 39

Garnet Textures and Garnet Zoning.................................... 42

DISCUSSION .................................................................. 45

CONCLUSIONS.................................................................. 49

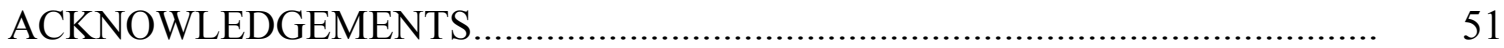

REFERENCES........................................................... 52 


\section{Introduction}

During the 1960s Anna Hietanen mapped a large area of northern Idaho underlain by metapelites of the Precambrian Belt-Purcell Supergroup (Hietanen, 1963 a,b,c, 1967, 1968) Hietanen noted that the metamorphic grade increased southwestward toward the Idaho Batholith and that there were signs of two episodes of recrystallization that occurred during separate metamorphic events (Hietanen 1968). She backed this theory with the presence of pseudomorphs and the coexistence of the three aluminum-silicate polymorphs found near Boehls Butte (Fig. 1; Hietanen, 1957). Lang and Rice (1985) also described relict fabrics preserved in the rocks suggesting at least two episodes of metamorphism, and estimated pressures and temperatures for the later metamorphic event (M2). The calculated temperatures range between $470^{\circ} \mathrm{C}$ and $560^{\circ} \mathrm{C}$ with pressures estimated around 6 kbar (Lang and Rice, 1985c). They described the earlier metamorphic event as producing a strong foliation and the later as a static event possibly associated with intrusion of the Idaho Batholith during the Cretaceous (Hietanen, 1957, 1963b, 1968; Lang and Rice, 1985). However, new technologies developed for dating metamorphic minerals, in this case garnets, have revealed Mesoproterozoic garnet ages ranging from $1085 \pm 2.4$ to $1314 \pm 1.4 \mathrm{Ma}$ (Zirakparvar et al. 2010, Nesheim, 2009).

The recognition of the much older metamorphic ages generated renewed interest in the area and led our team of collaborators to reevaluate past geologic events. Recent detailed structural and chemical studies have tried to determine the extent of deformation 
for the two metamorphic events in light of these new discoveries (Nesheim et al. 2009; Lang et al. 2010; Flagg et al. 2010; Nesheim et al. 2010b; Nesheim et al. 2011). This project focuses on garnet textures, compositional zoning, and the multiple deformation patterns preserved in samples in the Snow Peak area (Fig. 2) produced by changing metamorphic conditions that were accompanied by multiple deformational events. Selected samples from throughout the Snow Peak area were chosen because they have been dated by collaborators and also cover the range of different metamorphic grades across the area. Thin sections of these samples were analyzed optically and semiquantitative compositional maps of garnet were collected by an electron microprobe in order to distinguish overprinted fabrics and relate deformation to metamorphic mineral growth. I was able to identify deformation fabrics and correlate them with metamorphic mineral growth during the two separate events.

My results are compared with results from other related studies (Nesheim, 2009; Nesheim, 2012 et al.) in the surrounding area in order to help interpret the relationship between metamorphism and deformation on a regional scale. I have also chosen two samples from the Clarkia area (Fig. 3) that I will analyze in the same manner as my samples from the Snow Peak study area to use for comparison with the results of Nesheim et al. (2012).

\section{Regional Setting}

\section{Geologic Background}


The Belt-Purcell Supergroup is made up of predominately continental sediments deposited in the Belt-Purcell basin between approximately 1470 and $1380 \mathrm{Ma}$ (Zirakparvar et al., 2010). Figure 1 is a geologic map of northern Idaho based on Hietanen's mapping in 1956 and later mapping by Lewis and collaborators at the Idaho Geological Survey (Lewis, et al., 2007). In this area of northern Idaho the fine grained clastic rocks that make up the Belt-Purcell Supergroup are shown in blues and browns. The Snow Peak study area (Fig. 2) is underlain mainly by the Wallace Formation. Anna Hietanen (1968) separated the Wallace Formation into an upper schist unit and a lower quartzite unit. The schist unit, shown in light blue in Figure 2, is the main focus of this study. The upper Wallace unit contains amphibolite facies metamorphic rocks, originally argillaceous sedimentary rocks that form key index minerals according to metamorphic grade. Hietanen (1968) and Lang and Rice (1985c) mapped and described five metamorphic zones, biotite, garnet, staurolite, kyanite/staurolite, and kyanite preserved in the Upper Wallace metapelites of the Snow Peak area (Fig. 2). Figure 2 shows isograds in the Upper Wallace separating it into metamorphic zones based on the first appearance of a new metamorphic mineral. The middle and lower Wallace, shown in teal blue in Figure 2 , is a quartzite unit of little importance to this study, because it lacks the chemical composition needed to produce index minerals used to track the metamorphic events and deformation phases. The other units in the area are composed of pre-Belt basement rocks 
shown in red and gray on Figure 2, and post-Belt units shown in pinks and yellows which include the Cretaceous/Tertiary Intrusions associated with the Idaho Batholith (Fig. 1).

\section{Metamorphism and mineral assemblages}

The upper Wallace unit in the Snow Peak area (Fig. 2) shows evidence of two distinguishable metamorphic events labeled M1 and M2 (Hietanen, 1968, Lang \& Rice, 1985c). The metamorphic grade for M1 increased southward leaving behind large porphyroblastic minerals in the rock fabric (Fig. 2; Lang and Rice, 1985c). Although the M1 mineral assemblage has been overprinted by later events, evidence of M1 minerals has been preserved in pseudomorphs found only south of the relict M1 isograd shown as a black dashed line in Figure 2 (Lang \& Rice, 1985c). Figure 4 shows a photomicrograph of a pseudomorph taken from sample 09HL02a that is made up of large, randomly arranged grains of muscovite. It is thought that this used to be a staurolite even though none of the parent mineral remains, because the shape is similar to staurolite porphyroblasts. Some of the pseudomorphs still have parent minerals remaining in their interiors or have the morphology of the parent mineral preserved (Lang and Rice, 1985c). Evidence for the M1event has also been preserved in the rock's fabric and inside of large porphyroblastic minerals such as garnets as will be described below.

The metamorphic grade for M2 increases southwestward, superimposing on the M1 metamorphic effects, and leaving isograds nearly perpendicular to the relict M1 isograd (Fig. 2; Hietanen, 1968; Lang and Rice, 1985c). Lang and Rice (1985c) described the M2 
episode as a static event that did not produce a strong penetrative foliation. This is evident by the randomly aligned grains of micas preserved in M1 pseudomorphs which lack evidence of penetrative deformation. More recent studies have found that M2 was not a static metamorphic event and document a penetrative M2 fabric that correlates between the Snow Peak and Clarkia areas (Nesheim, 2009). Retrograde metamorphism occurred subsequent to M2 but had minimal effects on the M2 mineral assemblage. M2 is responsible for the mineral assemblages presently observed in the rocks that vary from chlorite-biotite to kyanite grade (Fig. 2), formed at temperatures that ranged from approximately $470^{\circ} \mathrm{C}$ to $560^{\circ} \mathrm{C}$ and pressures around $\sim 6 \mathrm{kbars}$ (Lang \& Rice, $1985 \mathrm{~b}$ ).

The metamorphic zones garnet, staurolite, staurolite/kyanite, and kyanite mapped in Figure 2 are bounded by isograds marking the first appearance of these index minerals. The metamorphic assemblage in the lowest grade rocks in the north consists of biotite, chlorite, muscovite, quartz, plagioclase, ilmenite, and graphite. Garnet is the first porphyroblastic mineral to appear (Lang and Rice, 1985a). Growth of the garnet was interpreted by Hietanen (1968) as post-kinematic in the garnet zone north of the relict isograd because it overgrows the foliated matrix. The next isograd marks the appearance of staurolite (Fig. 2). The matrix curves around the garnet and staurolite within the staurolite zone, so growth is considered pre/syn-kinematic. Staurolite pseudomorphs replaced by muscovite and chlorite south of the relict isograd are common, and recrystallization of staurolite occurred mainly after deformation ceased (Hietanen, 1968). 
The kyanite/staurolite zone shows evidence for syn/post-kinematic growth of staurolite along with kyanite, and in this zone the second episode was at a higher temperature than the first (Hietanen, 1968). Evidence of the first generation of staurolite still exists in some pseudomorphs, but in others it was completely replaced. This is indicated by second generation staurolite nucleated randomly around pseudomorphs (Fig. 4). The matrix curves around the garnets indicating pre/syn-kinematic growth. The garnets in the kyanite/staurolite zone also have distinct inclusion rich rims that have a high $\mathrm{Ca}$ concentration relative to the cores. Further to the southwest, chlorite and then staurolite disappear (Lang \& Rice, 1985c), the highest grade assemblage is kyanite, garnet, biotite, muscovite, quartz, ilmenite, plagioclase, and graphite (Lang and Rice, 1985c).

\section{Rock Deformation and textures}

I identified planar S-surfaces in my samples and determined the relationship of metamorphic mineral growth, especially garnet, to the different deformation phases. I used techniques adopted from Passchier and Trouw (2005) to describe the planar fabrics. I observed three planar foliations, $\mathrm{S}_{0}, \mathrm{~S}_{1}$, and $\mathrm{S}_{2}$, in the selected samples. $\mathrm{S}_{0}$ is the original depositional layering still evident in low grade metamorphic samples. Low grade metamorphism associated with compaction upon burial parallel to depositional layering has been identified (Nesheim, 2009), but is hard to distinguish from $S_{0}$. $S_{0} / S_{1}$ is when compositional layering associated with deposition is parallel to the $S_{1}$ foliation. $S_{1}$ fabric was produced by the earlier metamorphic event (M1) which was contemporaneous with 
the initial phase of deformation (D1). $\mathrm{S}_{1}$ is a penetrative fabric with an elongation of matrix minerals (mainly micas) parallel to foliation and the growth of M1 porphyroblasts concurrent with D1 (Lang and Rice, 1985c; Nesheim, 2009). Evidence of M1 porphyroblasts has been preserved in pseudomorphs. $\mathrm{S}_{2}$ is concurrent with the later metamorphic event M2 and the second deformation phase D2. M2 is responsible for the current mineral assemblage in the study area. $\mathrm{S}_{2}$ displays parallel elongation of higher grade M2 minerals such as kyanite and is commonly oblique to $S_{1}$. Other general descriptions for foliations that will be used are $\mathrm{S}_{\mathrm{e}}$ for foliations external to porphyroblasts, $S_{i}$ for foliations found inside of porphyroblasts, and $S_{D}$ to symbolize a rocks dominant matrix foliation.

\section{Methodologies}

\section{Sample selection}

I participated in sample collection in the Snow Peak study area during the summer of 2009. Other samples used in this study were collected by Helen Lang and by collaborators Timothy Nesheim and Bill McClelland in summer 2008. Table 1 shows a list of the samples selected for this study arranged in order of increasing metamorphic grade. The samples in the Snow Peak area were selected in order to cover each metamorphic zone. They also include samples that were also used by collaborators for structural interpretation and Lu-Hf dating of garnets (Nesheim 2009; Nesheim et al. 2010; Zirakparvar et al., 2010; Nesheim et al. 2012). Figure 2 shows the locations of 
samples in Table 1 in the study area. Three additional samples from west of Clarkia (Fig. 1 and 3) were chosen to compare with the textures from samples in the Snow Peak area. These three particular samples were chosen because they had already been dated and interpreted structurally by Nesheim (2009).

\section{Electron Microprobe Analysis}

Polished thin sections from all the samples in Table 1 were made to be used for electron microprobe analysis. The samples were analyzed using standard techniques on the Cameca SX-100 electron microprobe in the Department of Earth and Environmental Sciences at Rensselaer Polytechnic Institute in Troy, New York. For each sample I obtained compositional point analyses of all the key metamorphic minerals present ( $\mathrm{Pl}$, Chl, Ms, Bt, Grt, St, Ky; abbreviations according to Kretz, 1983). Semi-quantitative x-ray maps of garnet with accompanying point analyses and traverses were also obtained from each sample. For $\mathrm{x}$-ray maps the microprobe was calibrated to collect $\mathrm{x}$-ray counts for elements $\mathrm{Mn}, \mathrm{Ca}, \mathrm{Fe}$, and $\mathrm{Mg}$ continuously in a raster pattern with constant spacing over a selected area of the polished section. We used the data from the maps to produce false color images of the garnets that show changes in elemental concentrations from core to rim. The warmer colors represent higher concentrations and the cooler colors represent lower concentrations (Fig. 38). The data was processed using the image analysis program Image (Rasband, 1997-2012). The garnet formula is (Ca, $\mathrm{Mg}, \mathrm{Fe}, \mathrm{Mn})_{3} \mathrm{Al}_{2} \mathrm{Si}_{3} \mathrm{O}_{12}$, and zoning in $\mathrm{Ca}, \mathrm{Mn}, \mathrm{Mg}$, and $\mathrm{Fe}$ is preserved in metamorphic garnets. High resolution 
traverses across some of the mapped garnets were set up so that we had quantitative garnet analyses, the results of which detect subtle changes in compositional zoning. Garnet zoning is related to $\mathrm{P} / \mathrm{T}$ conditions during growth.

\section{Garnet Textures and Garnet Zoning}

Garnet porphyroblasts are useful for examining metamorphic histories of pelites, because they are refractory minerals and once formed are not easily modified. This enables them to preserve textures and compositional zoning that give insight into past deformation and metamorphic phases. Garnets were analyzed optically to identify internal foliations and other textures recorded by mineral inclusions of different mineralogy, size, and shape. I have examined garnets in these samples using the petrographic microscope and have use the electron microprobe to produce semiquantitative maps showing distribution of garnet components in the porphyroblasts. I have examined the results to find possible correlations between patterns in inclusions and compositional zoning of garnets to help interpret the metamorphic history.

\section{Sample Descriptions}

Thirteen samples were selected, 10 from the Snow Peak area and 3 from near Clarkia (Fig. 1), for in depth analysis of the metamorphic fabrics. These samples were collected in order to cover each metamorphic zone and include most dated samples. Table 1 shows a list of the samples in order of M2 metamorphic grade, which increases from the northeast to southwest in the Snow Peak area (Fig. 2). Characterization of the growth 
textures and compositional zoning of the garnets is one of the main focuses of this study. In each sample x-ray element maps of $\mathrm{Mn}, \mathrm{Ca}, \mathrm{Fe}, \mathrm{Mg}$ of at least one garnet has been produced by an electron microprobe and the deformational fabrics have been described based on techniques explained by Passchier and Trouw (2005). Using techniques described above, the following is a detailed description of the fabrics and textures related to metamorphic mineral growth for the thirteen samples.

\section{$\underline{\text { Snow Peak }}$}

\section{$\underline{\text { 08TN80a }}$}

Sample 08TN80a was collected from the northern edge of the M2 garnet zone, approximately one kilometer north of the staurolite isograd (Fig. 2). This sample is a low grade, fine grained schist with the original bedding surfaces from deposition still intact. The mineral assemblage is graphite, ilmenite, muscovite, biotite, quartz and garnet with minor plagioclase. It has undergone low grade metamorphism and displays parallel elongation of micas, quartz, ilmenite, and dusty graphite trails in the matrix (Fig. 5), forming a secondary foliation oblique to compositional layering, identified as original bedding surfaces, the primary foliation. Few biotite crystals are aligned with muscovite in the matrix, while most are coarser grained, equant crystals that have no preferred orientation, suggesting mineral growth was post-kinematic. The sample has small garnets peppered throughout (Fig. 5). The garnets range in size from approximately $0.5 \mathrm{~mm}$ to 1 $\mathrm{mm}$ in diameter. Garnet growth cross-cuts the matrix fabric and has very little effect on 
the alignment of the adjacent matrix minerals (Fig. 6). This indicates that the garnet growth was syn or post-kinematic.

False color images of garnet components for 08TN80a do not show abrupt changes in composition from core to rim (Fig. 7). The Mn concentration is the highest in the center and decreases to lower concentrations on the rim (Fig. 7a), which is a typical pattern for Mn zoning in garnets in which Mn is preferentially incorporated in the cores of growing garnets. There is a zone with an abrupt decrease in Mn concentration very near the rim. The Ca concentration (Fig. 7b) is relatively uniform throughout the entire garnet, although it is slightly higher in the core. There is a zone with a slight, but abrupt dip in Ca concentration near the rim. The abrupt low Ca rim does mimic the very low $\mathrm{Mn}$ rim in Fig 7a. The Fe map shows low and uniform concentration in the core, gradually becoming more iron-rich toward the rim (Fig. 7c). The Mg concentration is mostly uniform throughout the garnet, showing only a slight decrease right at the rim (Fig. 7d). This garnet provides no evidence of multiple episodes of garnet growth in its zoning patterns, but suggests a slight possibility of change in metamorphic conditions at the rim.

The lack of evidence of polymetamorphism in this sample suggests it was mostly affected by one metamorphic event. Based on the fact that it is far north of the M1 relict isograd and has been mapped in the garnet zone by Lang and Rice 1985c for the most recent metamorphic event, M2, it was determined that this sample was mainly affected by the M2 event. That means M2 is responsible for the metamorphic assemblage and the 
main matrix foliation is $\mathrm{S}_{2}$ produced by D2. The fact that inclusions inside of the garnet are aligned with the matrix foliation $\mathrm{S}_{2}$ (Fig. 6) is evidence that garnet growth happened in one episode, M2, after the fabric was already formed. That means there was no garnet growth in this sample during M1. The original bedding planes formed during deposition are still present as compositional layers and are labeled $\mathrm{S}_{0}$ (Fig. 5). The compositional layering represents bedding planes because it is planar with varying thicknesses and sedimentary structures such as graded bedding have been identified (Nesheim, 2009; Passchier \& Trouw, 2005). The M1 event must have had very little effect, if any at all, on this and adjacent samples.

\section{HL09}

Sample 09HL09 was collected in the garnet zone approximately $3.5 \mathrm{~km}$ east of the staurolite isograd and $25 \mathrm{~km}$ southeast of sample 08TN80a in the east-central part of the Snow Peak study area (Fig. 2). Unlike 08TN80a, this sample is located south of the M1 relict isograd. The mineral assemblage is graphite, ilmenite, chlorite, muscovite, biotite, quartz, and garnet. This sample has undergone low grade metamorphism and the fabric consists of parallel alignment of micas, quartz, and ilmenite. It is made up of interbedded layers of two different compositions. One type of the layers consists of coarser grained quartz and biotite while the other type consists of finer grained muscovite, graphite, and ilmenite. The garnets, which are more common in the muscovite rich layers (Fig. 8) comprise approximately 5-10\% of the sample and range in size from 
0.2 to $1.0 \mathrm{~mm}$. The matrix foliation adjacent to the garnets is draped around them, indicating that garnet growth was pre-syn-kinematic (Fig. 9). There are no pseudomorphs present in this sample even though it is located south of the M1 relict isograd.

False color images of the analyzed garnet in sample 09HL09 do not show dramatic zoning in any of the main compositional elements (Fig 10). The Fe and Mg concentrations are nearly constant from core to rim (Fig 10c, d). The Mn concentration is typical of garnet growth, with higher concentrations in the core decreasing to lower concentrations at the rim (Fig. 10a). The Ca concentration is lower in the core and increases closer to the rim. There are oscillating zones of high and low Ca near the rim that are very faint. There are a few very distinctive patches of high Ca concentration on the outermost edge of the rim (Fig. 10b; see arrows pointing to red-yellow patches at upper left and lower right). The relatively uniform concentrations in the interior followed by a sudden sharp increase in $\mathrm{Ca}$ at the very edge of the rim suggest a small amount of garnet growth during the later metamorphic episode. Low $\mathrm{Mn}$, low $\mathrm{Ca}$, and high $\mathrm{Mg}$ bands with no change in Fe are observed across the upper right and lower corners part of the garnet (Fig. 10a, b, c). It is a small, well defined zone where Mn and Ca decrease and the Mg increases. These zones are coincident with cracks in the garnet (Fig. 9) which may explain their origin.

There are definite signs of polymetamorphism in this sample, such as the abrupt increase of $\mathrm{Ca}$ at the garnets rim and the two foliations, $\mathrm{S}_{1}$ and $\mathrm{S}_{2}$, identified. $\mathrm{S}_{1}$ is parallel 
to compositional layering of the sample and defines the main matrix foliation (Fig. 8, 9). Garnets grew over this $\mathrm{S}_{1}$ preferred orientation of elongate quartz crystals, preserving them as elongate inclusions in the garnet core (Fig. 9). $\mathrm{S}_{2}$ is a crenulation foliation oblique to the compositional layering highlighted by fold hinges in the matrix minerals (Fig. 8, 9). Evidence that the majority of garnet growth happened during M1 is supported by the Ca garnet map showing an abrupt increase in concentration in a very narrow zone at the outermost edge of the garnet (Fig. 10b). This high Ca zone must define a separate episode of garnet growth at different conditions. Therefore the majority garnet growth occurred during the $\mathrm{M} 1$ event, preserving $\mathrm{S}_{1}$, which was formed by the deformation phase, D1, in the core and matrix. M2 is responsible for the growth of the small, but distinct high $\mathrm{Ca}$ rims, and the crenulation foliation are considered to be $\mathrm{S}_{2}$ formed during the later deformation event D2.

\section{$\underline{\text { 09HL10b }}$}

Sample 09HL10b is located in the center of the Snow Peak area in the staurolite zone a little over one kilometer south of the relict M1 isograd (Fig. 2). This sample has undergone medium grade metamorphism, and the mineral assemblage is ilmenite, chlorite, muscovite, biotite, quartz, and garnet with minor traces of plagioclase and graphite. Staurolite is not present in this sample, but there is a fine grain pseudomorph that is thought to have originally been staurolite (Fig. 11). The shape of the pseudomorph resembles a staurolite porphyroblast and the interior has a poikiloblastic texture 
characteristic of staurolite. Staurolite in the interior of the pseudomorph has been mostly replaced by retrograde sericite except for a few garnet porphyroblasts and quartz rich compositional layers aligned with the matrix foliation (Fig. 11). The pseudomorph rim has an inner layer of coarse-grained, randomly aligned muscovite and an outer layer of coarse-grained biotite that is aligned with the matrix foliation. Parallel alignment of micas, quartz and ilmenite define the matrix foliation. Biotite porphyroblasts in the matrix are oriented both with the matrix and randomly meaning growth was both synand post-kinematic (Fig. 11, 12). Garnets comprise about $5 \%$ of this sample and range in size from 0.5 to $2.0 \mathrm{~mm}$. Many of the garnet rims have been partially replaced by chlorite attributed to retrograde metamorphism, which is also responsible for the sericite pseudomorph after M2 staurolite. The foliation is folded around the garnet porphyroblasts, so garnet growth must have been pre- and syn-kinematic. The matrix foliation is also deformed around the sericite pseudomorph (Fig. 11).

The false colored images of the different elements in garnet for this sample show a few signs of polymetamorphism. Mn has a higher concentration in the garnet core, and gradually decreases toward the rim (Fig. 13a). However, at the edge of the rim there is an increase in Mn, which is not typical growth zoning of Mn in garnet. This may indicate garnet consumption late in the metamorphic history. The interior of the Ca map (Fig. 13b) shows that the core has low and uniform $\mathrm{Ca}$, with an abrupt increase followed by a gradual decrease, and then another zone of increasing Ca near the rim. At the very edge 
of parts of the rim there is an abrupt change to much higher Ca concentrations (Fig. 13b; arrow pointing to red at lower left, upper left and right). The high $\mathrm{Ca}$ parts on the rim coincide with high Mn parts of the rim. Both the Fe map and the Mg map show relatively uniform concentrations across the entire garnet (Fig. 13c, d).

There are a few signs of polymetamorphism in this sample. The increase in $\mathrm{Ca}$ mid-way through the garnet suggests a change in metamorphic conditions, but the more significant increase in $\mathrm{Ca}$ concentrations at the outermost edge of the rim is most likely the result of a separate metamorphic event. The dominant foliation in this sample is defined by the alignment of matrix minerals, but the presence of slight crenulation folds means that a later foliation was superimposed on this dominant matrix foliation. The quartz inclusions inside of the garnet porphyroblasts are mostly aligned parallel to the matrix foliation (Fig. 12, Fig. 13d) as well as to the quartz rich layer in the pseudomorph (Fig. 11). This suggests that garnets grew during the earlier metamorphic event, M1, preserving the earlier foliation, $\mathrm{S}_{1}$, as elongated quartz inclusions. The superimposed crenulation foliation was likely formed by the most recent deformation phase, D2, and is labeled $\mathrm{S}_{2}$ (Fig. 11, 12). The outer most edge of the garnet with the high Ca content (Fig. 13b) marks a separate, more recent metamorphic event, M2.

\section{$\underline{08 T N-124 b}$}

$08 \mathrm{TN}-124 \mathrm{~b}$ is located in the middle of the staurolite zone approximately $1 \mathrm{~km}$ above the relict staurolite isograd and 3km northwest of sample 09HL10b (Figure 2). The 
mineral assemblage is graphite, ilmenite, chlorite, muscovite, biotite, quartz, and garnet with minor plagioclase and tourmaline. The matrix foliation is defined by the parallel alignment of elongated quartz, muscovite, biotite, graphite, and ilmenite. There are biotite rich layers, quartz rich layers, and graphitic muscovite layers interbedded throughout the sample. There are a few randomly oriented biotite crystals suggesting some growth was post-kinematic. This sample contains about $10 \%$ idioblastic garnets ranging from 0.5 to $2.5 \mathrm{~mm}$ in diameter. The matrix foliation wraps around the garnets (Fig. 14) indicating garnet growth was pre-syn kinematic (Passchier \& Trouw, 2005). Plagioclase is found mainly in garnet pressure shadows, and tourmaline is found throughout the matrix. There are no staurolite porphyroblasts in this sample.

The maps showing the concentration of chemical components of garnet (Fig.15) show definite signs of multiple episodes of garnet growth. The Mn map shows higher Mn concentration in the center gradually decreasing to lower concentration at the rim (Fig. 15a). Diffusion adjacent to the cracks in this garnet has significantly lowered Mn concentration (Fig. 15a). Note that diffusion adjacent to the cracks in this garnet did not affect $\mathrm{Ca}$ or $\mathrm{Mg}$ concentrations and only a minor effect on Fe as it did Mn. The Ca map shows an oscillatory pattern of idioblastic, concentric zones with sharp boundaries between higher and lower concentrations (Fig. 15b). Ca starts out low, gets a little higher, goes back to low, higher, low, even higher yet, then slightly lower again before there is a abrupt increase to high $\mathrm{Ca}$ at the very edge of the rim (Fig. 15b). The Fe and Mg maps 
show fairly uniform concentrations across the entire garnet except near the rim $\mathrm{Fe}$ increases slightly and at the very edge of the garnet, Fe and $\mathrm{Mg}$ both decrease at the same location as the high $\mathrm{Ca}$ rim (Fig. $15 \mathrm{c}, \mathrm{d})$.

This sample shows signs of polymetamorphism not only in the garnet maps but in the fabric as well. There are two foliations in this sample. The dominant foliation is marked by the parallel alignment of the matrix minerals, which is parallel to compositional layering in the sample (Fig. 14b). The other is a slight crenulation foliation superimposed on the matrix foliation. The crenulation foliation must have formed during the later deformation phase D2, and is thus labeled $\mathrm{S}_{2}$ (Fig. 14). The matrix foliation formation must have formed during the earlier deformation phase D1 and is labeled $\mathrm{S}_{1}$. This is also when most of the garnet growth in this sample took place, during M1. The oscillatory high and low Ca concentrations' in garnets (Fig. 15b) represent small changes in grossular content, and most likely mark small, but abrupt changes in pressure or temperature during M1. The sudden increase of $\mathrm{Ca}$ at the rim represents growth attributed to the later metamorphic event M2 (Fig. 15b). There are few inclusions inside of garnets in this sample to allow a determination of an internal foliation, but garnets in sample 08TN125 (Fig. 14c) collected less than a mile northeast of 08TN124, clearly have an internal foliation parallel to $S_{1}$ (Fig. 14c). This further supports that the majority of garnet growth occurred during M1.

\section{HL01}


This sample was collected in the high grade part of the staurolite zone, adjacent to the kyanite isograd in the center of the study area (Fig. 2). The mineral assemblage is graphite, ilmenite, chlorite, muscovite, biotite, quartz, garnet, and staurolite. This sample has undergone moderate grade metamorphism, and shows parallel elongations of the matrix minerals in one preferred orientation. Coarser grained, quartz-rich layers and finer grained muscovite-rich layers that contain abundant graphite are interbedded in the sample. The chlorite appears to be primarily the result of retrograde metamorphism, because it occurs in the rims and strain shadows of garnet. Both coarse and fine grained muscovite occurs in this sample. The fine grained crystals are aligned parallel to foliation of the matrix, and coarse grain crystals are randomly oriented in a staurolite pseudomorph (Fig. 17). The biotite crystals are both elongated parallel to the matrix and randomly oriented throughout the sample. Garnets comprise about $15 \%$ the sample and range in diameter from approximately 0.5 to $3.0 \mathrm{~mm}$. The larger garnets have a zone rich in quartz inclusions, which suggests a change in garnet growth rate and in metamorphic conditions (Fig. 16). Staurolite in this sample is partially replaced by coarse-grained, randomlyoriented muscovite and chlorite in pseudomorphic rims (Fig. 17). The portion of the pseudomorphic rim directly adjacent to the staurolite is fine grained sericite with some chlorite, and the outer rim is coarse grained, randomly oriented muscovite (Fig. 17). The fine grain sericite is due to retrograde metamorphism. Other evidence of retrograde 
metamorphism in this sample includes the presence of chlorite and highly fractured garnets with hematite filling the cracks.

False color images of components in garnets of 09HL01 show signs of variation in metamorphic conditions and polymetamorphism. The Mn map has the typical high concentration in the center, decreasing to a lower Mn concentration at the rim (Fig. 18a). It shows an abrupt, euhedral step down to low Mn near the garnet rim. The Ca map shows multiple concentric zones with idioblastic shapes of high and low $\mathrm{Ca}$ from the core to near the rim. There is an abrupt change to higher Ca, shown in green in Figure $18 \mathrm{~b}$, near the rim. At the outer most edge of the garnet rim the Ca concentration is much higher suggesting a different metamorphic event, not just minor changes in conditions. Both the $\mathrm{Mg}$ and Fe maps show uniform concentration across the entire garnet, except at the very edge of the garnet, $\mathrm{Mg}$ decreases slightly, which may be due to the abrupt increase in $\mathrm{Ca}$ (Fig. 18c, d).

There are definite signs of polymetamorphism in this sample. Not only the presence of pseudomorphs and the dramatic increase in $\mathrm{Ca}$ at the outer most edges of the garnet rims, but there are two fabrics identified as well; a dominant foliation overprinted by a later crenulation foliation. The dominant foliation in this sample is defined by parallelism of muscovite, biotite, ilmenite, and elongate quartz in the matrix (Fig. 16). Subtle crenulation folds in the micas in the matrix must have been the result of the later deformation phase D2, and is labeled $\mathrm{S}_{2}$. As a result, the matrix foliation is labeled $\mathrm{S}_{1}$ 
because it formed during the earlier deformation phase D1. The matrix wraps around the garnet porphyroblasts and the staurolite pseudomorph, so growth must have been pre-syn kinematic during the M1 event (Fig. 16). During this first metamorphic event, it appears that most of the garnets grew continuously, but experienced multiple, abrupt changes in metamorphic conditions (Fig. 18b). The high Ca outer garnet rim most likely grew during the M2 episode.

\section{HL07}

09HL07 was collected in the upper part of the staurolite zone, adjacent to the kyanite isograd in the western part of the study area (Figure 2). The mineral assemblage is ilmenite, chlorite, muscovite, biotite, quartz, garnet, and staurolite with traces of plagioclase and allanite. The sample has undergone moderate grade metamorphism and shows parallel elongation of the matrix minerals ilmenite, biotite, muscovite, and quartz (Fig. 19). The dominant foliation defined by the orientation of the matrix minerals is oblique $\left(\sim 45^{\circ}\right)$ to indistinct compositional layering in this sample. Ilmenite is aligned with the matrix foliation and is also present as inclusions in porphyroblasts. Ilmenite crystals in the cores of garnets are aligned parallel to compositional layering (Fig. 19). There is polysynthetic twinning in the chlorite, which occurs around the staurolite crystals and is scattered randomly throughout the matrix. Muscovite is both fine-grained parallel to matrix foliation and coarse-grained randomly oriented where it surrounds staurolite in partial pseudomorphs. Fine-grained biotite crystals are aligned parallel to the matrix 
foliation and coarser-grained, randomly oriented biotite crystals are scattered throughout the sample. There is a biotite rich compositional layer oblique to the matrix foliation but parallel to the preferred orientation of inclusions in the core of garnet (Fig. 20). Quartz is found in the matrix and as inclusions in the porphyroblasts. Garnet crystals comprise about $10 \%$ of the sample and range in size from 1.0 to $2.0 \mathrm{~mm}$ in diameter. There are two zones of quartz inclusions in garnets, one inclusion rich cluster in the core and one near the rim of the larger garnets (Fig.19, 20,21). The core of the garnets are rich with quartz inclusions which indicates that growth was fast and garnet was not able to exclude the excess $\mathrm{SiO} 2$. The quartz inclusions in the ring near the rim are coarser grained and aligned with the matrix foliation. The outer inclusion-rich zone coincides with the higher Ca zone described below. Coarse grained, hypidioblastic staurolite crystals with a sievelike texture (Fig. 20) are abundant in this sample. The outer-most edges of some of the larger staurolite crystals are partially replaced by randomly oriented muscovite and chlorite.

False color images of garnet components show definite signs of two distinct episodes of metamorphism. The Mn map shows high and relatively constant Mn concentration in the center, decreasing to lower concentrations toward the rim, but there is a distinct and abrupt decrease in Mn near the rim that is marked by a ring of coarse quartz inclusions (Fig. 21a). The Ca map shows concentric zones of higher and lower concentrations in the interior. It starts out with lower $\mathrm{Ca}$ in the inclusion-rich core, then 
higher, then slightly lower, and then slightly higher again. At the same ring of quartz inclusions that mark the abrupt change in Mn concentration, the Ca concentration abruptly increases, remains high, and then gradually decreases toward the outer edge of the rim (Fig. 21b). Fe and Mg concentrations are relatively uniform through out each garnet. However, at the same ring of quartz inclusions where Ca dramatically increases, both Fe and Mg decrease slightly (Fig. 21c, d). This decrease is likely due to dilution of the $\mathrm{Mg} \& \mathrm{Fe}$ concentrations by the high $\mathrm{Ca}$ concentration. At the outer rim both $\mathrm{Fe}$ and $\mathrm{Mg}$ increase to compensate for the lower Ca.

This sample shows signs of changing metamorphic conditions and polymetamorphism in the compositional zoning of garnet components and in the fabric. The preferred orientation of ilmenite inclusions inside of the garnet cores, which is parallel to compositional layering, indicates that an earlier foliation was preserved (Fig. 20). This could be a low grade foliation produced in the pelitic sediments due to compaction that is parallel to original bedding and so is labeled S0. From the garnet cores to the zone of quartz inclusions where the $\mathrm{Ca}$ increases dramatically marks the first growth zone though to have occurred during M1 (Fig. 19, 21b). The interior Ca zoning suggests that conditions changed multiple times during M1 garnet growth (Fig. 21b). Inclusions in the zone of quartz inclusions near the garnet rims are aligned with the dominant matrix foliation S1 in this sample, which is defined by the elongation of matrix minerals. The matrix foliation is thought to be $S_{1}$, the result of D1, because it is oblique to 
compositional layering and there is a later foliation superimposed on it forming a slight crenulation cleavage labeled $\mathrm{S}_{2}$. The garnet rim, marked by the distinct boundary in both compositional zoning and a ring of quartz inclusions, grew during M2. Randomly oriented muscovite and biotite crystals indicate that post-kinematic crystal growth continued after deformation ceased.

\section{$\underline{\text { 08BM216 }}$}

08BM216 is located in the kyanite/staurolite zone, directly across the kyanite isograd from 09HL07 in the western part Snow Peak area (Fig. 2). It has undergone moderate to high grade metamorphism, and the mineral assemblage is graphite, ilmenite, muscovite, biotite, quartz, garnet, staurolite, and kyanite, with minor plagioclase found mainly in the garnet pressure shadows. The parallel alignment of elongated quartz, micas, and ilmenite defines the dominant matrix foliation. Fine-grained muscovite is found in the matrix, and coarse-grained randomly oriented muscovite surrounds kyanite in pseudomorphs. Fine-grained biotite is aligned parallel to the matrix foliation, and coarser-grained biotite crystals occur in the pressure shadows of pseudomorphs and porphyroblasts. Garnets comprise about $20 \%$ of the sample and range in size from 0.5 to $3.0 \mathrm{~mm}$. The garnets have a distinct ring of quartz inclusions near the rim, but the cores are relatively inclusion free (Fig. 22). The staurolite crystals are hypidioblastic and twinned with sieve-like textures due to abundant quartz, graphite and ilmenite inclusions (Fig. 23). There is an inclusion free zone in the core of the staurolite, but concentric 
zones of dusty graphite trails and quartz inclusions appear from the edge of that core towards the rim. The outer zone of the rim has few graphite inclusions and forms a dendritic pattern growing out around large quartz grains. The kyanite porphyroblasts in this sample are located inside of coarse-grained, randomly aligned, muscovite pseudomorphs (Fig. 24).

The false colored images of 08BM216 garnet composition show signs of polymetamorphism and changing metamorphic conditions (Fig. 25). The Mn map shows a pattern typical of growth zoning in garnet. At the very edge of the rim, however, there is a sudden decrease in concentration that coincides with a ring of fine-grained quartz inclusions (Fig. 25a). The interior of the garnet has low Ca concentrations in the core, drops even lower outward, and then increases again (Fig. 25b.). At the first inner ring of abundant coarse-grained quartz inclusions there is a slight increase in $\mathrm{Ca}$ in garnet, which suggests a change in metamorphic conditions. At the very edge of the garnet crystal, there is a dramatic and abrupt increase in $\mathrm{Ca}$, which coincides with the decrease in $\mathrm{Mn}$ and seems to define a separate metamorphic event (Fig. 25b.). Both the Fe and the $\mathrm{Mg}$ show uniform concentrations across the whole garnet, except at the very edge, where Ca content increases, they both decrease slightly (Fig. 25 c, d).

There is evidence of polymetamorphism in this sample; such as the sudden increase of $\mathrm{Ca}$ in the garnet rims and the presence of pseudomorphs. The dominant foliation is defined by the parallel alignment of the matrix minerals. The matrix foliation 
wraps around the porphyroblasts, meaning that porphyroblast growth was pre- to synkinematic. The garnet cores are almost inclusion free except for a few ilmenite crystals, but all garnets have one distinct ring of quartz \pm ilmenite inclusions (Fig. 22). Some ilmenite inclusions inside of the porphyroblasts and pseudomorphs are not aligned with the matrix foliation but they also do not have a preferred orientation, so one cannot definitively say whether it is an earlier foliation. The main matrix foliation is thought to be $S_{1}$, produced by the earlier deformation phase D1. Most of the garnet volume grew during the earlier M1 event. The rim of the garnet marked by a zone of increased Ca content and a ring of quartz inclusions separates the M1 garnet growth from the M2 garnet growth. The very edge of the garnet where the abrupt increase in Ca concentration occurs marks the garnet growth during M2. There is not an obvious foliation attributable to $S_{2}$, but there is evidence of shear strain in the pressure shadows of garnets that suggests orientation of stress has changed indicating a later deformation event, D2. Also, the matrix wraps around the porphyroblasts, indicating that it was present prior to the most recent deformation (Passchier \& Trouw, 2005).

\section{HL02a}

Sample 09HL02 is located in the kyanite/staurolite zone approximately $2 \mathrm{~km}$ west of the kyanite isograd (Fig. 2). It has experienced moderate to high grade metamorphism, and the mineral assemblage is graphite, ilmenite, muscovite, biotite, quartz, garnet, and staurolite. There is no kyanite in this particular thin section. The muscovite in the matrix 
is fine-grained and aligned parallel with the dominant foliation. Muscovite in pseudomorphs is randomly oriented and coarse-grained (Fig. 4). Biotite is mostly finegrained and aligned parallel to the matrix foliation. There are a few coarse-grained biotite crystals surrounding the pseudomorph that are randomly oriented. Quartz occurs as elongated grains parallel to matrix foliation and as inclusions inside of porphyroblasts and pseudomorphs. Garnets comprise approximately $15 \%$ of the sample and range in diameter from $0.5-2 \mathrm{~mm}$. The matrix foliation is wrapped around the garnets, indicating that garnet growth was pre- to syn-kinematic (Fig. 26). There are two concentric rings of inclusions, mainly quartz, inside the garnet crystals. One narrow ring of inclusions is situated about $2 / 3$ of the garnet diameter out from the center and one with larger quartz inclusions at the rim (Fig. 26). There is a small staurolite porphyroblast that nucleated outside the large coarse-grained muscovite pseudomorph which may have replaced M1 staurolite (Fig. 4). Quartz inclusions in the staurolite give it a sieve-like texture and the matrix just slightly draped around it suggesting its growth was synkinematic.

The false colored images of garnet components for 09HL02a show definite signs of changing metamorphic conditions and two separate metamorphic events (Fig. 27). The Mn map shows a pattern typical of growth zoning; however there is a distinct boundary near the rim where Mn decreases abruptly (Fig. 27a). This zone of low Mn at the rim is also defined by a ring of quartz inclusions. The Ca map shows low $\mathrm{Ca}$ concentration in 
the core, and has a few subtle concentric zones of higher and lower concentrations as it nears the rim (Fig. 27b). At the rim, which is defined by a ring of quartz inclusions, the $\mathrm{Ca}$ abruptly increases at the same boundary where Mn decreases. At the outer-most edge of the garnet rim there is another zone of low Ca defined by an abrupt change in concentration. The Fe map is uniform in the interior of the garnet, but at the rim where $\mathrm{Ca}$ abruptly increases and then decreases, the Fe decreases then increases (Fig. 27c). The $\mathrm{Mg}$ concentration is uniform in the interior of the garnet, but near the rim where $\mathrm{Ca}$ increases, Mg also increases (Fig. 27d). Mg starts to increase before the zone of inclusions at the rim, decreases slightly at the boundary, and then increases again.

Sample 09HL02a shows definite signs of polymetamorphism such as pseudomorphs and an abrupt increase in Ca near the garnet rim. The dominant foliation in this sample is defined by the parallelism of the matrix minerals. This foliation is also preserved as the parallel alignment of inclusions in the rims of garnets and in the staurolite porphyroblast (Fig. 4, 26). Inclusions inside of the porphyroblasts and pseudomorphs do not appear to be aligned in a preferred orientation, so no internal foliation can be identified. The external foliation is thought to be $S_{1}$, the result of D1 that accompanied M1. M1 is considered responsible for the majority of garnet growth from the core out to the distinct high Ca rim marked by a ring of quartz inclusions and dramatic compositional zoning. There is no foliation in this sample identified as $\mathrm{S}_{2}$, but there are signs of the effects of D2. There are signs of shearing around garnets, indicating 
a change in the direction of stress that could be attributed to a separate deformation phase, D2 (Fig. 26). The pseudomorph consists of randomly-aligned coarse-grained muscovite crystals that completely consumed the previous mineral. It was most likely an M1 staurolite was replaced by a muscovite pseudomorph, because there is a perfectly idioblastic staurolite porphyroblast that nucleated adjacent to the pseudomorph during M2 where all of the essential chemical components were available. Also, the pseudomorph has a poikiloblastic texture indicative of staurolite.

\section{$\underline{\text { BT34.2 }}$}

Sample BT34.2 is located in the kyanite/staurolite zone of the Snow Peak study area near the staurolite-out isograd (Fig. 2). It has undergone high grade metamorphism, and the mineral assemblage is tourmaline, ilmenite, muscovite, biotite, quartz, garnet, staurolite, and kyanite with minor plagioclase. The matrix consists of tourmaline, ilmenite, muscovite, biotite, and quartz aligned in a preferred orientation that defines the dominant foliation for this sample. When compared to the others, this sample has a significant amount of euhedral tourmaline in the matrix. Ilmenite is found in the matrix and as inclusions in the garnet porphyroblasts (Fig. 28). Fine-grained muscovite in the sample defines the matrix foliation, and coarse-grained muscovite in the sample is randomly oriented in pseudomorphs. Biotite crystals are fine- to medium-grained and aligned with the matrix foliation. Quartz is found in the matrix and as inclusions in the porphyroblasts. There are a few small idioblastic staurolite porphyroblasts present 
throughout the sample in the matrix aligned with foliation, but most staurolite has been consumed by this point due to the high grade metamorphism. M2 kyanite in the sample is fine-grained, deformed and has odd growth textures. This may be due to it nucleating in an M1 muscovite-pseudomorph or from it replacing an M1 staurolite or andalusite crystal.

False colored images of garnet components show signs of multiple metamorphic events and changing metamorphic conditions (Fig. 30). Mn has a higher concentration in the garnet core and gradually decreases toward the rim which is typical of Mn zoning in garnets (Fig. 30a). There is an abrupt decrease in Mn at the rim, marked by a sharp compositional boundary and by a ring of large quartz inclusions that are elongate parallel to the main foliation (Fig. 28). The Ca map shows concentric rings of zoning (Fig. 30b). It has low concentrations in the core, and then gradually gets higher, then lower, higher and then lower again before an abrupt change to high Ca near the rim followed by lower concentrations at the outer-most edge of the garnet (Fig. 30b). The dramatic increase in $\mathrm{Ca}$ at the rim is the same zone where Mn decreases abruptly, which suggests a separate metamorphic event. Fe and $\mathrm{Mg}$ concentrations are uniform throughout the garnet, but at the same rim where $\mathrm{Ca}$ increases, they both decrease and then increase (Fig. $30 \mathrm{c}, \mathrm{d}$ ). There are definite signs of polymetamorphism in this sample, not only in the compositional zoning of garnet components and the presence of pseudomorphs, but also in the three foliations identified in the fabric. There are compositional layers that have 
been sheared and transposed by later deformation events that are thought to be bedding planes and thus labeled $\mathrm{S}_{0}$ (Fig. 28, 29). The dominant foliation that is defined by the parallelism of the matrix minerals is considered $\mathrm{S}_{1}$, formed by D1. The third foliation is a crenulation cleavage superimposed on $S_{1}$ that is most obvious in the micaceous domains. The crenulation cleavage is labeled $\mathrm{S}_{2}$ and is interpreted to be formed by D2. M1 is thought to be responsible for the majority of garnet growth, from the core all the way to the boundary of quartz inclusions and high $\mathrm{Ca}$ concentration near the rim. The internal foliation in the garnets $(\mathrm{Si})$ is aligned with the matrix foliation, reaffirming the extent of M1 garnet growth (Fig. 28). The boundary with the large quartz inclusions and high $\mathrm{Ca}$ concentrations all the way to the outermost edge of the rim marks M2 garnet growth (Fig. 28,30 ). The garnet rim grew over the matrix foliation, barely causing any deflection, indicating M2 garnet growth was syn-kinematic (Passchier \& Trouw, 2005).

\section{$\underline{\text { 09HLO4 }}$}

Sample 09HL04 was collected at the same outcrop as BT34.2 near the stauroliteout isograd in the kyanite/staurolite zone in the Snow Peak area (Fig. 2). It experienced high grade metamorphism, and the mineral assemblage is muscovite, biotite, quartz, garnet, staurolite, and kyanite with accessory minerals ilmenite and tourmaline. Finegrained muscovite is found in the matrix aligned with foliation, and coarse-grained muscovite is found randomly oriented in pseudomorphs. Most of the biotite in this sample is fine-grained and aligned with the matrix foliation, but some is coarse-grained at 
the margins of muscovite pseudomorphs and in garnet pressure shadows. Quartz is found in the matrix and as inclusions in porphyroblasts and pseudomorphs. There are a few small idioblastic staurolite porphyroblasts aligned with the matrix foliation indicating that staurolite growth was syn-kinematic. Coarse-grained M1 staurolite has been consumed and converted to pseudomorphs due to high grade M2 metamorphism. Kyanite in the sample displays unique growth textures that may be due to replacing a lower grade, M1 metamorphic mineral.

The false colored garnet images show definite signs of changing metamorphic conditions and at least two separate metamorphic events (Fig. 32). The Mn concentration is high in the core and gradually decreases as it nears the rim. Near the rim there is an abrupt decrease in concentration to uniformly low $\mathrm{Mn}$ in the outer rim, marking a clear boundary separating rim from core (Fig. 32a). The core has the lowest concentration of Ca, followed by higher, lower, and then high and higher again up until the same rim distinguished by the abrupt decrease in Mn (Fig. 32b). At the inner margin of this outer rim there is a dramatic increase of $\mathrm{Ca}$, which forms a very narrow high $\mathrm{Ca}$ zone, followed by a gradual decrease in $\mathrm{Ca}$ toward the outermost edge of the rim. The Fe concentration is fairly uniform throughout the garnet (Fig. 32c). Mg concentration is lower in the core and gets higher at the rim. The concentration $\mathrm{Mg}$ increases just before the distinct rim marked by low Mn and high Ca (Fig. 32d). Mg also decreases slightly at the outermost edge of the garnet. 
There are other signs of polymetamorphism and changing metamorphic conditions present in this sample besides compositional zoning in garnets and pseudomorphs, such as the presence of multiple foliations. Some of the inclusions inside of garnet porphyroblasts are aligned oblique to the matrix foliation, but it is not obvious enough to assign it a foliation (Fig. 31). It could be preserved evidence of an earlier deformation phase, or it could be the preservation of the dominant matrix foliation that slightly rotated over time due to later deformation (Passchier and Trouw, 2005). The dominate matrix foliation is labeled $\mathrm{S}_{1}$ formed by D1. Most of the interior of the garnet grew during the first metamorphic episode M1. The multiple increases and decreases in $\mathrm{Ca}$ in the core, which are accompanied by changes in inclusion density, indicate changes in metamorphic conditions during M1. The rim marked by a ring of quartz inclusions and the abrupt change to high $\mathrm{Ca}$ concentration grew during the second metamorphic event M2. This sample does not show definitive evidence for $S_{2}$, except for crenulation folds only seen in micaceous layers throughout. This is probably due to the fact that this thin section is dominated by a large muscovite pseudomorph, and as a result the matrix only makes up a small portion of this sample.

\section{Clarkia}

\section{$\underline{08 T N-01 a}$}

Sample 08TN-01a is located WNW of Clarkia in the staurolite zone (Fig. 3), and has undergone moderate grade metamorphism. The matrix foliation defined by quartz and 
muscovite is superimposed on an older relict foliation. The mineral assemblage is ilmenite, graphite, chlorite, muscovite, biotite, quartz, garnet, and staurolite. The ilmenite crystals are prismatic and found as inclusions in porphyroblasts and in the matrix. Dusty graphite trails are aligned with the matrix foliation. There is minor chlorite that appears to have replaced biotite and is probably the result of retrograde metamorphism. Muscovite is fine-grained and parallel to the matrix foliation. Biotite is coarse-grained, and is aligned with the matrix foliation and randomly oriented suggesting growth was syn and post kinematic. Quartz is present in the matrix and as inclusions in the porphyroblasts. Quartz in the matrix is aligned with the foliation, but in the porphyroblasts orientation of elongate quartz inclusions is nearly perpendicular to the matrix foliation (Fig. 33). Garnets are idioblastic and range in size from $\sim 0.5 \mathrm{~mm}$ to $1.5 \mathrm{~mm}$. The matrix minerals are slightly deformed around garnets, but some garnets cross-cut the matrix foliation suggesting syn/post kinematic growth. The staurolite crystals are idioblastic and overgrow the matrix minerals, which indicate post-kinematic growth. Compositional layering continues to be visible as inclusion trails in the staurolite porphyroblasts (Fig. $33)$.

The maps showing the concentrations of components in garnet for sample 08TN01a show signs of changes in metamorphic conditions, but not necessarily polymetamorphism. The Mn map (Fig. 34a) shows the typical distribution of Mn during garnet growth, however, there is a distinct boundary near the rim where the $\mathrm{Mn}$ 
concentration drops suddenly. The Ca maps show three distinct zones, a high concentration zone in the center with a sharp outer boundary where the concentration decreases and then rises to another zone of higher concentration at the rim (Fig. 34b). The sharpest boundary is between the higher concentration in the core and the zone of low $\mathrm{Ca}$ concentration. The $\mathrm{Fe}$ and $\mathrm{Mg}$ concentrations are fairly uniform, but Fe increases toward the garnet edge, while the $\mathrm{Mg}$ increases to form a wide high $\mathrm{Mg}$ zone near the rim and then decreases right at the rim (Fig. 34 c, d).

This sample shows signs of both changing metamorphic conditions but no definitive evidence of polymetamorphism. There are two foliations preserved that are nearly perpendicular. The earlier foliation is defined by compositional layering, and the later matrix foliation is superimposed nearly perpendicular to the compositional layering (Fig. 33). The earlier compositional layering is unevenly spaced and indicative of layering associated with deposition so it is labeled $\mathrm{S}_{0}$. The $\mathrm{S}_{0}$ layering is also preserved as poikiloblastic trails of quartz and graphite rich inclusions inside of staurolite porphyroblasts (Fig. 33). The matrix foliation is labeled $\mathrm{S}_{1}$. The garnets in this sample do not show signs of multiple episodes of crystallization so growth is attributed entirely to the M1 episode. There is no evidence for the effects of M2 on this particular sample, so S2 is not labeled.

\section{HL04}


According to Hietanen (1984) 08HL04 is located in the kyanite/sillimanite zone about 6 miles west of Clarkia (Fig. 3). This sample has undergone moderate to high-grade metamorphism. The mineral assemblage is ilmenite, muscovite, biotite, quartz, garnet, and kyanite with traces of sillimanite. Ilmenite is found as inclusions in porphyroblasts and in the matrix. Fine grain muscovite is aligned with the matrix foliation and is also randomly oriented throughout the sample. Coarse grained muscovite is present in this sample as a large pseudomorph that appears to have replaced either kyanite or sillimanite. The coarse grain muscovite pseudomorph has been sheared into alignment with the matrix foliation. Biotite is fine grained and aligned with the matrix foliation. Quartz is found in the matrix where it is elongate parallel to the foliation and also as inclusions in the garnet porphyroblasts. Garnet is found peppered throughout the matrix and inside of the pseudomorph. It ranges in diameter from approximately $0.5 \mathrm{~mm}$ to $4.0 \mathrm{~mm}$. They are idioblastic in the mica rich layers and hypidioblastic in the quartz rich layers. The larger garnets have concentric rings of mostly quartz inclusions and show evidence changing metamorphic conditions (Fig. 35). There is no kyanite in this particular sample, but there is sillimanite found inside of the pseudomorph.

The false colored images of garnet composition in 08HL04 show signs of subtle and abrupt changes in metamorphic conditions. The Mn map (Fig.36a) shows the typical high $\mathrm{Mn}$ in the core decreasing to lower concentration at the rim, but near the rim the concentration drops abruptly leaving a wide, low Mn margin rim. The general trend for 
Ca distribution goes from lower concentrations in the core to higher concentrations in the rim. There are four obvious zones with the most abrupt boundaries where $\mathrm{Ca}$ increases. The first zone is the inclusion free low Ca core marked by a sharp boundary where $\mathrm{Ca}$ slightly increases. The next zone is inclusion rich, has slightly higher $\mathrm{Ca}$, and has a distinct boundary separating it from the next zone which has significantly higher $\mathrm{Ca}$ concentration and fewer, larger inclusions. The final zone is at the outermost edge of the rim and is marked by a large and abrupt increase in Ca (Fig. 36b) The Mg and Fe maps show fairly uniform concentrations throughout the entire garnet, but where the outer high Ca rim is located, the Mg decreases in concentration slightly (Fig.36c, d)

There are definite signs that metamorphic conditions changed during the growth of this sample. The presence of pseudomorphs indicates that at least two separate metamorphic episodes, M1 and M2 affected this sample. There also appear to be 2 foliations preserved in this sample. The dominant foliation is defined by the matrix minerals and the coarse grain muscovite at the margins of the pseudomorph. The matrix foliation bends around most of the garnets, but some garnets and muscovite crystals cross-cut matrix minerals meaning mineral growth was both syn- and post-kinematic. There are few ilmenite inclusions inside of the garnets that are aligned oblique to the matrix foliation. This could be evidence of preservation of the earlier $\mathrm{S}_{1}$ foliation. That would mean the dominant matrix foliation is $\mathrm{S}_{2}$, which was formed by D2. 


\section{Results:}

Samples analyzed in this study cover all of the Snow Peak metamorphic zones. All but one of the samples were collected either near or south of the M1 relict isograd. Sample 80TN80a was collected far to the north of the M1 relict isograd and is unlikely to have been affected by the M1/D1 event. The other samples collected in the central and western parts of the study area were likely affected by both events.

\section{Structural Results:}

Evidence left behind in the sample's fabric shows there were two deformation phases that caused two regional metamorphic events and subsequent foliation development in the Snow Peak area. In this study, the earlier deformation phase, labeled D1, accompanied $\mathrm{M} 1$, and produced the foliation labeled $\mathrm{S}_{1}$. The later deformation event, labeled D2, coincided with M2 and produced a foliation labeled $\mathrm{S}_{2}$. Original bedding (compositional layering) can be identified in most samples, but maybe highly deformed. If there is irregularly spacing of compositional layering, it is considered original bedding and labeled S0. Each sample collected in the field was oriented, and the strike and dip data obtained for the dominant matrix foliation, $\mathrm{S}_{\mathrm{D}}$, helped determine which samples were affected by which deformation phase. Each sample was also analyzed optically to identify dominant and relict foliations and other textural fabrics that help interpret metamorphic history. The optical and field structural results were then compiled for each metamorphic zone in the Snow Peak area to characterize deformation and foliation 
development across the study area. Based on these it was possible to give a general description for the effects of the two main deformation phases that accompanied the metamorphism of the metapelites.

The strike and dip data collected in the field measures the dominant matrix foliation, $S_{D}$, for each of the oriented samples (Table 1). This data was plotted on a lower hemispheric stereonet projection to determine the relationship between the data points for different samples (Fig. 37). The dominant foliation of all but one of the samples has a low dip angle and the poles cluster around the center of the stereonet. 08TN80a is the only sample located in the upper northeast quadrant of the stereonet away from the other Snow Peak samples, and is thought to have a different foliation.

Optical analysis was used to identify and label all foliations and textural fabrics present in the samples that help distinguish the effects the deformation phases and metamorphic events had on the samples. There are three different foliations identified. S0 is the original compositional layering associated with deposition that is still distinguishable in many samples. S1 is the earlier metamorphic foliation based on parallel alignment of elongate minerals. When $\mathrm{S} 1$ is parallel to $\mathrm{S} 0$ the foliation is labeled $\mathrm{S} 0 / \mathrm{S} 1$. $\mathrm{S} 2$ is the later foliation that cross-cuts, offsets, or folds S1 when both are present. In most samples the deformation during D2 was not strong enough to redefine the dominant S1 matrix foliation, so the results are crenulation folds (Fig. 8) and/or asymmetric shear strain shadows around porphyroblasts (Fig. 22). This is true for all samples except 
08TN80a, which does not show evidence of polymetamorphism (Fig. 5). This designation of D1/M1 and D2/M2 is different from the designation by Nesheim (2009); Nesheim et al. (2010b, 2012). He determined that sample 08TN80 has an $\mathrm{S}_{\mathrm{D}}$ labeled $\mathrm{S} 1$ and the other samples had an $\mathrm{S}_{\mathrm{D}}$ labeled S2 (Fig. 2). This study shows that all samples, except 08TN80a, have the same S1 matrix foliation. This will be described in further detail in the discussion.

Each metamorphic zone was affected differently by deformation in the study area and all results are displayed in Table 2. Most samples were affected by the earlier M1/D1 event and have an $\mathrm{S}_{\mathrm{D}}$ identified as $\mathrm{S} 1.09 \mathrm{HL} 09$ has an $\mathrm{S}_{\mathrm{D}}$ labeled $\mathrm{S} 1$, which is also parallel to S0 (Fig. 8). S1 is defined by the elongation and parallel alignment of matrix minerals. There is a crenulation cleavage identified as S2 that is superimposed on S1 (Fig. 8). The four samples in the staurolite zone (Fig. 2) all have an $\mathrm{S}_{\mathrm{D}}$ identified as $\mathrm{S} 1$. 08TN124 and 09HL10b have internal foliations in the porphyroblasts that are aligned with the dominant S1 matrix foliation (Fig. 14c, 12). 09HL10b has a crenulation foliation labeled S2 (Fig. 12), which the other staurolite zone samples do not have. However, the other samples do show asymmetrical shearing of the matrix and pressure shadows around porphyroblasts, which is evidence for S2 (Fig. 14, 16). The four samples in the staurolite/kyanite zone (Fig. 2) also have an $\mathrm{S}_{\mathrm{D}}$ identified as S1. 08BM216 and 09HL02 have shear strain shadows around the porphyroblasts indicating that a later deformation event affected these samples (Fig. 22, 26). BT34.2 has evidence for all three foliations 
S0, S1, and S2. The compositional layering is highly deformed by S1 (Fig. 29), S1 is the dominant foliation (Fig. 28), and is S1 is slightly crenulated indicating it was over-printed by S2. The adjacent sample, 09HL04, does not obviously have all three foliations, but in the fine-grained, mica-rich layers near the top of the sample show slight crenulation folds, indicating that $\mathrm{S} 2$ is present

The only sample that does not show evidence of polymetamorphism is 08TN80. It is also located farthest from the relict M1 isograd in the northwestern portion of the map (Fig. 2) and plots away from all other samples on the stereonet (Fig. 37). Because of this and garnet growth described next, it was determined this samples was affected very little, if at all, by the M1/D1 event.

Structural analysis alone does not definitively determine to what degree the two deformation phases affected all of the samples, because when dealing with multiple deformation phases, a foliation can change drastically or disappear altogether from one sample to the next (Passchier \& Trouw 2005). This is typical of metamorphosed shales because of varying compositions and structural discontinuities. This is why another major focus of this study was to analyze garnet porphyroblasts and relate their growth to deformation.

\section{Garnet Textures and Garnet Zoning}

Some of the garnets in the samples contain many inclusions. Inclusions may be clustered into inclusion rich zones, inclusion poor zones, or preserve an internal foliation. 
Many samples have internal foliations preserved as elongate quartz and ilmenite that are parallel to the external matrix foliation, indicating that the garnet nucleated and grew during the formation of the dominant matrix foliation (Fig. 6, 8, 12, 14b, 28, 31). Other samples (09HL07, 08BM216) have internal foliations that are oblique to the dominant foliation, indicating that an earlier foliation was preserved. All of the higher grade samples in the southwest portion of the map (Fig. 2) have distinct rims that contain abundant coarse-grained, quartz inclusions, creating a dendritic pattern (Fig. 19, 22, 26, $28,31)$. Many of the samples have 2 or 3 zones that are rich in quartz inclusions, but there does not seem to be a consistent pattern from sample to sample.

The garnets in the Snow Peak area have distinct compositional zoning, especially in $\mathrm{Ca}$ content. There is also zoning in Mn content for a few samples. Garnets in samples with M1 growth have zoning of Ca starting with lowest concentrations in the core, and then have at least two or more low/high, low/high cycles forming concentric, euhedral zones towards the rims (Fig. 38). For these samples, M2 growth is marked by a sudden and significant increase in $\mathrm{Ca}$ at or near the rim in Figure 38. In the lower grade samples, the high $\mathrm{Ca}, \mathrm{M} 2$ growth zone is only found in small patches along the outer most edge of the rim (Fig. 38 a, b, c, d). M2 growth in the higher grade samples have a sudden increase in $\mathrm{Ca}$ at the M1/M2 boundary followed by a zone of decrease in Ca (Fig. $38 \mathrm{e}, \mathrm{f}, \mathrm{g}, \mathrm{h}$ ). A few samples show zoning in Mn at this boundary. Samples 09HL07 (Fig. 21a) and 09HL02 (Fig. 27a) show a distinct zone where the Mn concentration drops dramatically 
instead of a gradual decrease typical of Mn distribution in garnets. In the high grade samples, this boundary is also marked by a zone of coarse grained quartz inclusions (Fig. $38 \mathrm{e}, \mathrm{f}, \mathrm{g}, \mathrm{h})$. For all the samples, except $08 \mathrm{TN} 80$, the majority of the garnet grew during the M1/D1 event. The approximate percentages for growth during the separate events are displayed in Table 2.08TN80 nucleated and grew entirely during the M2 event. It only has two Ca zones, starting out with highest concentrations in the core, and at the very outermost edge of the rim there is a zone where Ca slightly decreases.

There are correlations between garnet zoning and inclusion patterns. The most obvious is at the high Ca boundary that marks the M1/M2 transition in the garnet rim. This boundary is marked by coarse-grained inclusions found in all higher grade samples. There are other correlations among adjacent samples. All of the staurolite zone samples (08TN124b, 09HL10b, 09HL01a, 09HL07) have low Ca in core followed by one or two zones where Ca concentration slightly increases before a sudden increase then decreases again before reaching the high Ca boundary marking the M2/D2 event. A few samples (09HL01a, 09HL10b, 08BM216, 09HL02 09HL04, BT34.2) have a ring of inclusions in the center of the garnets where the first noticeable increase in Ca occurs. This zone is attributed to a time where garnet growth was rapid and did not incorporate all of the $\mathrm{SiO}_{2}$ in quartz inclusions. The changes in garnet compositions and inclusion density inside the M1 garnet probably correlate with pressure and temperature changes during the M1/D1 event. 


\section{Discussion:}

Lu-Hf garnet ages from the Wallace Formation of northern Idaho range from 967 Ma to $1353 \mathrm{Ma}$, and Nesheim et al (2010b, 2012) documented two different metamorphic ages of $1102 \pm 43 \mathrm{Ma}$ and $1347 \pm 10 \mathrm{Ma}$ from rim and core of chemically and isotopically zoned garnets in sample 08HL04. Based on evidence compiled from this data, it was determined that the earlier event (M1/D1) dated approximately $1330 \mathrm{Ma}$ and the later event (M2/D2) 1080 Ma (Nesheim et al, 2012). The Lu-Hf garnet ages and $\mathrm{S}_{\mathrm{D}}$ foliation orientations obtained by Nesheim $(2009,2010)$ for the Snow Peak and Clarkia samples used in this study are listed in Table 2, and will be used to compare and discuss results.

The two garnet zone samples have different metamorphic and deformational histories. Garnet zone sample 08TN80a is far north of the relict M1 isograd, and that sample was not affected by M1/D1. This is the lowest grade sample and does not show evidence of multiple metamorphic episodes. The young Lu-Hf age $(\sim 1085 \mathrm{Ma})$ of 08TN80a and a different orientation for the dominant matrix foliation (Fig. 37) suggest that this sample was only affected by the later M2/D2 event and has an $\mathrm{S}_{\mathrm{D}}$ labeled S2. The other garnet zone sample 09HL09, located south of the relict M1 isograd, is higher grade and was clearly affected by both events. This was determined based on the identification of two external foliations (Fig. 8, 9), the chemical zoning in the garnets, and a much older Lu-Hf age ( $\sim 1314 \mathrm{Ma})$. Given the old age, the majority of the garnet growth must have occurred during the earlier M1/D1 event, so the $\mathrm{S}_{\mathrm{D}}$ must be $\mathrm{S} 1$ and the 
crenulation cleavage $\mathrm{S} 2$. The Ca zoning shown in the garnet maps further support this, and the very thin high $\mathrm{Ca}$ rim growth (Fig. 10) is attributed to the M2 event. The structural results from the field for 09HL09 comply with Nesheim (2009), but are very different for 08TN80a. Nesheim (2009) assigned $\mathrm{S}_{\mathrm{D}}$ as $\mathrm{S} 1$, not $\mathrm{S} 2$ as in this study. Given the young age comparable to the age given for the M2/D2 event and lack of evidence of polymetamorphism, it does not seem possible to attribute garnet growth and $S_{D}$ in 08TN80a to the earlier M1/D1 event. The results for 08TN80a mirror the results for 08TN01a in Clarkia (Fig. 3). Both have young ages, both plot side by side on the stereonet, and neither have a high Ca rim. The 08HL04 sample southeast of 08TN01a has a much older age and shows evidence for both events.

The four samples in the staurolite zone were affected by the two events in distinctive ways, even though all samples have a dominant $\mathrm{S}_{1}$ foliation. The three samples, 08TN124, 09HL10b, 09HL01, found in the center of the Snow Peak map (Fig. 2) possess a lower volume of high Ca rim attributed to M2 growth than 09HL07 found further west and adjacent to the kyanite isograd (Fig. 2). This could be attributed to 09HL07 having been exposed to high temperature and pressure for a longer time during M2/D2. If this is true, and 09HL07 has a higher volume of M2 garnet, it should have a younger age. This particular sample was not dated, but an adjacent sample, 08AMTO21, was dated by Timothy Nesheim at $1079 \pm 3 \mathrm{Ma}$. Two of the other staurolite zone samples were dated. $09 \mathrm{HL} 10 \mathrm{~b}$ has a date of $1198 \pm 79$ and $08 \mathrm{TN} 124$ has a date of $1255 \pm 28$ 
(Nesheim et al., 2012). 09HL07 is in an area of samples with younger ages than the cluster of samples in the center of the study area, suggesting it was more affected by the M2/D2 event (Nesheim et al., 2012; Zirakparvar et al., 2010). For all the staurolite zone samples, however, the majority of garnet growth was during the M1/D1 event (Table 2). Thus the $\mathrm{S} 1$ fabric is still the $\mathrm{SD}$, and $\mathrm{S} 2$ was superimposed on $\mathrm{S} 1$ leaving behind crenulation cleavages and shear strain around porphyroblasts.

There are some differences between the structural interpretation of Nesheim (2009) and this study's structural analysis of the staurolite zone samples. Nesheim (2009) assigned the dominant foliation to be $\mathrm{S}_{2}$ for the staurolite zone samples, and attributed the crenulation cleavages to a third deformation phase later than the M2/D2 event. According to this study's structural analysis, that interpretation does not seem likely, because all the samples cluster together on the stereonet, some have older ages close to M1/D1, and some have porphyroblasts with a parallel external and internal foliation. That is why it was determined that the dominant foliation is $S_{1}$. In this study the crenulation cleavage is attributed to S2 formed by the M2/D2 event.

Two of the lower grade samples in the kyanite/staurolite zone, 08BM216 and 09HL02, have similar fabrics. Both have an $S_{1}$ matrix foliation and coarse grained muscovite pseudomorphs. There is not much textural evidence for the effects of the M2/D2 in either sample, except for pressure shadows strained by shear stress (Fig. 22, 26). The matrix foliation is draped around the porphyroblasts in both samples, indicating 
that garnet growth was syn-kinematic. No ages were obtained from either sample, but a sample adjacent to sample 09HL02 was dated by Timothy Nesheim at $1296 \pm 25$ Ma. This is older than the other surrounding samples, but both samples have an $\mathrm{S}_{\mathrm{D}}$ that clusters in the center of the stereonet, have shear-shadows around the garnet porphyroblasts, and have that zone of high $\mathrm{Ca}$ at the rim, so the matrix foliation is labeled $\mathrm{S} 1$ and the majority of garnet growth happened during the M1/D1 event (Table 2).

The final two samples to discuss in the Snow Peak area, 09HL04 and BT34.2, both fall in the highest grade part of the kyanite/staurolite zone and both have a dominant S1 matrix foliation. They are the highest grade and the most deformed samples in this study. There is an internal foliation preserved inside of the garnets subparallel to the dominant matrix foliation still attributed to $S_{1}$. The M2/D2 event that formed $S_{2}$ superimposed a crenulation cleavage on $\mathrm{S}_{1}$ (Fig. 29). A date of $1206.6 \pm 8.4$ was obtained for 09 HL04 by Nesheim et al. (2012). That intermediate age further supports the interpretation that both metamorphic events affected these samples. The garnet core, up until the high Ca rim, grew during M1 and the high Ca rim grew during M2. Again, the dominant foliations in both of these samples cluster with the other samples in the center of the stereonet, suggesting they are all $\mathrm{S}_{1}$. Also, the majority of the garnet grew during this earlier M1/D1 event. 


\section{Conclusions}

This study of the metapelites of the Snow Peak area in northern Idaho, along with previous work, led to the following conclusions:

- Samples in the Snow Peak study area were affected by two significant metamorphic events and two deformation phases. The earlier metamorphic event labeled M1 coincides with the early deformation phase D1 and produced s-planar fabric S1. The later metamorphic event labeled M2 coincides with the later deformation phase D2 and produced s-planar fabric S2.

- The S1 fabric in samples affected by the M1/D1 event was not reoriented by the $\mathrm{M} 2 / \mathrm{D} 2$ event. Inclusions inside of porphyroblasts in most samples are aligned parallel to the $\mathrm{S} 1$ fabric. $\mathrm{S} 2$ in these samples is defined by crenulation cleavages and strain shadows around porphyroblasts.

- Most garnets especially in the higher grade samples show an abrupt rise in Cacontent in garnet and a ring of coarse-grained quartz inclusions that is attributed to M2 garnet growth. Garnets in some samples have zoning in $\mathrm{Mn}, \mathrm{Fe}$, and $\mathrm{Mg}$ at this boundary as well.

- Volume percentages of garnet growth were estimated for the M1 and M2 events in each sample. The majority of garnet growth for samples affected by both events occurred during the M1/D1 event. Samples with more M2/D2 garnet growth reflect younger ages. 
- Sample 08TN80a, which is furthest from the M1 relict isograd, but still within the M2 garnet zone (Fig. 2), shows no sign of polymetamorphism and has a different dominant matrix foliation than the other samples in the area. This foliation is interpreted as $\mathrm{S} 2$. The young garnet age obtained from this sample (Nesheim, 2010) suggest that garnet growth occurred only during the later M2/D2 event. Thus, sample 08TN80a was not affected by the earlier M1/D1 event.

- Comparisons between the Snow Peak and Clarkia samples show a correlation between the low grade M2 garnet samples that appear to have grown during one event. Both have similar dominant matrix foliations and younger garnet ages suggesting M2 garnet growth and an S2 matrix foliation. Sample 08HL04 shows evidence of both M1 and M2 growth. The core is attributed to M1 and the rim to M2. 


\section{Acknowledgments:}

I would like to thank my adviser Dr. Helen Lang for the opportunity to help with her research, her colleague Dr. Bill McClellend and his master's student Timothy Nesheim for their structural and garnet dating work, and the NSF for providing grant number EAR-0710939 for funding the project. I would also like to thank Dr. Jaime Toro and Dr. Shikhax Sharma for serving on my committee, and many other professors at WVU, Dr. Tom Kammer and Dr. Joe Lebold to name a few, for supporting me throughout my studies, as well as my friends and family for providing me with the moral support I need. 


\section{References:}

Allmendinger, R. W., Cardozo, N., and Fisher, D., 2012. Structural geology algorithms: Vectors and tensors in structural geology: Cambridge University Press.

Carey, J.W., Rice, J.M., Grover, T.W., 1992. Petrology of Aluminous Schist in the Boehls Butte region of northern Idaho: geologic history and aluminum-silicate phase relations, American Journal of Science. 292:455-473

Flagg, E.M., McClelland, W.C., Gilotti, J.A., Lang, H.M., Largent, K.J., Vervoort, J.D., Nesheim, T.O., and Spear, F.S., 2010. U-Th-Pb monazite evidence of Proterozoic metamorphism in the Belt-Purcell Supergroup of northern Idaho. Geological Society of America Abstracts with Programs. 42(5):293

Hietanen, A.M., 1956, Kyanite, andalusite, and sillimanite in the schist in Boehls Butte Quadrangle, Idaho: American Mineralogist. 41:1-27.

Hietanen, A., 1962, Metasomatic metamorphism in western Clearwater County, Idaho: U.S. Geological Survey Professional Paper 344-A:116.

Hietanen, A., 1963a, Anorthosite and associated rocks in the Boehls Butte quadrangle and vicinity, Idaho: U.S. Geological Survey Professional Paper 344-B:B78.

Hietanen, A., 1963b, Metamorphism of the Belt Series in the Elk River-Clarkia Area Idaho: United States Geological Survey Professional Paper 344-C:C1-C49.

Hietanen, A., 1963c, Idaho batholith near Pierce and Bungalow, Clearwater County, Idaho: Geological Survey Professional Paper 344-D:D42.

Hietanen, A., 1967, Scapolite in the Belt Series in the St. Joe-Clearwater Region, Idaho. US Geological Survey Special Papers number 86:1-51.

Hietanen, A., 1968, Belt Series in the Region around Snow Peak and Mallard Peak, Idaho. US Geological Survey Professional Paper 344-E:E1-E34.

Hietanen, A., 1984, Geology along the northwest border zone of the Idaho Batholith, northern Idaho: United States Geological Survey Bulletin. pp. 1-17.

Kretz, R., 1983, Symbols of rock-forming minerals: American Mineralogist. 68: 277-279. 
Lang, H.M., Rice, J.M., 1985a. Regression modeling of metamorphic reactions in metapelites, Snow Peak, northern Idaho: Journal of Petrology. 26:857-887.

Lang, H.M., Rice, J.M., 1985b. Geothermometry, geobarometry and T-X (Fe-Mg) relations in metapelites, Snow Peak, northern Idaho.: Journal of Petrology. 26:889-924.

Lang, H.L., Rice, J.M., 1985c. Metamorphism of pelitic rocks in the Snow Peak area, northern Idaho: Sequence of events and regional implications, Geological society of America Bulletin. 96:731-736.

Lang, H.M., Largent, K.J., Nesheim, T.O., McClelland, W.C., Vervoort, J.D., Flagg, E.M., Gilotti, J.A., 2010. Garnet zoning as a record of Proterozoic polymetamorphism in Belt-Purcell Supergroup metapelites, Western Laurentia. Geological Society of America Abstracts with Programs. 42(5):308

Lewis, R.S., Burmester, R.F., McFaddan, M.D., Kauffman, J.D., Doughty, P.T., Oakley, W.L., Frost, T.P., 2007, Geologic Map of the Headquarters 30 x 60 Minute Quadrangle, Idaho: Idaho Geologic Survey.

Nesheim, T.O., 2009. Are $1.1 \mathrm{Ga}$ deformational fabrics present in metasedimentary rocks of the Belt Supergroup in northern Idaho?: Unpublished M.S. Thesis, University of Iowa, $125 \mathrm{p}$.

Nesheim, T.O., Gilotti, J.A., McClelland, W.C., Lang, H.M., Foster, C.T., Vervoort, J.D., 2010a. Microstructural analysis of Belt Supergroup metapelites in the Clarkia area of northern Idaho: implication of 1.0-1.1 Ga garnet, Northwest Geology. 39:3140.

Nesheim, T.O., Vervoort, J., McClelland, W.C., Lang, H.M., and Gilotti, J.A., $2010 \mathrm{~b}$. Evidence from Lu-Hf garnet geochronology of regional Proterozoic polyphase metamorphism in western Laurentia. Geological Society of America Abstracts with Programs. 42(5):197

Nesheim, T.O., Vervoort, J.D., McClelland, W.C., Gilotti, J.A., Lang, H.M., 2012. Mesoproterozoic syntectonic garnet within Belt Supergroup metamorphic tectonites: Evidence of Grenville-age metamorphism and deformation along northwest Laurentia. Lithos.134-135:91-107 
Passchier, C.W., Trouw, R.A.J., 2005. Micro-tectonics: Springer-Verlag Berlin Heidelberg, Germany, 366 p.

Rasband, W.S., ImageJ, U. S. National Institutes of Health, Bethesda, Maryland, USA, http://imagej.nih.gov/ij/, 1997-2012.

Richard, M.G., Vervoort, J.D., Lewis, R.S., McClelland, W.C., 2010. Migrating magmatism in the northern US Cordillera: in situ U-Pb geochronology of the Idaho batholith, Contributions to Mineralogy and Petrology. 159:863-883.

Zirakparvar, N.A., Vervoort, W.M., Lewis, R.S., 2010. Insights into the metamorphic evolution of the Belt-Purcell basin; evidence from Lu-Hf garnet geochronology; Canadian Journal of Earth Science. 47:161-179. 

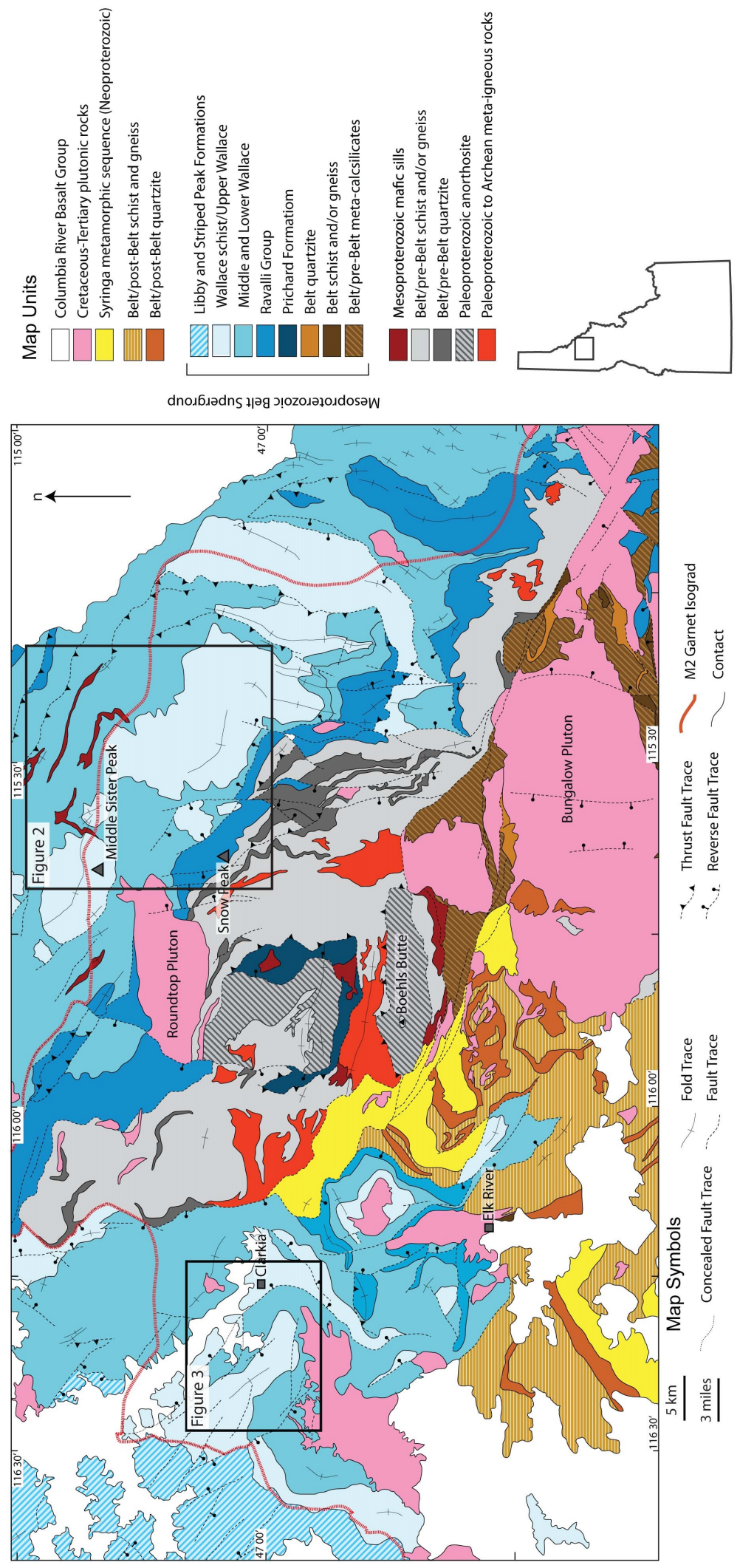


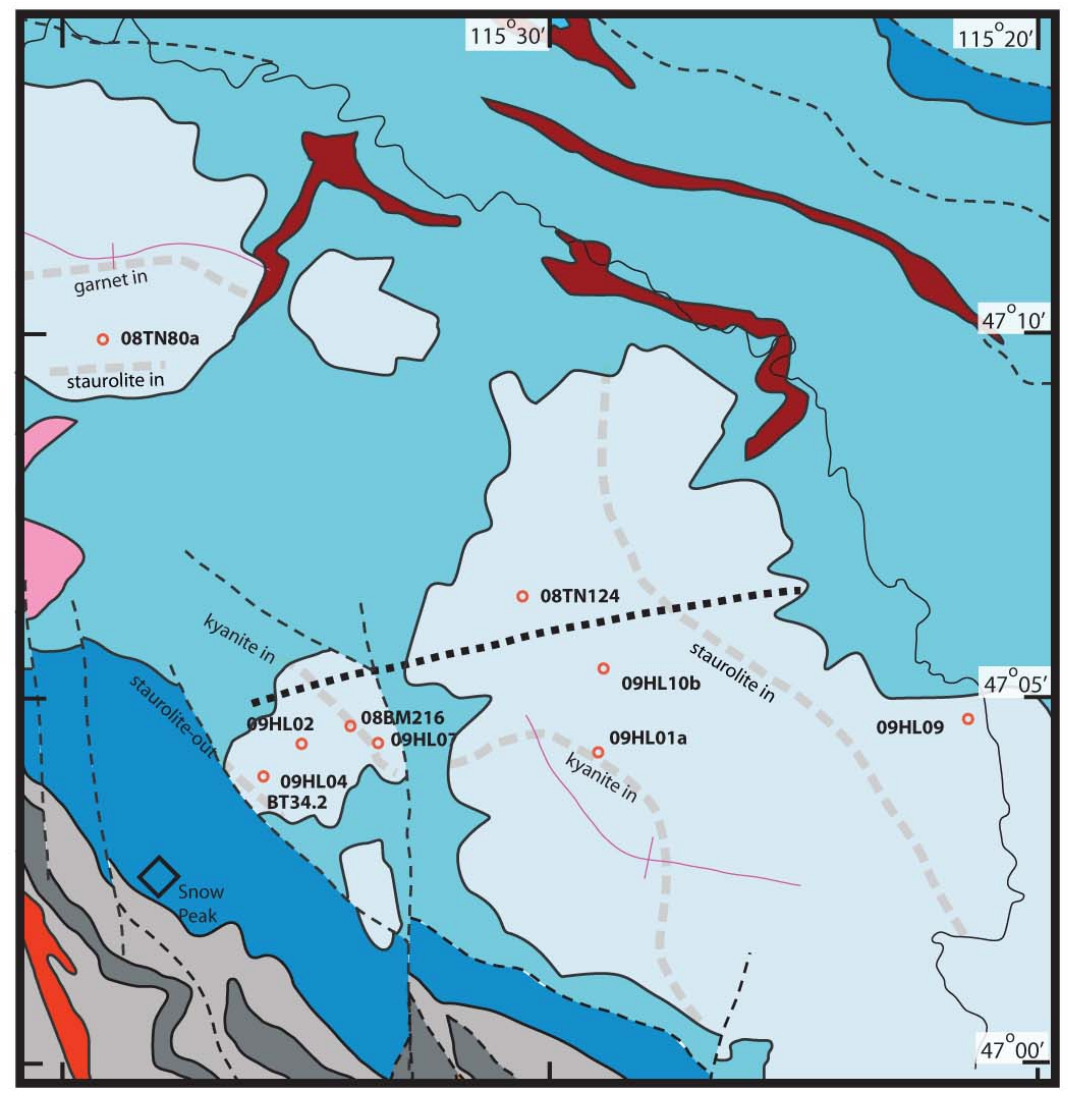

\section{Legend}

Map Units

$\square$ Cretaceous-Tertiary plutonic rocks

$\square$ Wallace schist/Upper Wallace

Middle and Lower Wallace

Ravalli Group

Mesoproterozoic mafic sills

Belt/pre-Belt schist and/or gneiss

Belt/pre-Belt quartzite

Paleoproterozoic to Archean meta-igneous rocks

Map Symbols

$=$ M2 Isograd

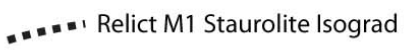

$\sim$ St. Joe River

-- ${ }^{-}$Fault Line

Fold axis

- Sample Location

$\uparrow \frac{3 \text { Miles }}{5 \text { Kilometers }}$

Figure 2 


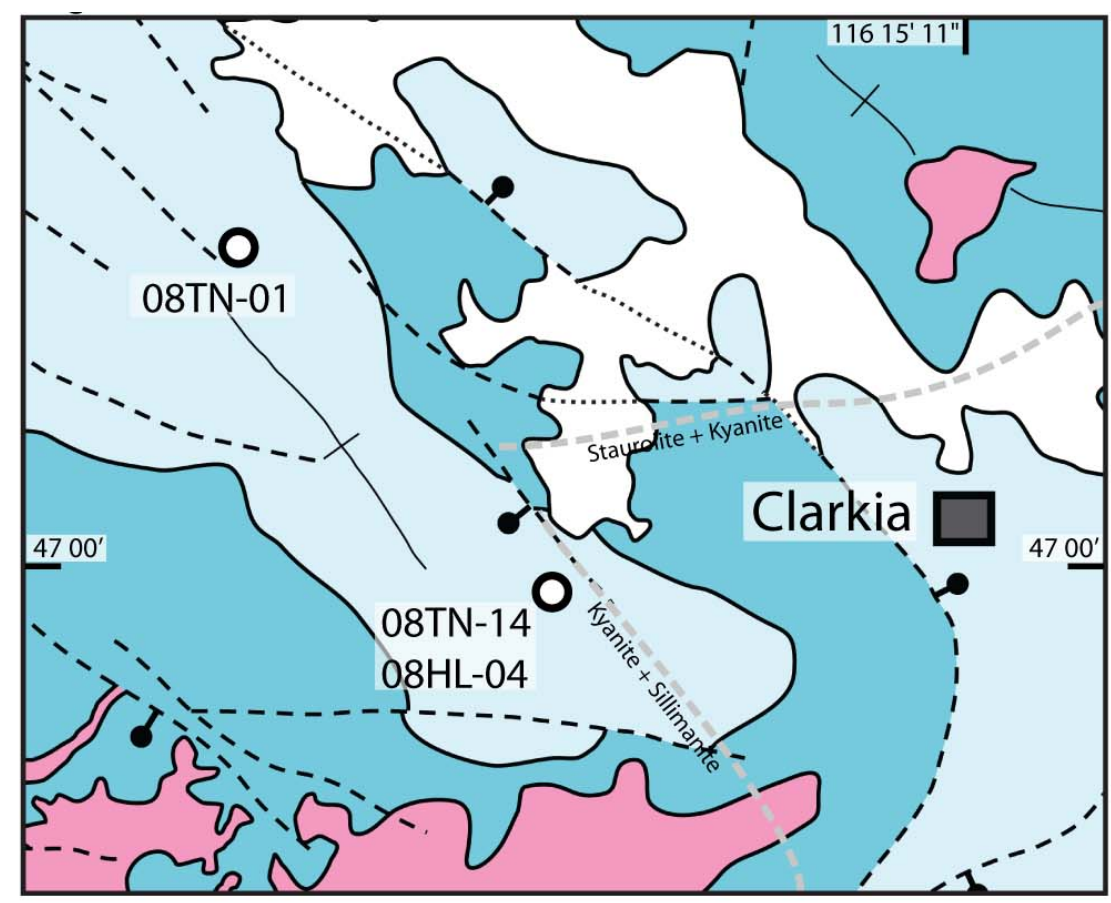

Legend

$\square$ Columbia River Basalt

$\mathrm{K} / \mathrm{T}$ plutonic rocks

Upper Wallace schist

Middle \& Lower Wallace quartzite

$>$ Fold Trace

- - Fault Trace

- s. Normal Fault Trace

$\sim$ Contact

$\because \ddots \ldots$ Concealed Fault Trace

O Sample Location

- - M2 Isograd

$\uparrow_{\mathrm{N}}^{\frac{5 \mathrm{~km}}{3 \text { miles }}}$

Figure 3 


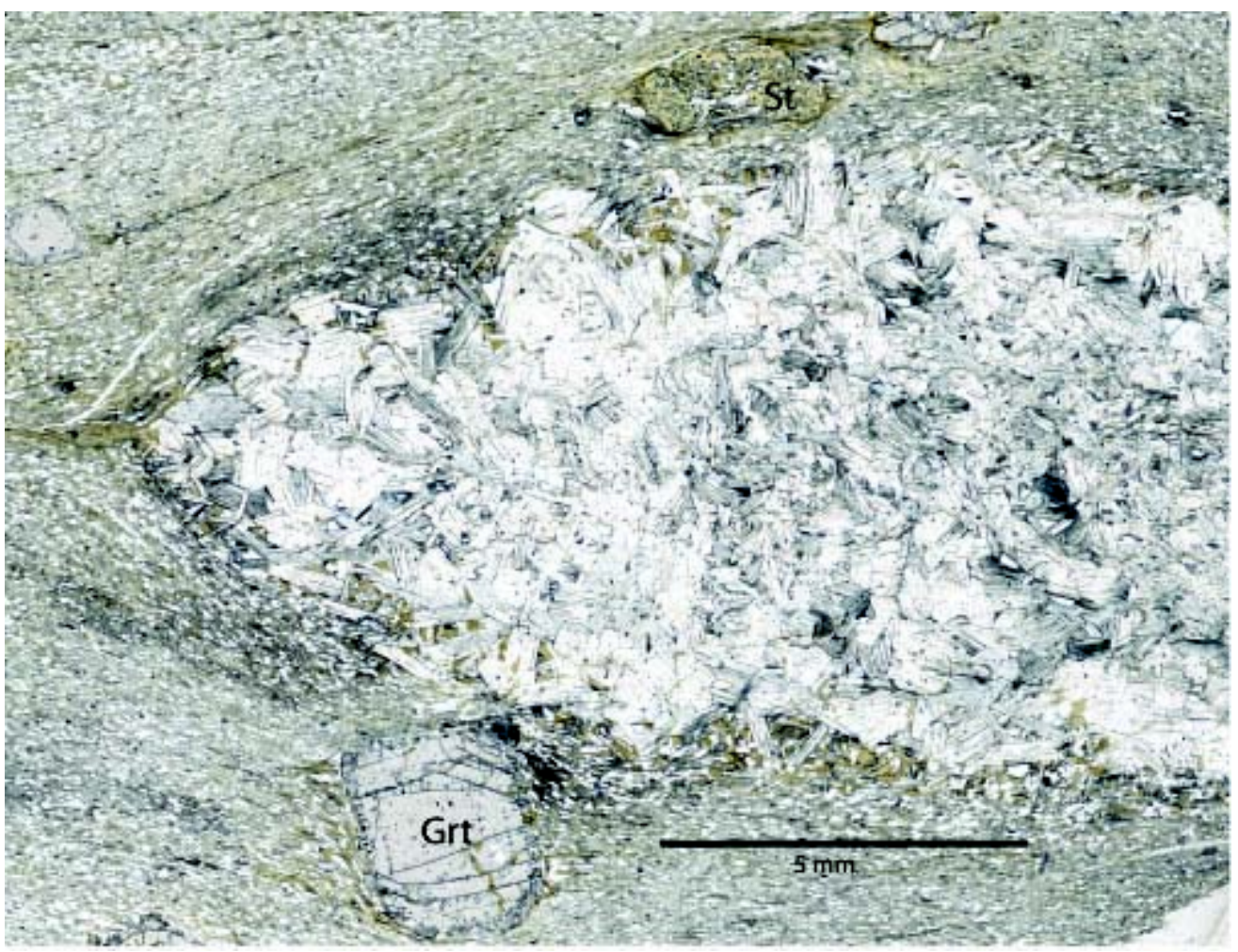

Figure 4 


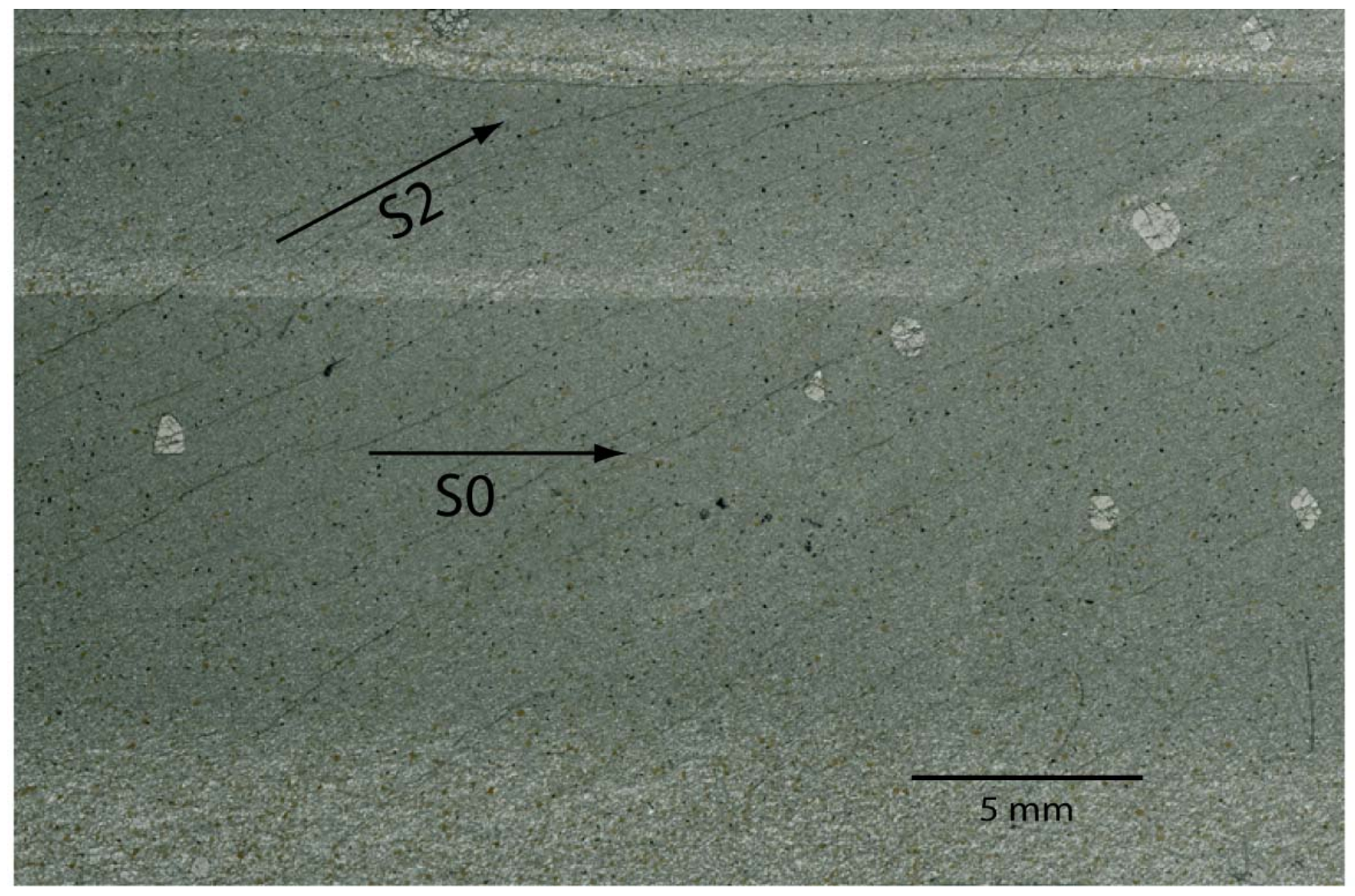

Figure 5 


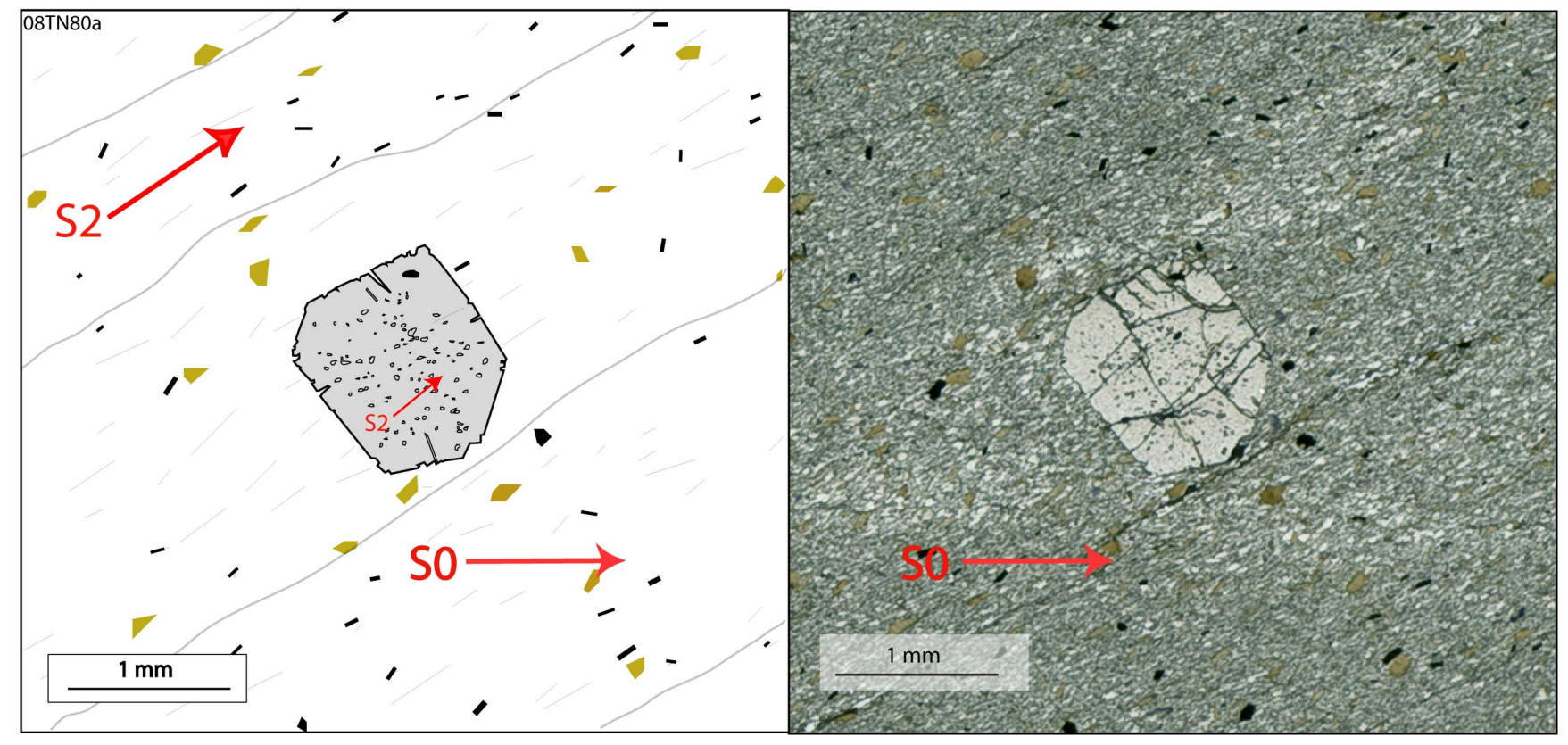

Figure 6 


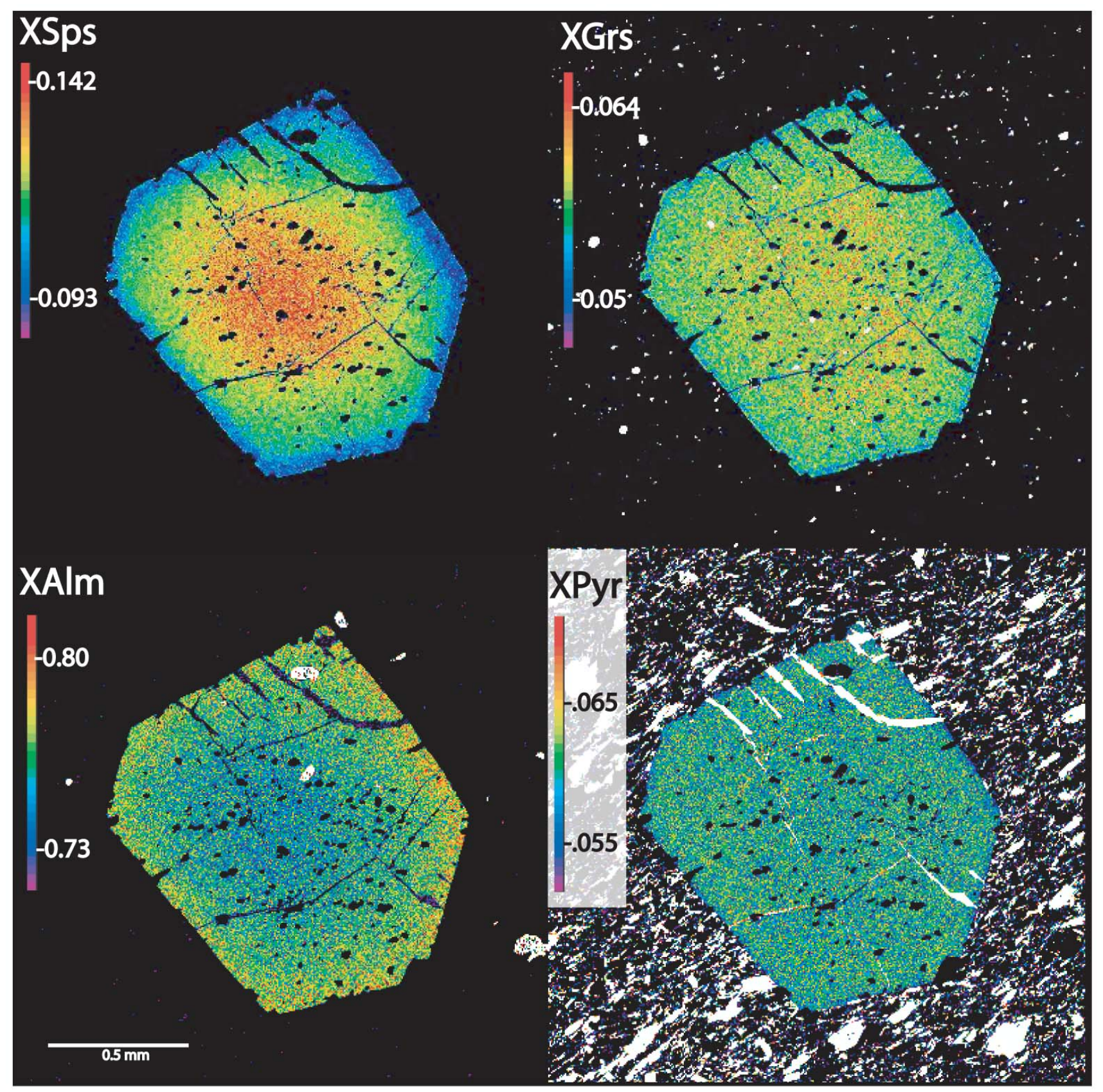

Figure 7 


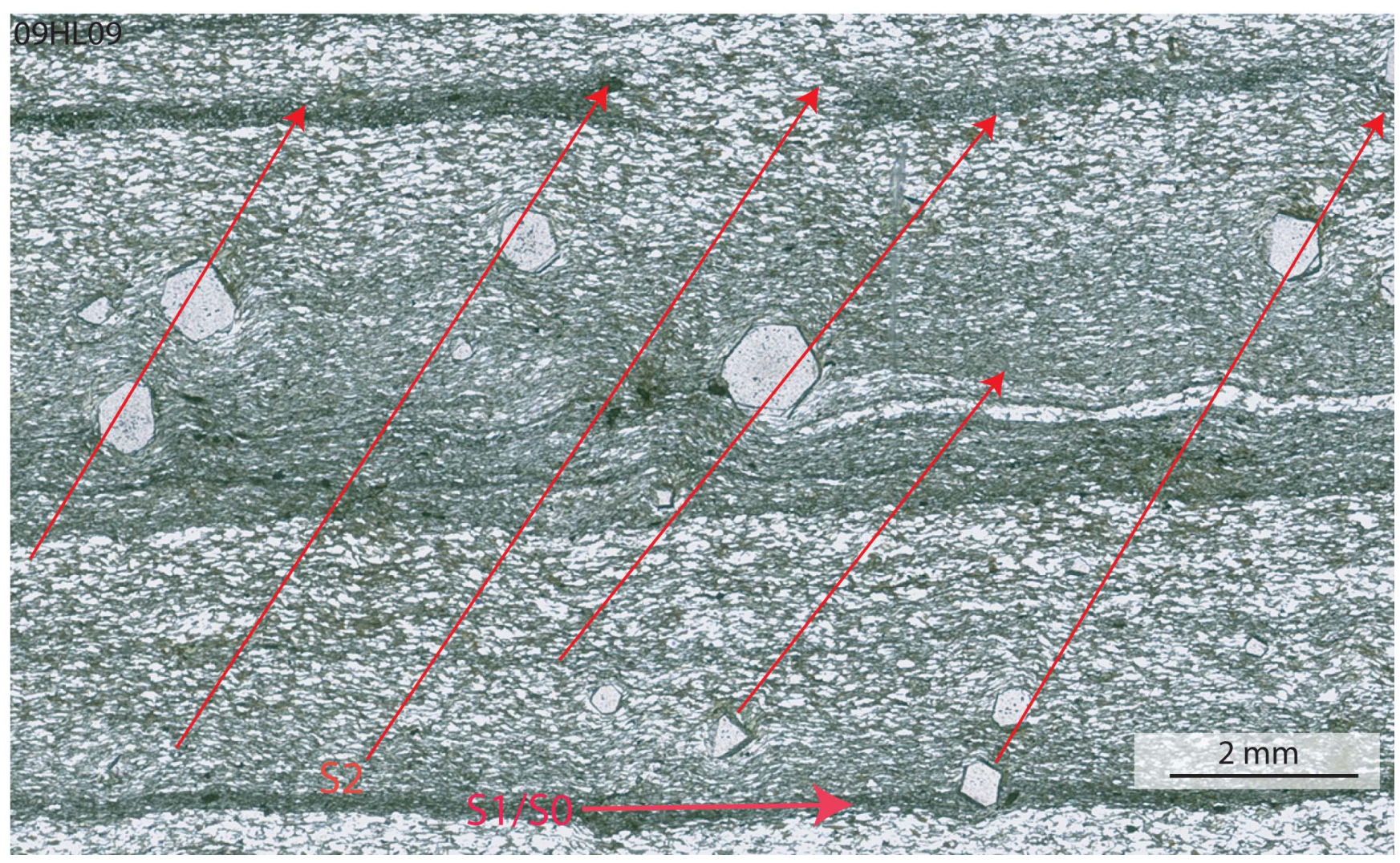

Figure 8 


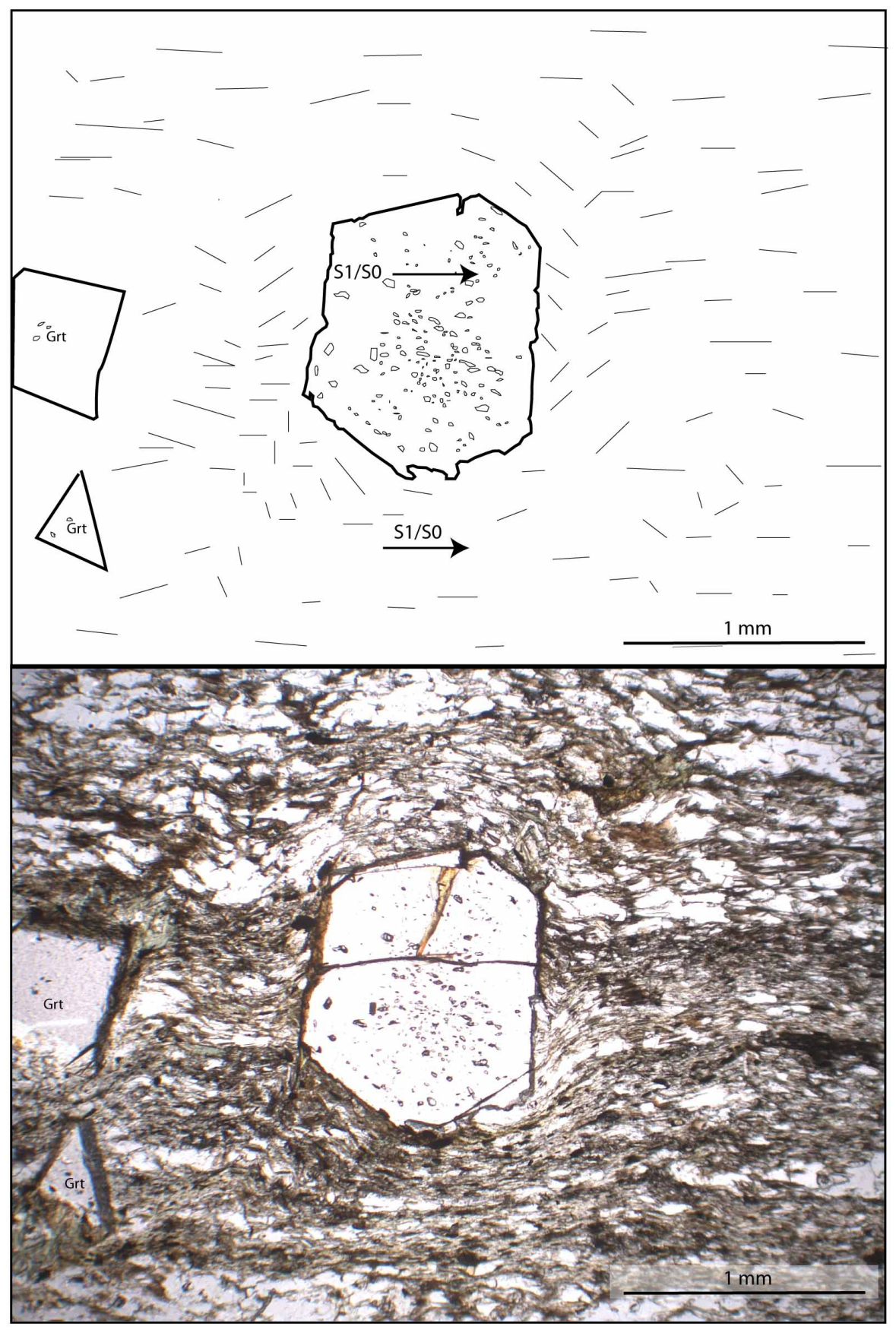

Figure 9 


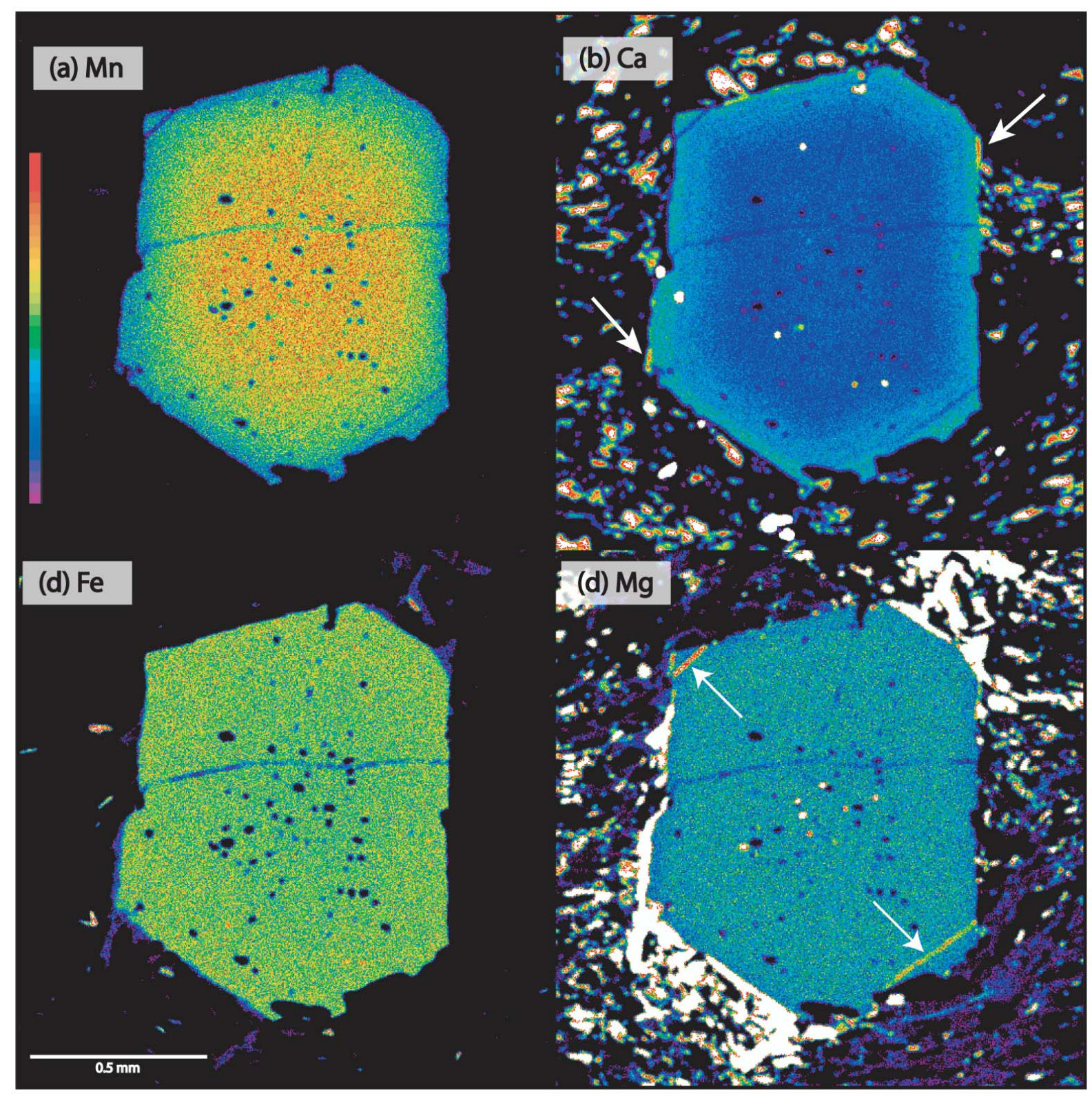

Figure 10 


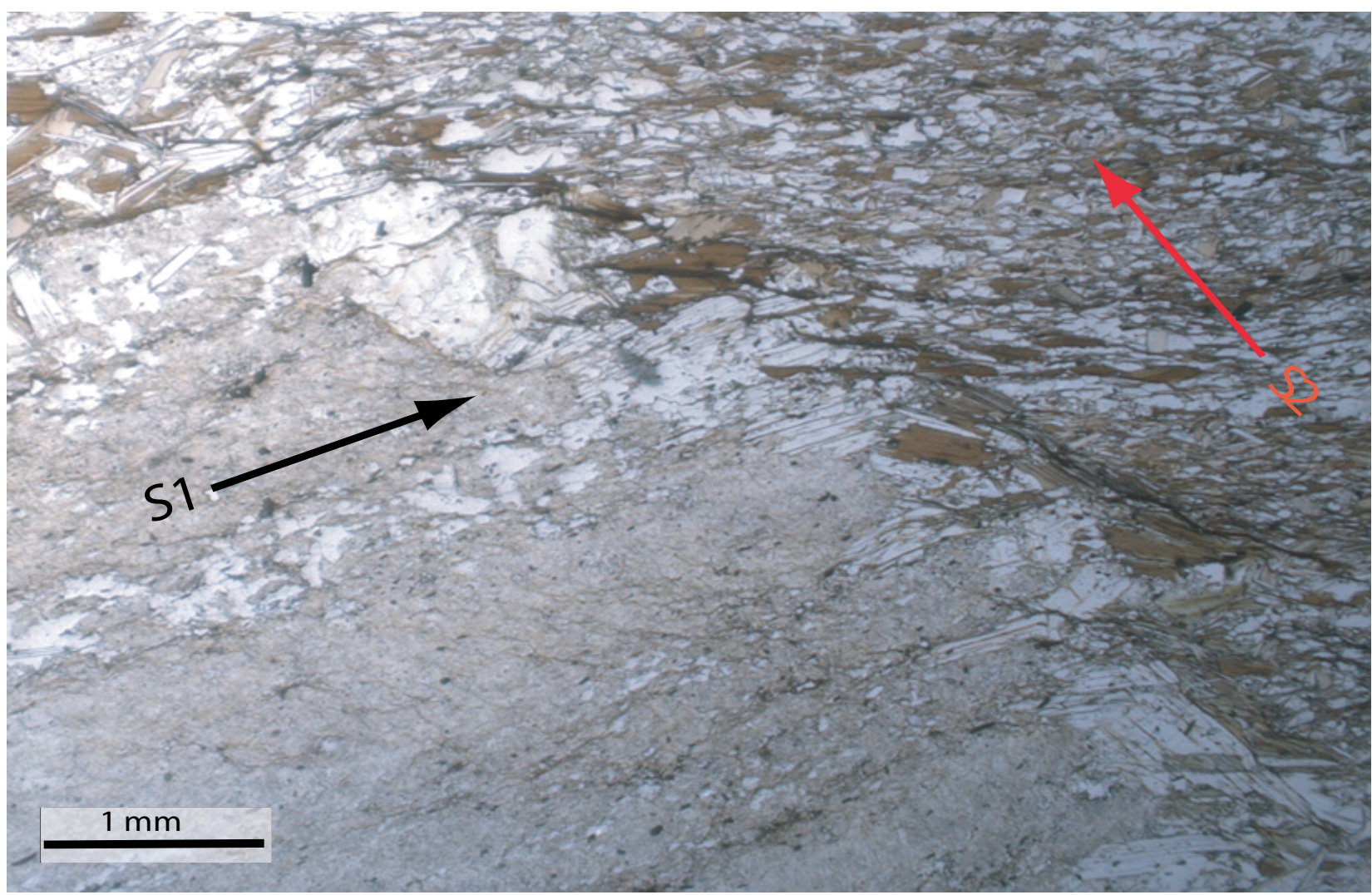

Figure 11 


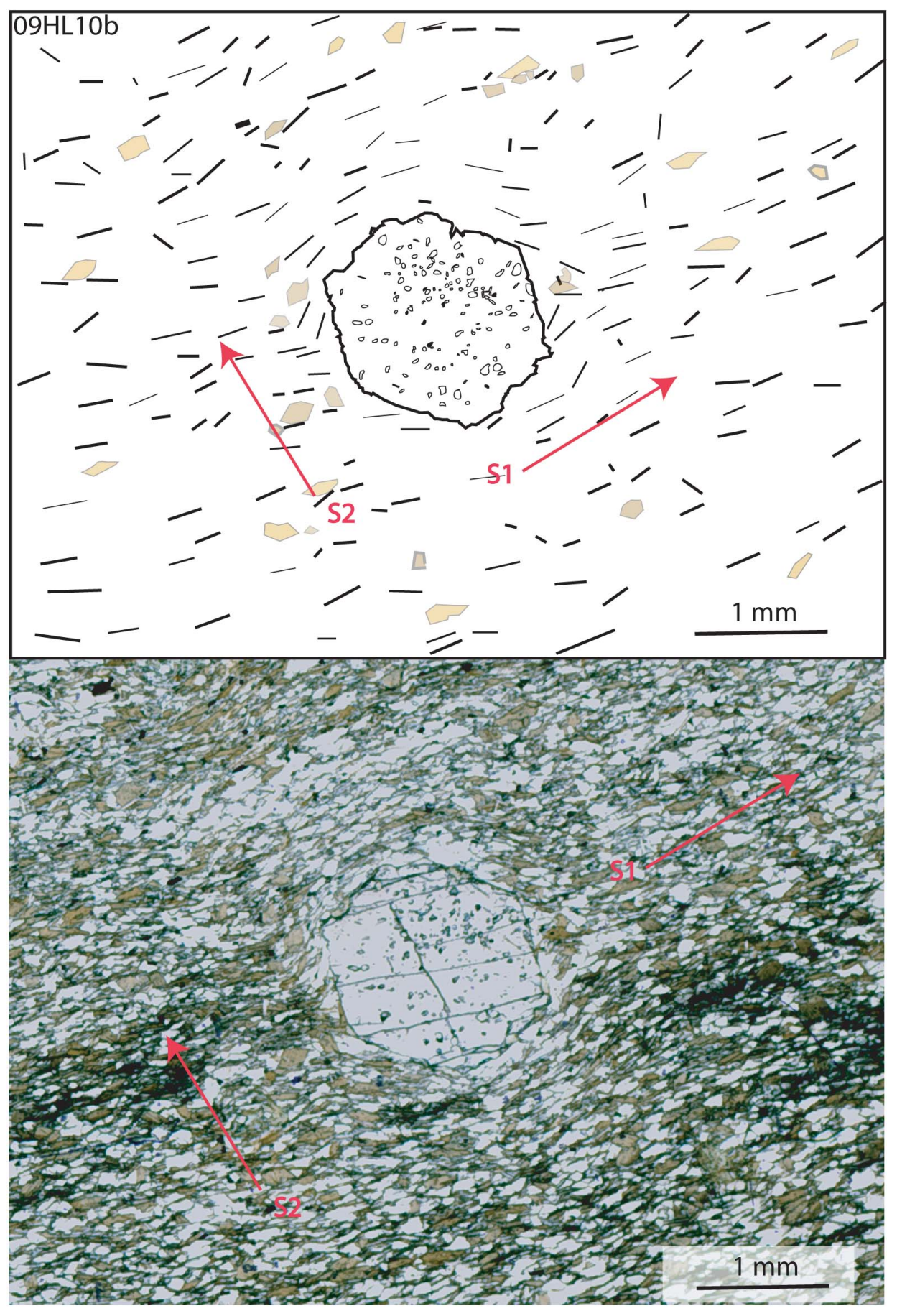

Figure 12 


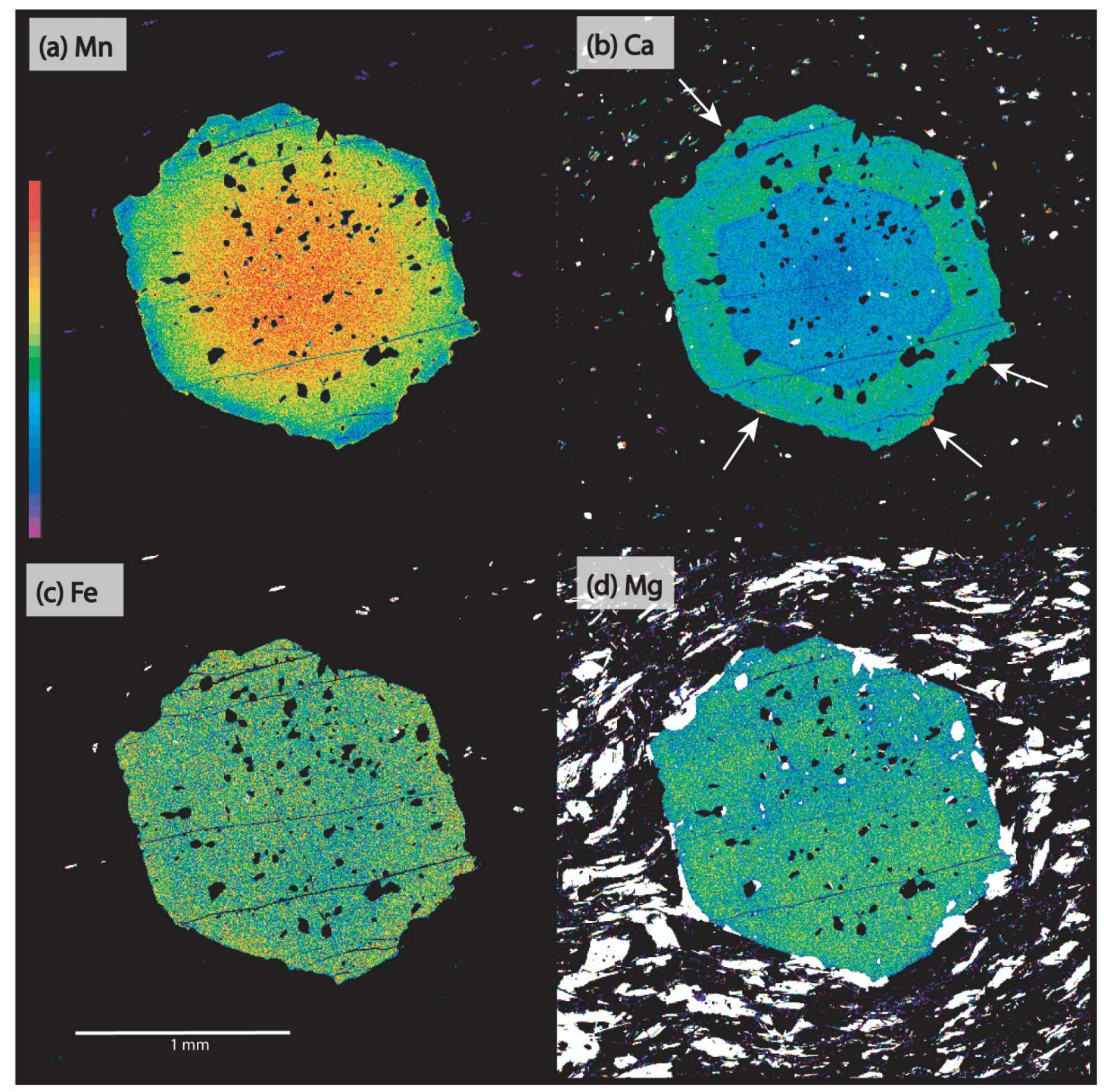

Figure 13 


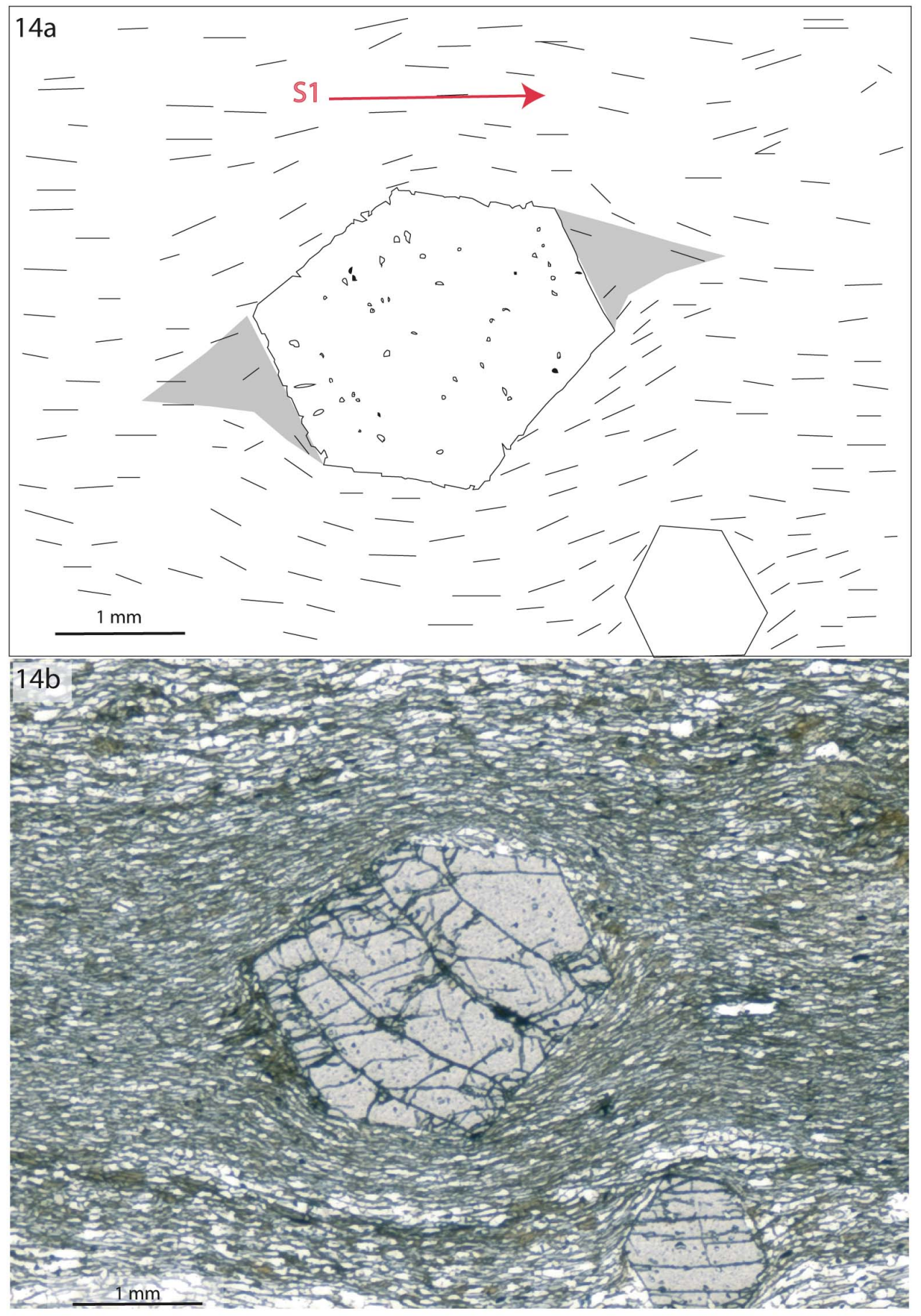

Figure 14a,b 


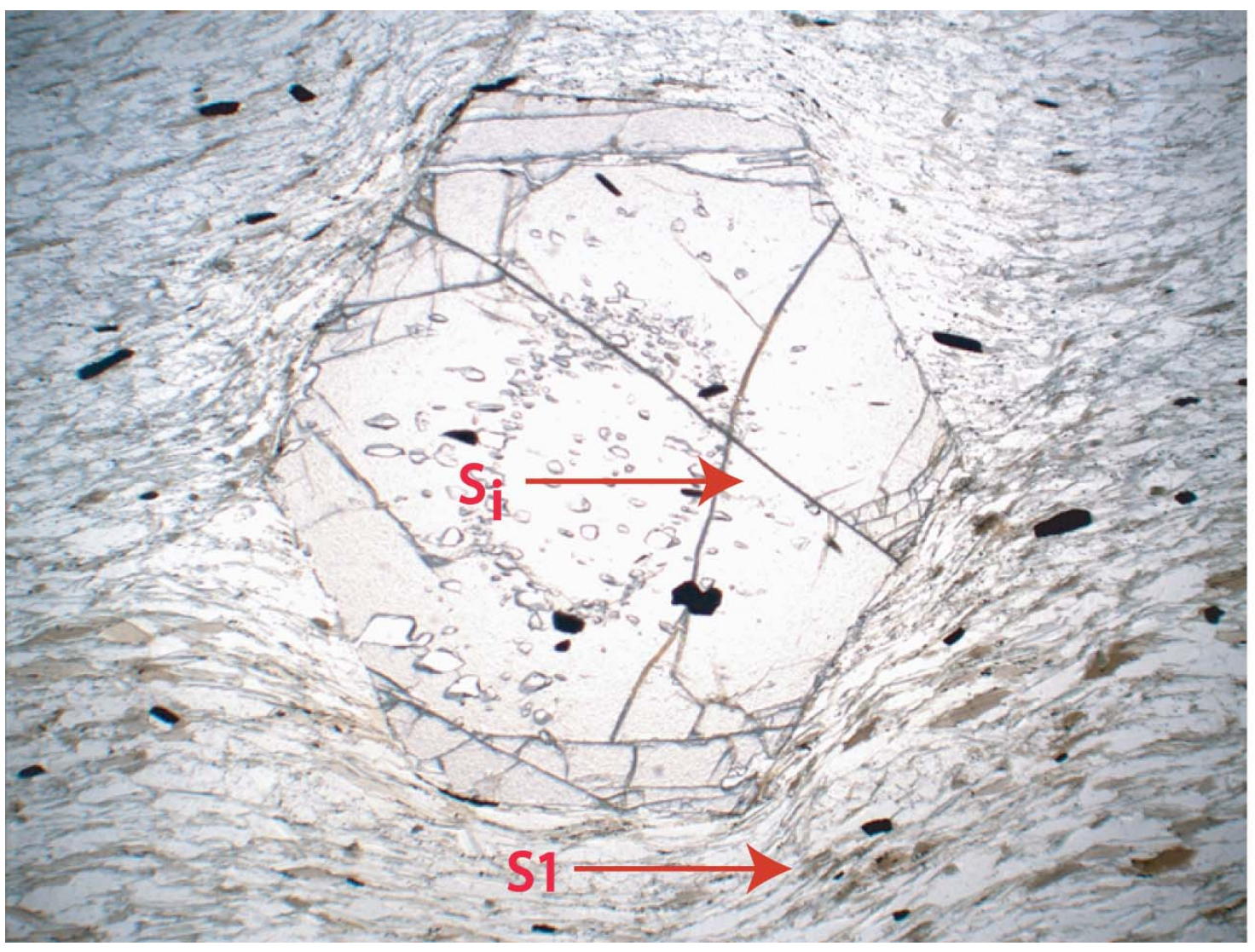

Figure 14c 

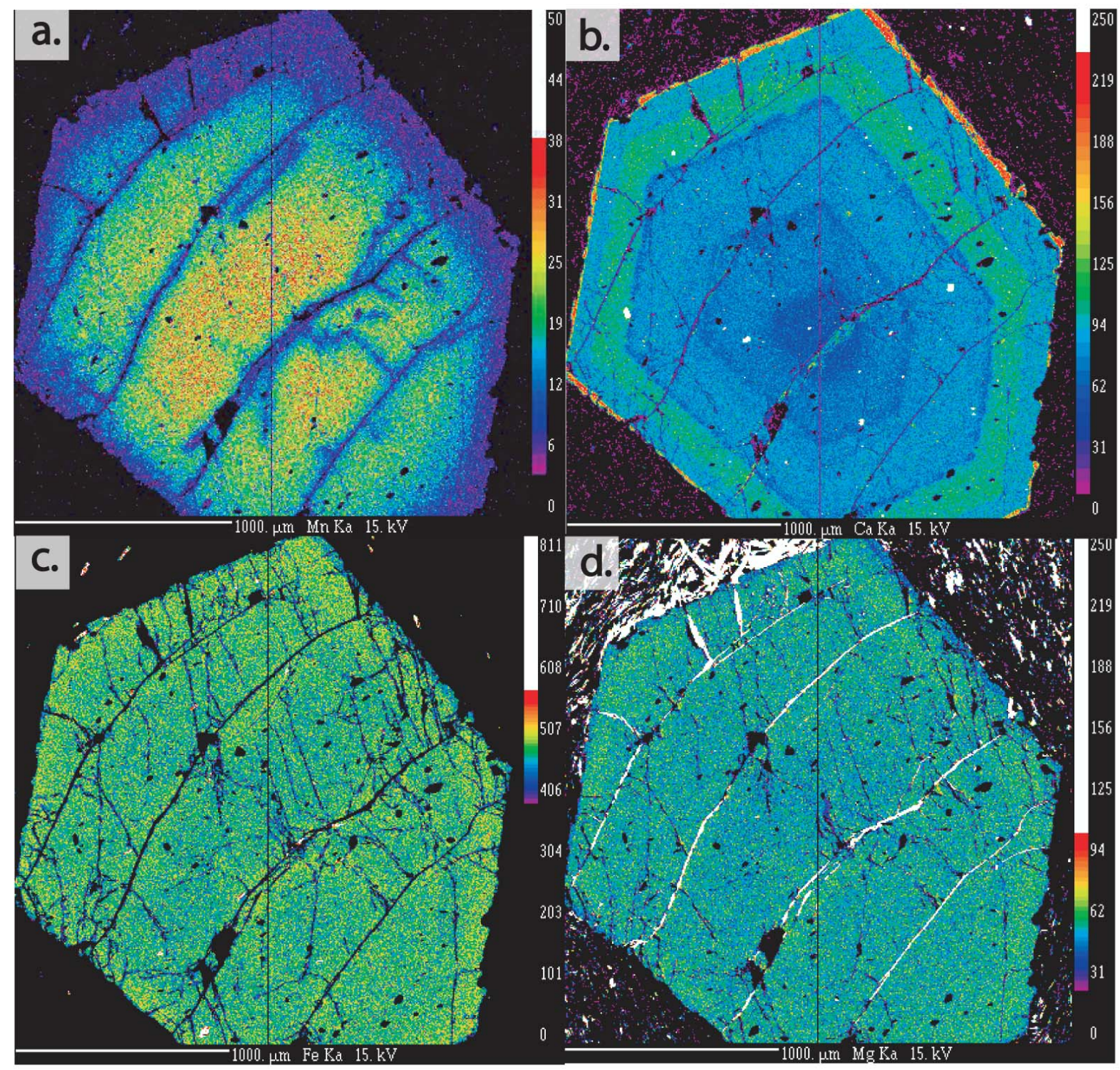

Figure 15 


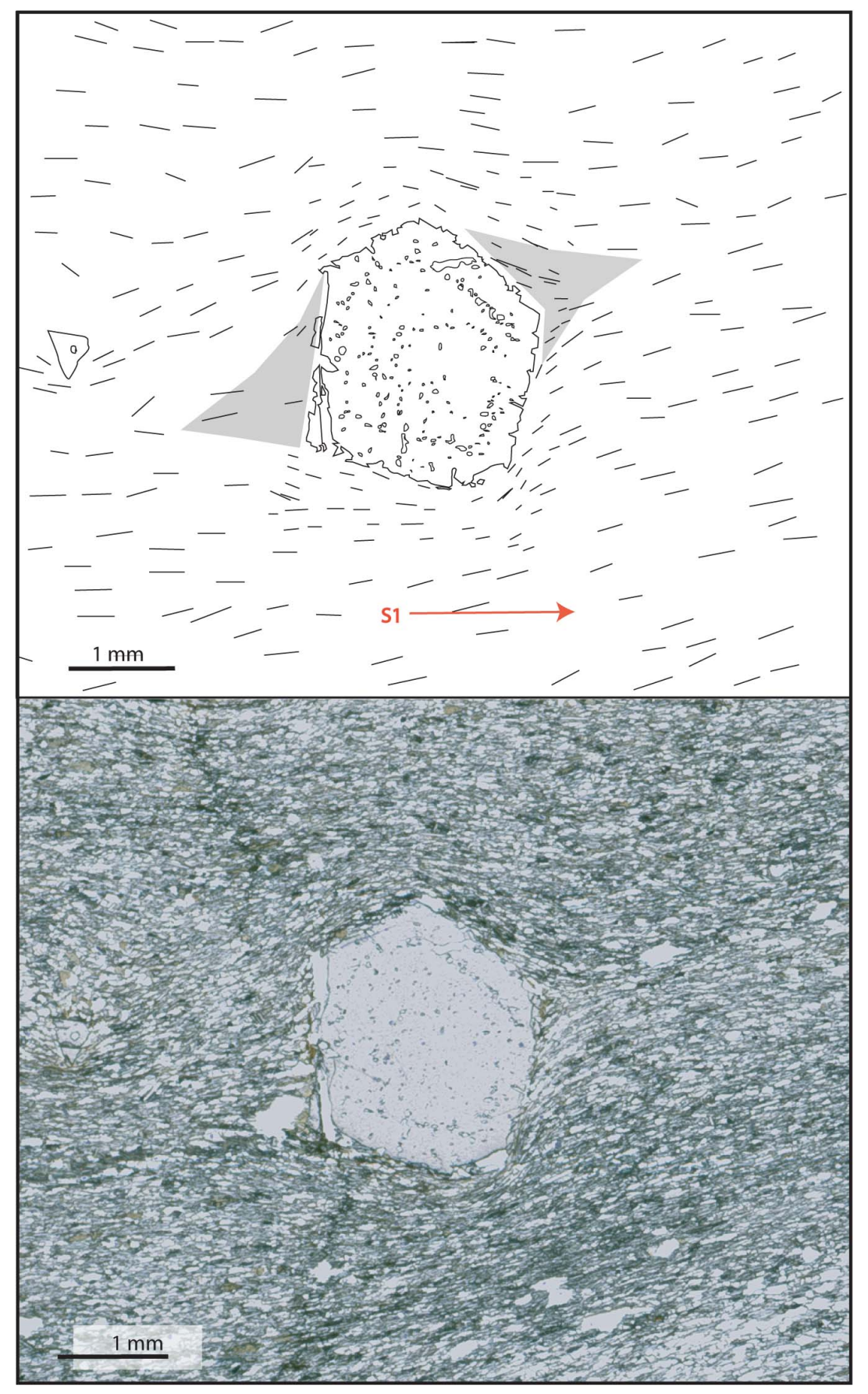

Figure 16 


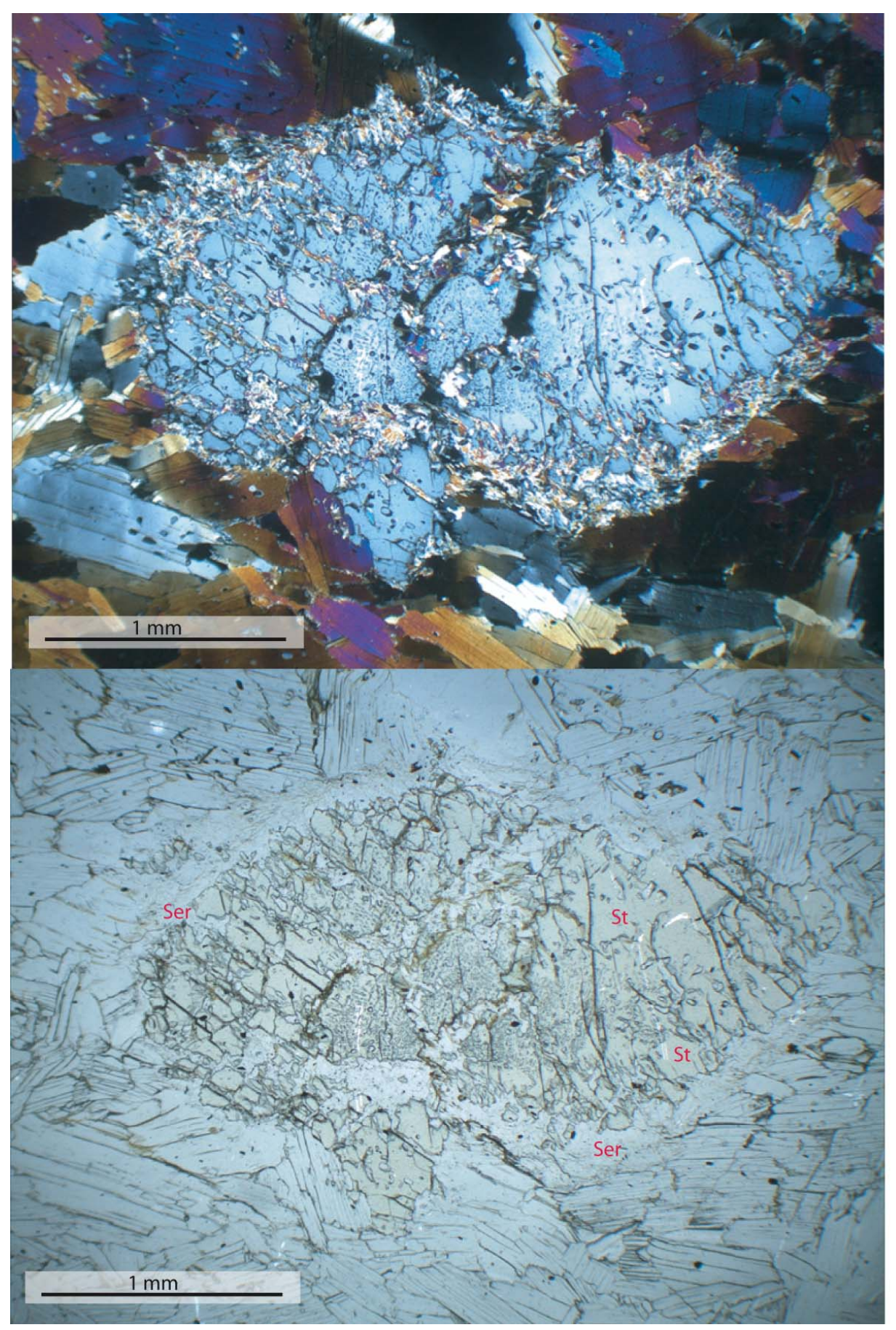

Figure 17 


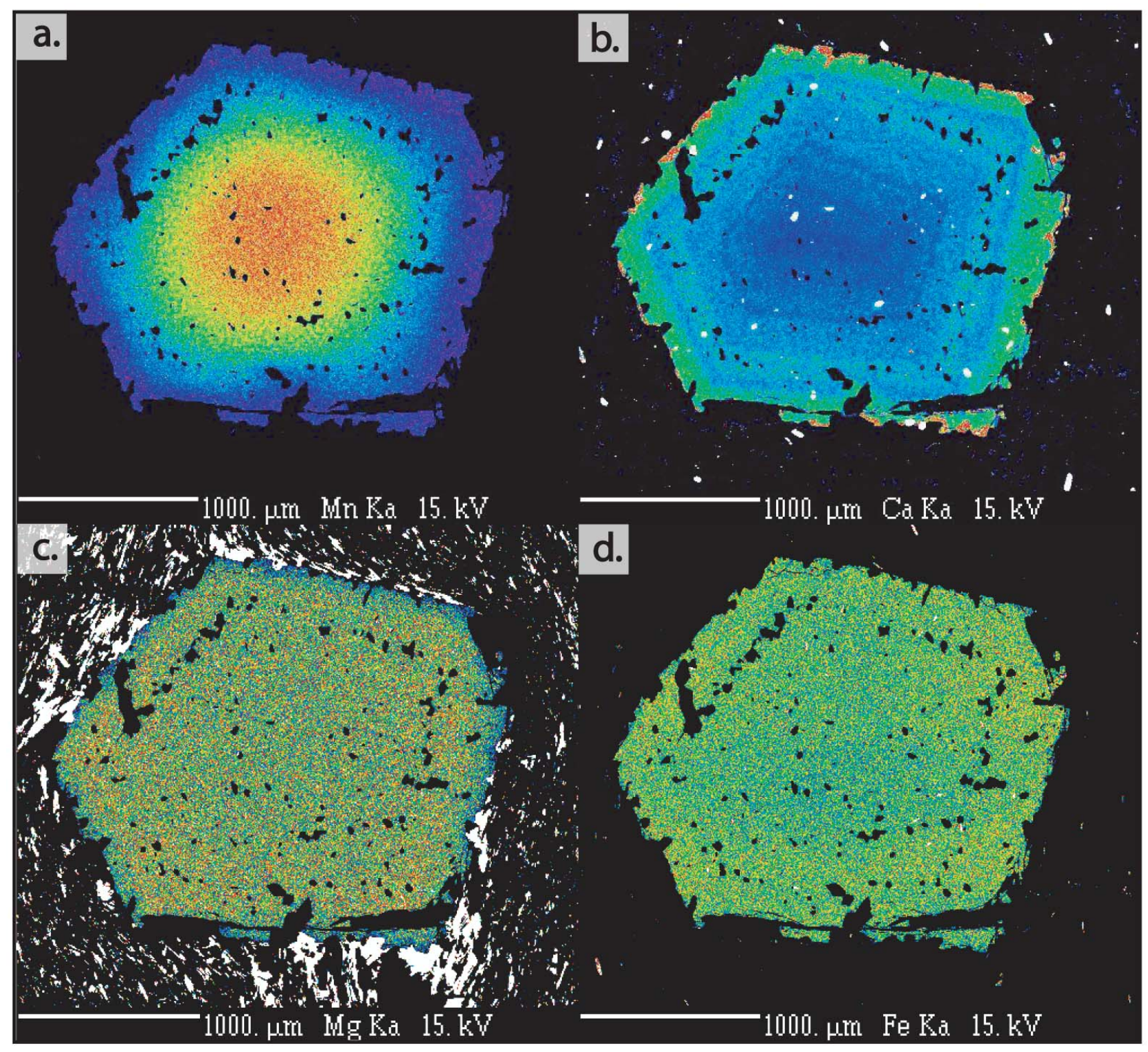

Figure 18 


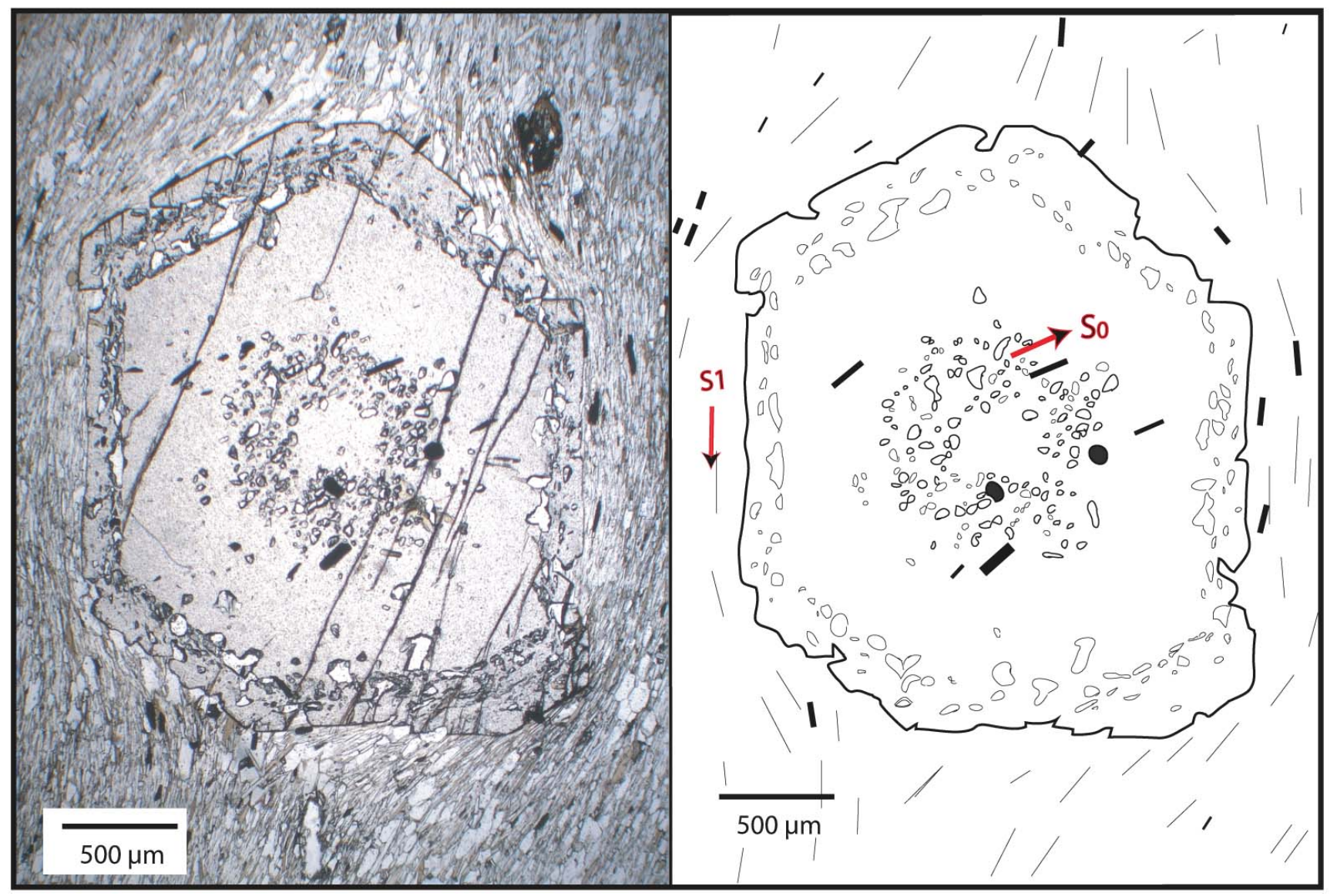

Figure 19 


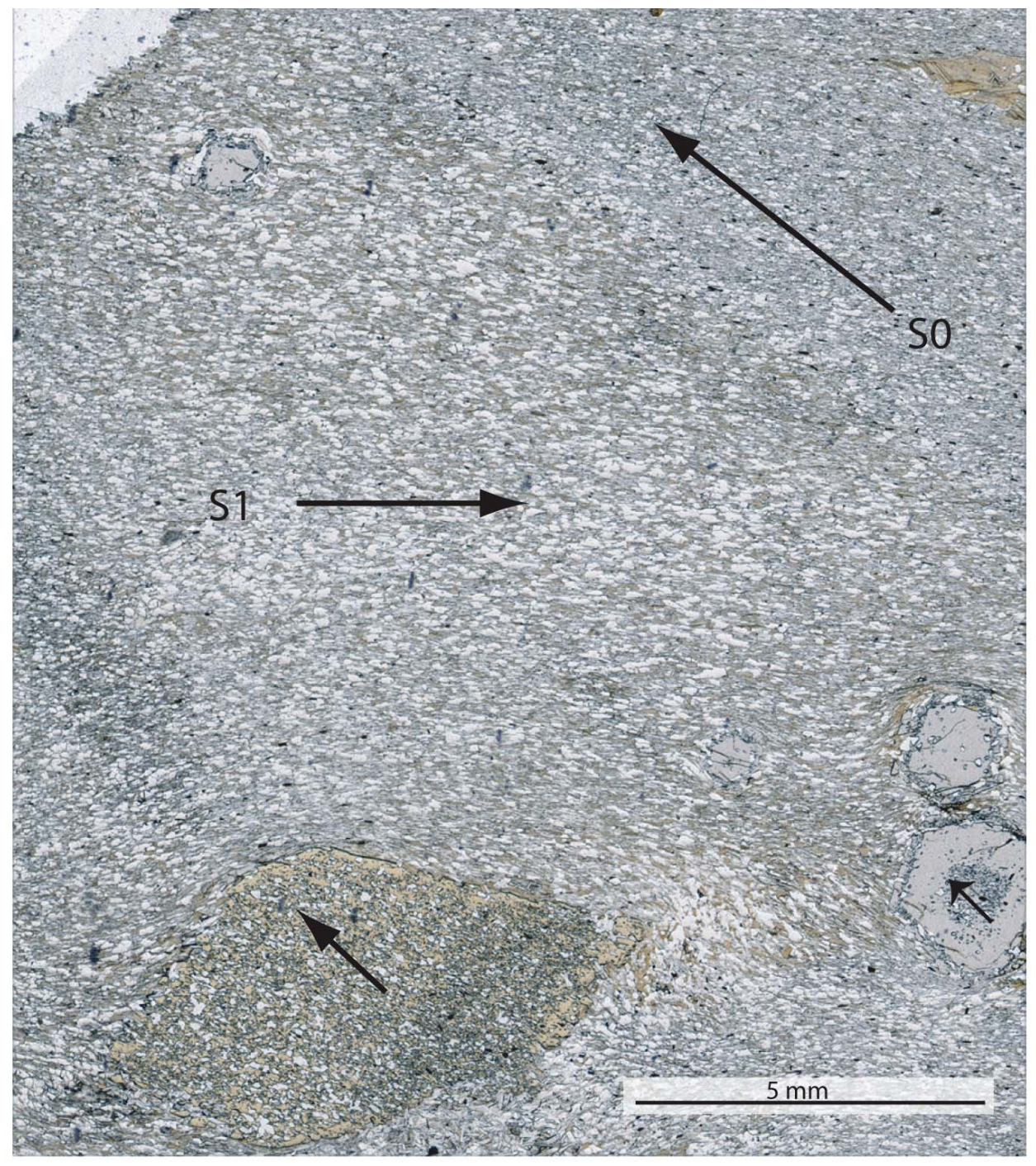

Figure 20 


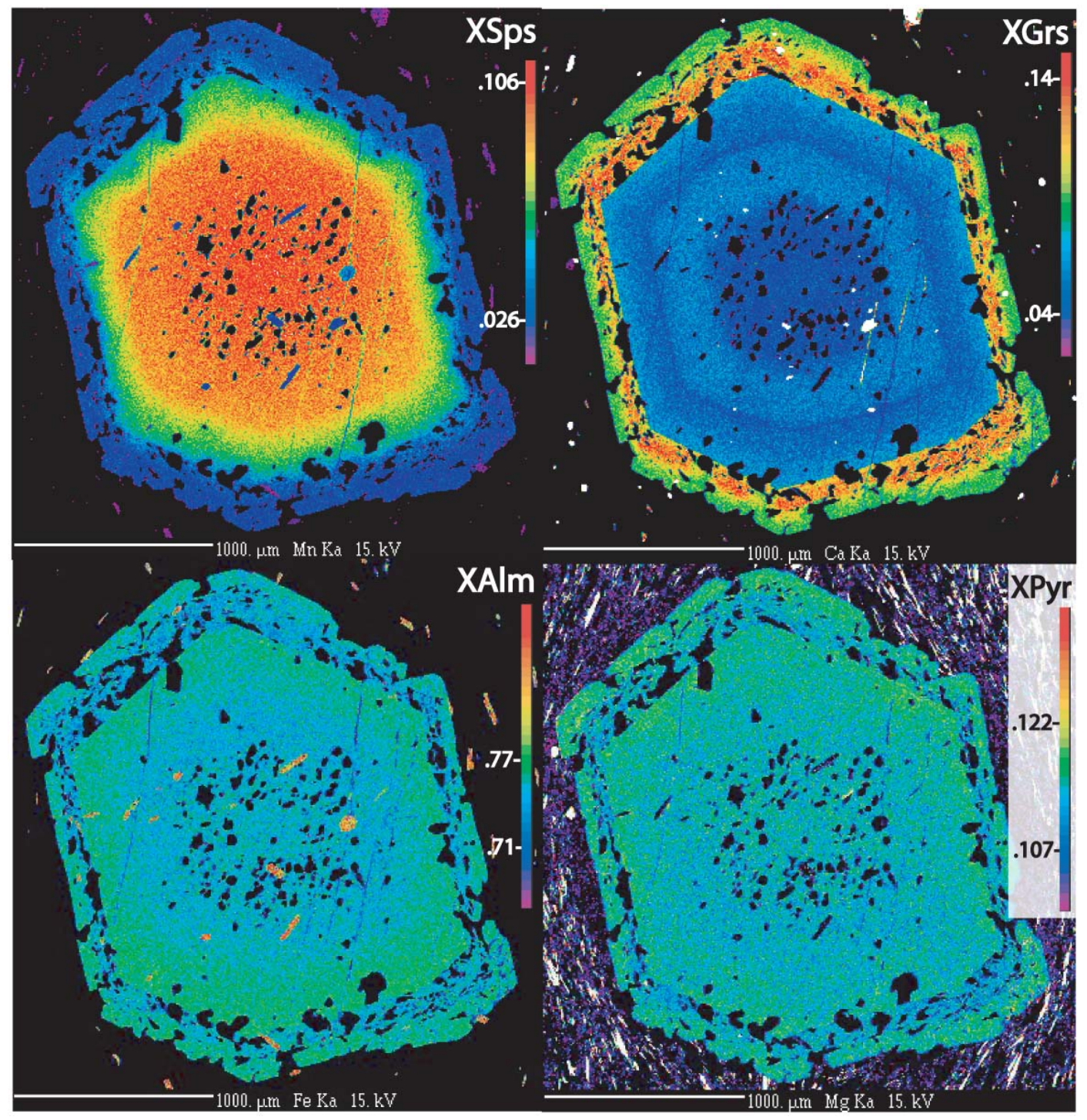

Figure 21 


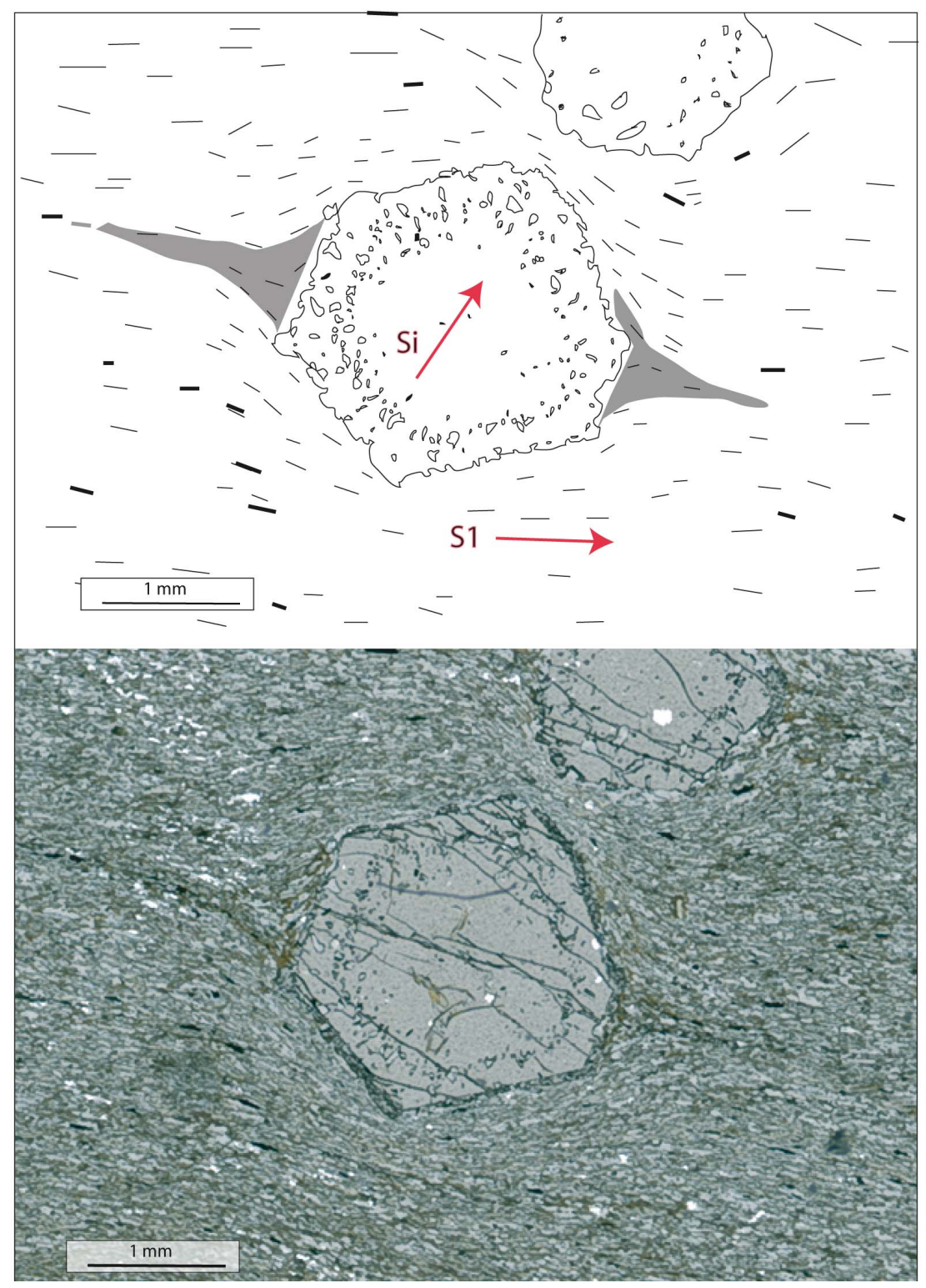

Figure 22 


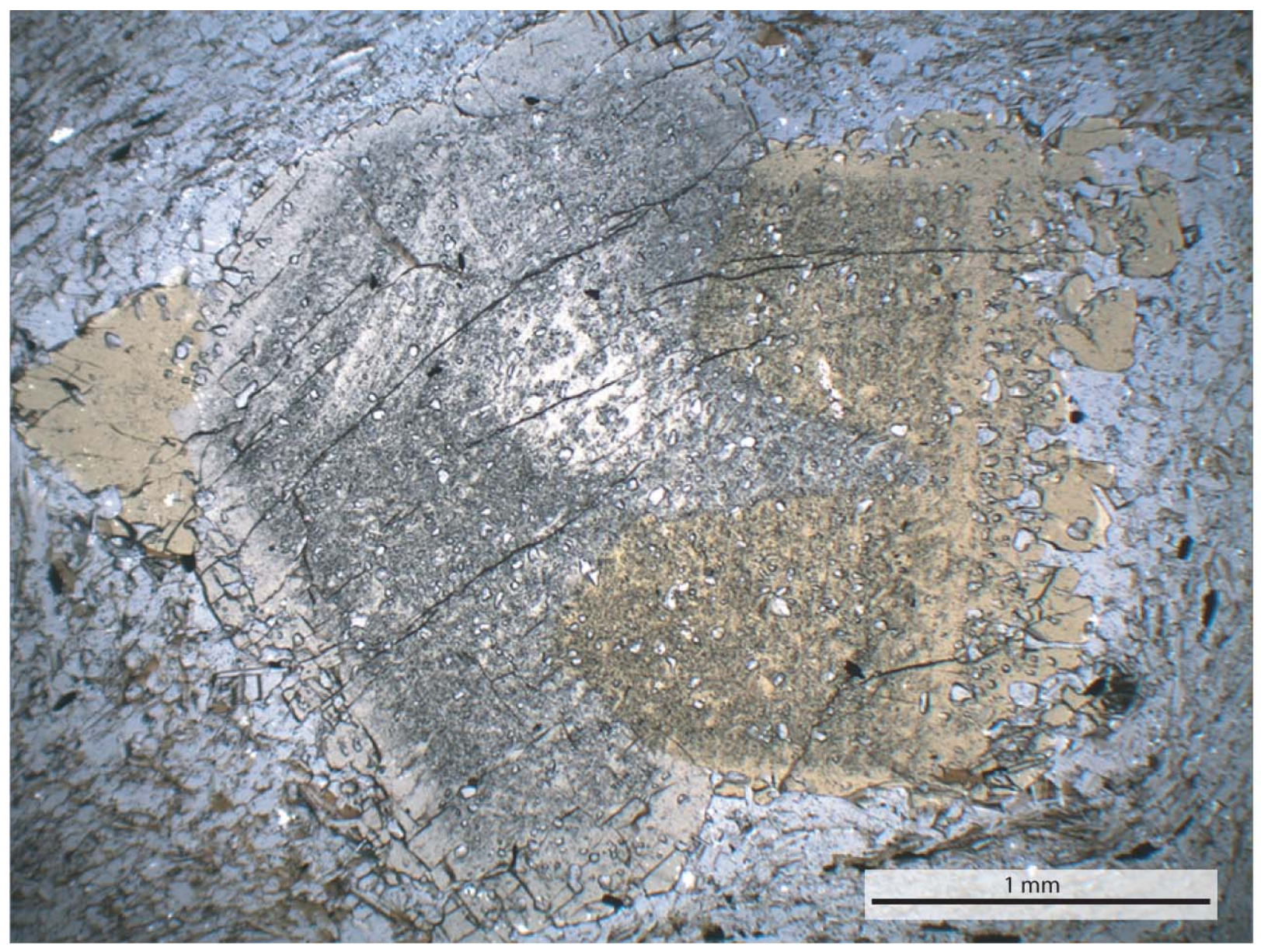

Figure 23 


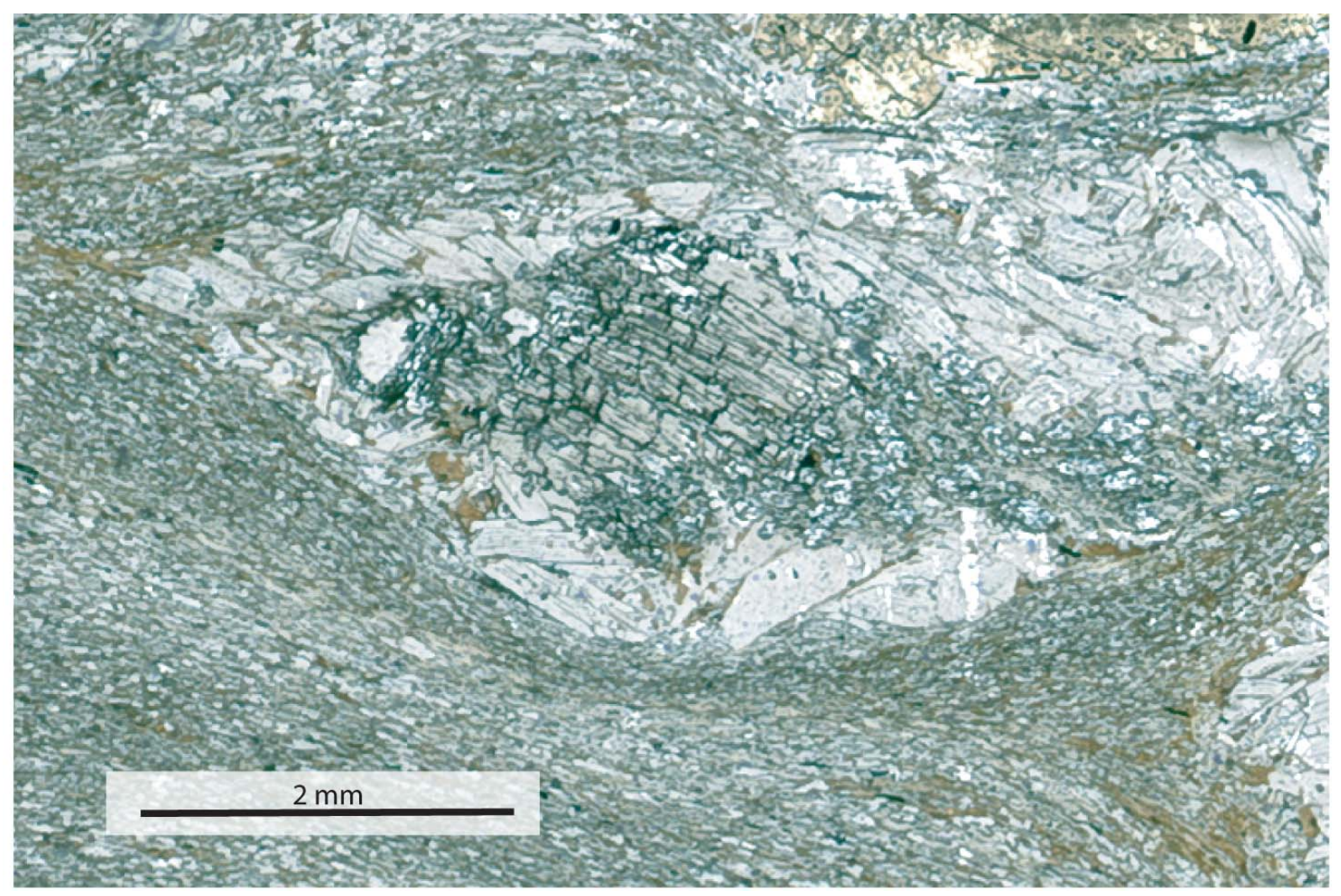

Figure 24 


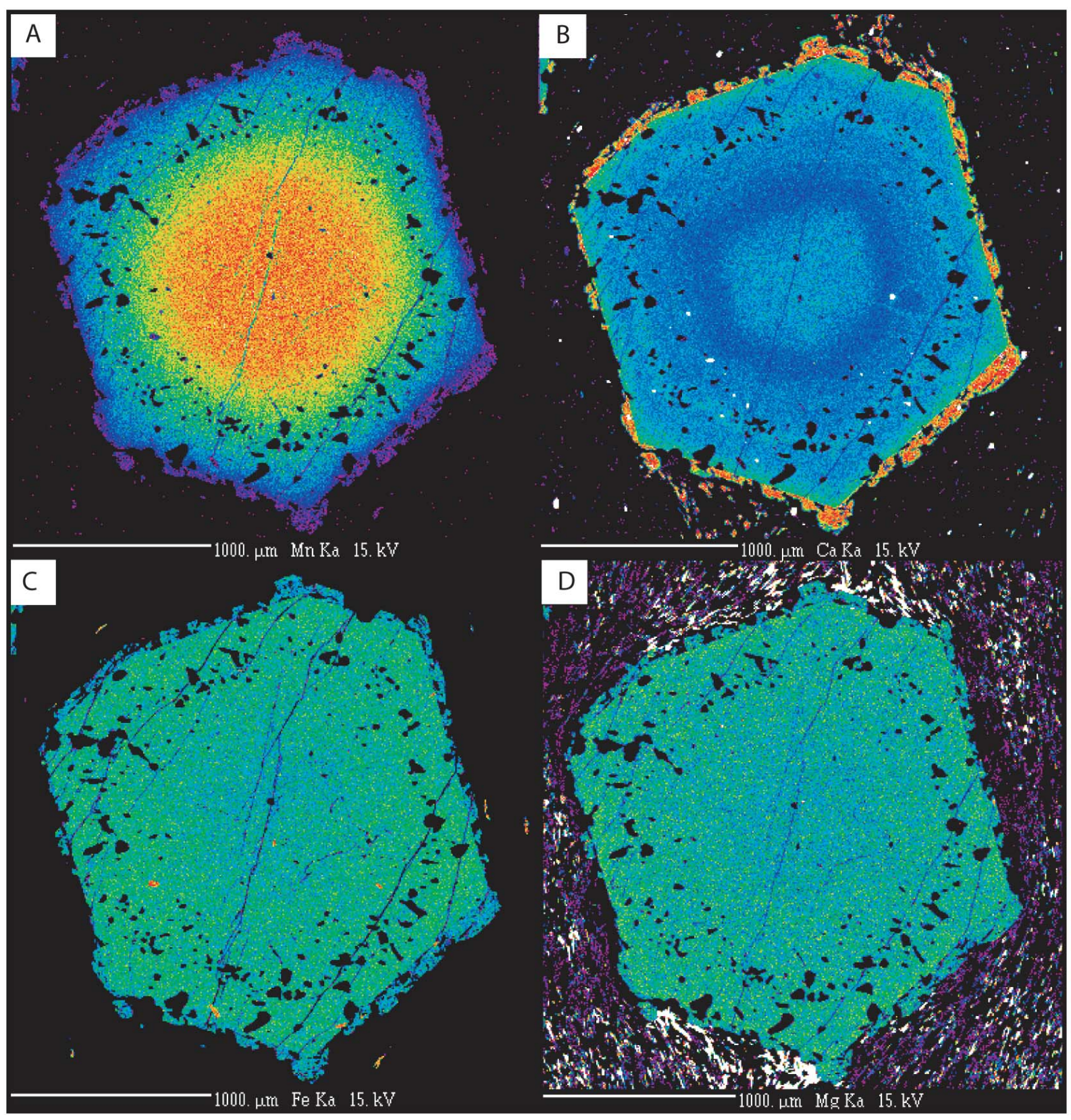

Figure 25 


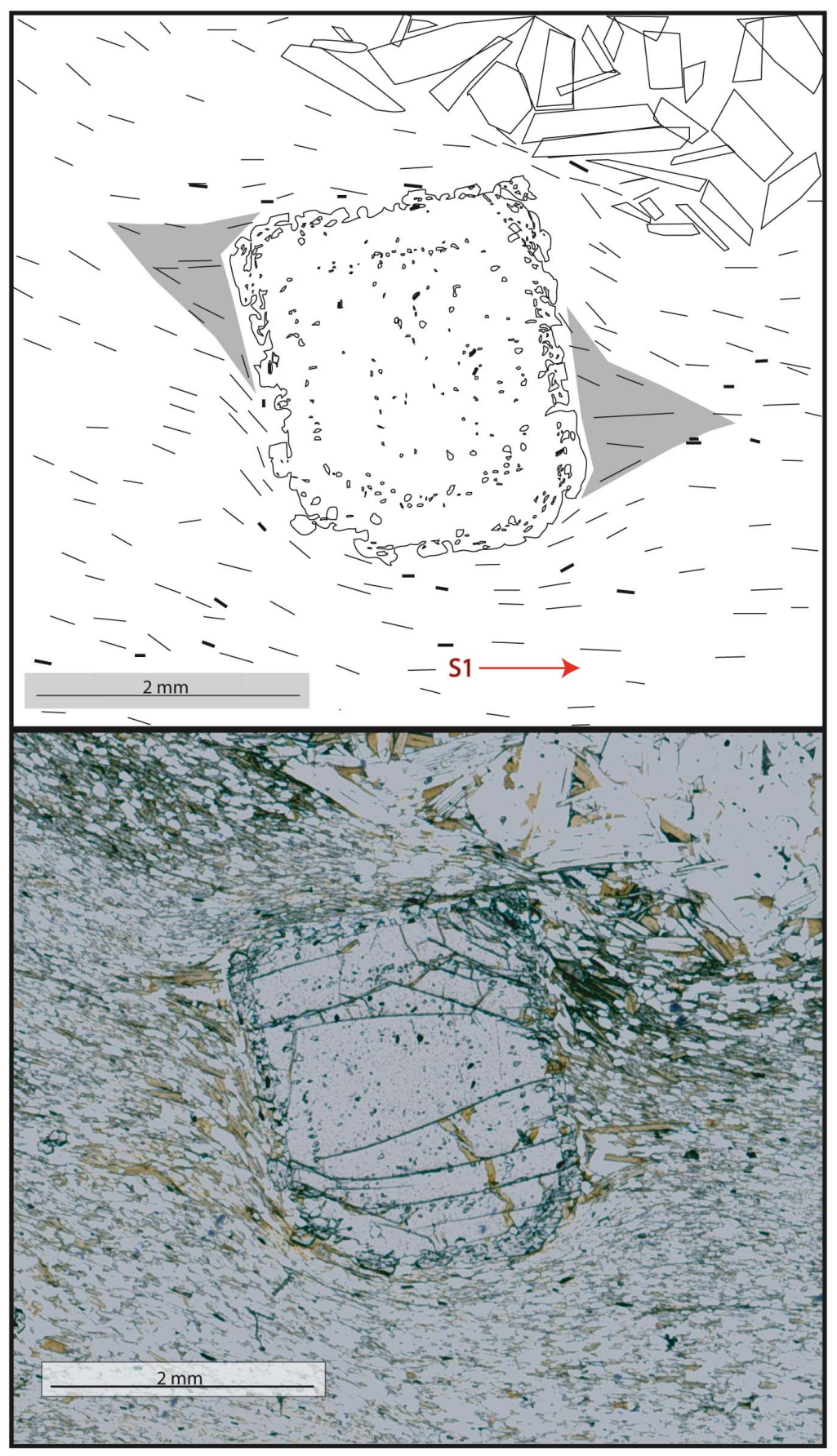

Figure 26 


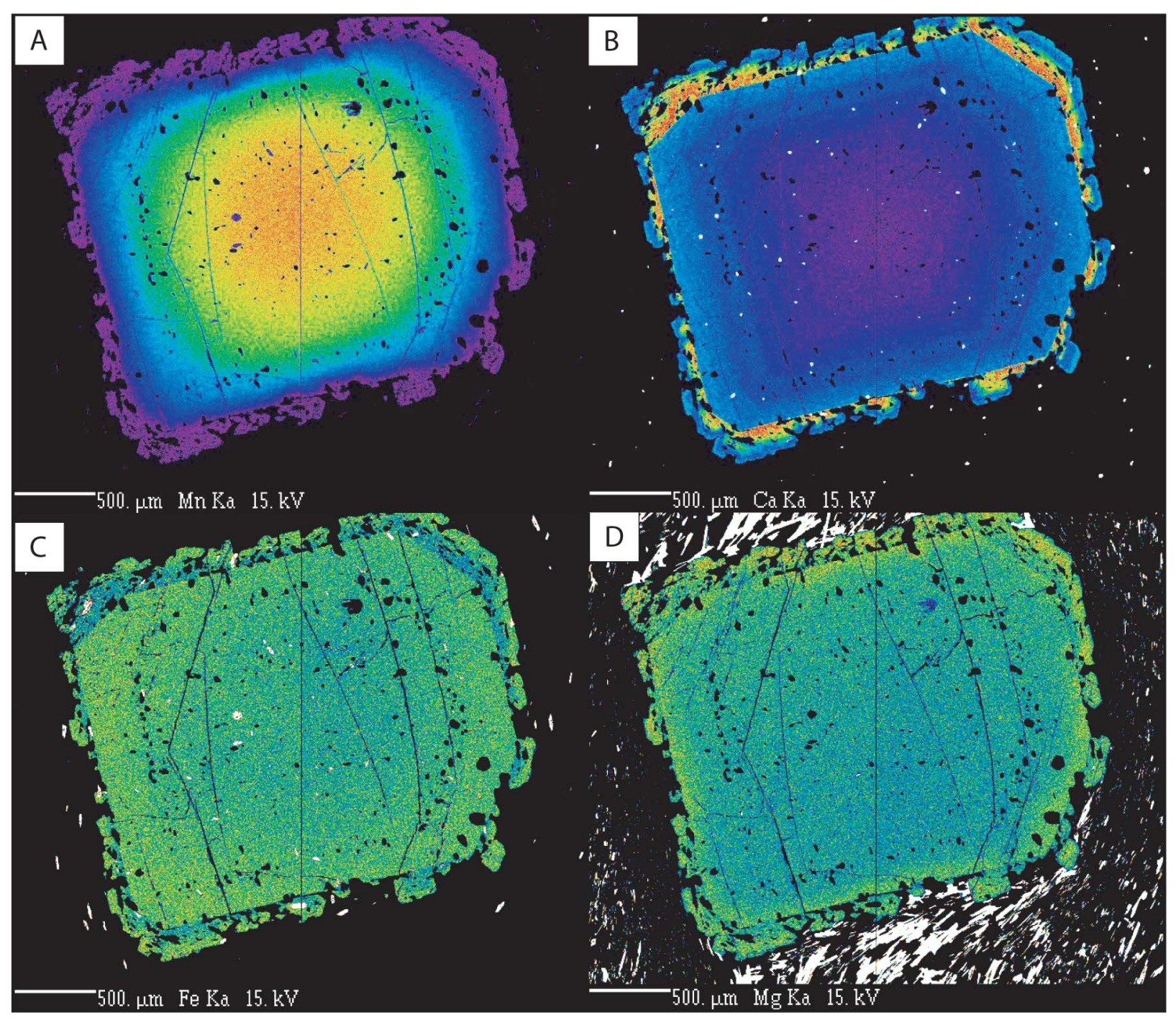

Figure 27 


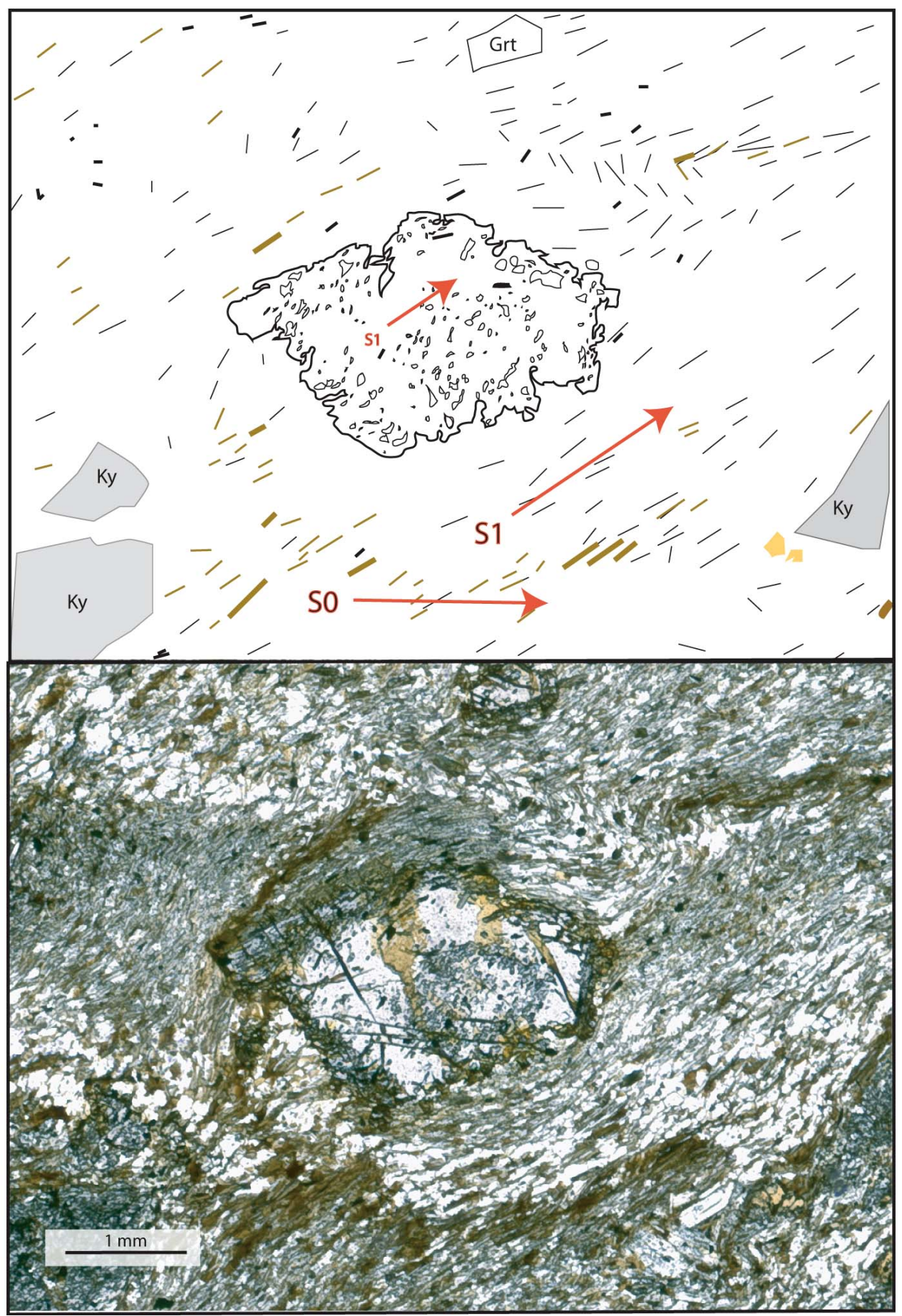

Figure 28 


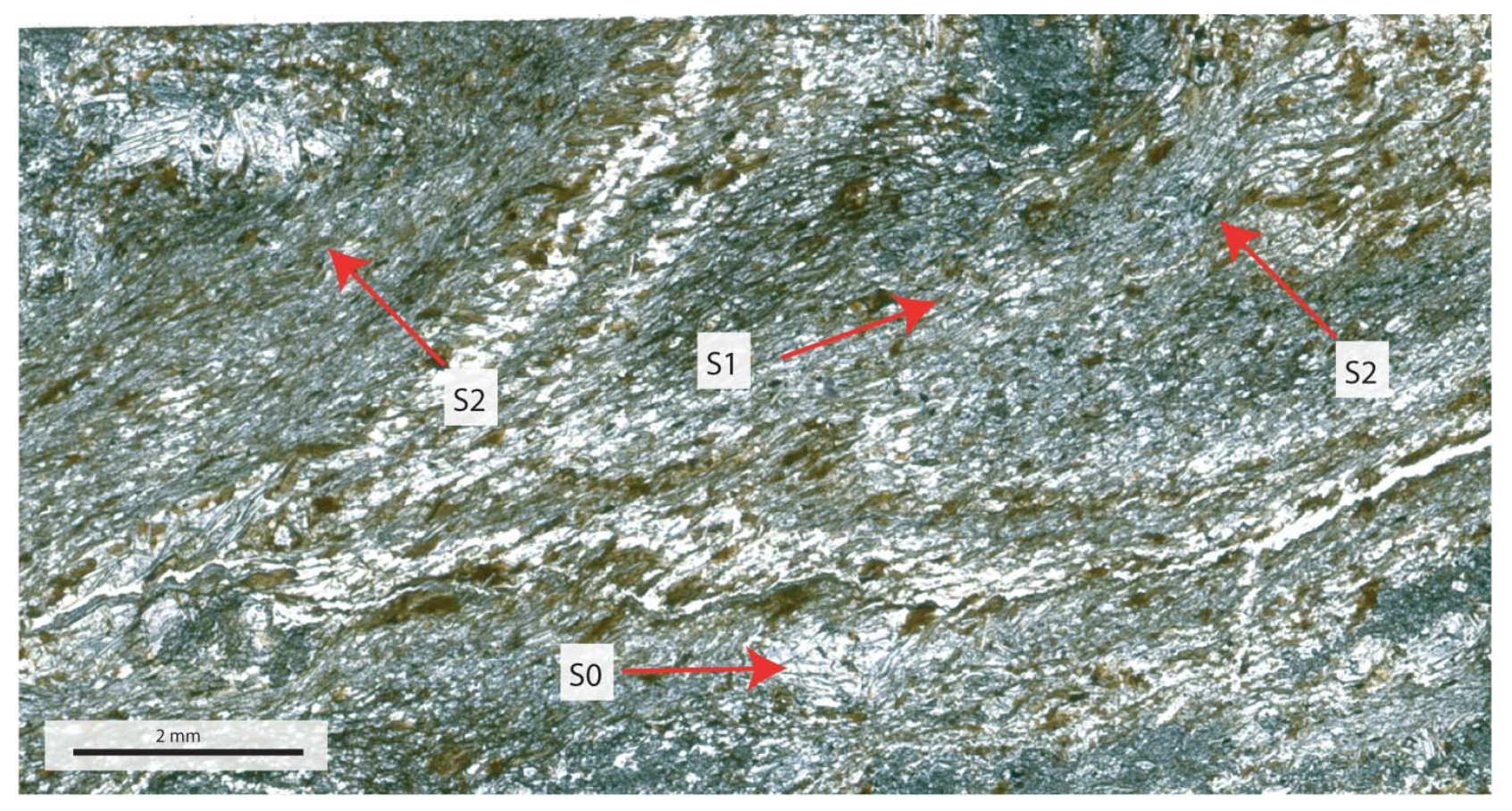

Figure 29 


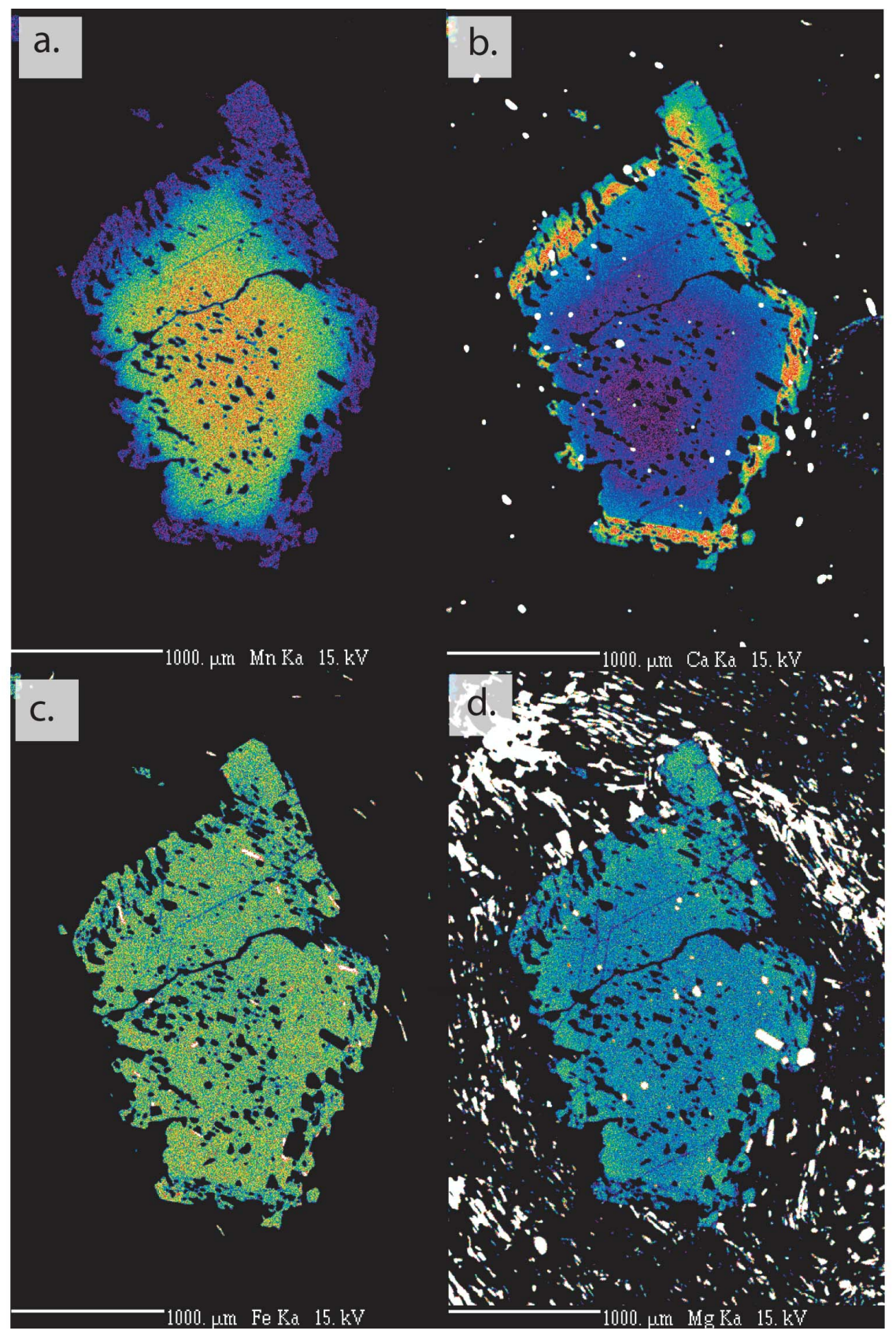

Figure 30 


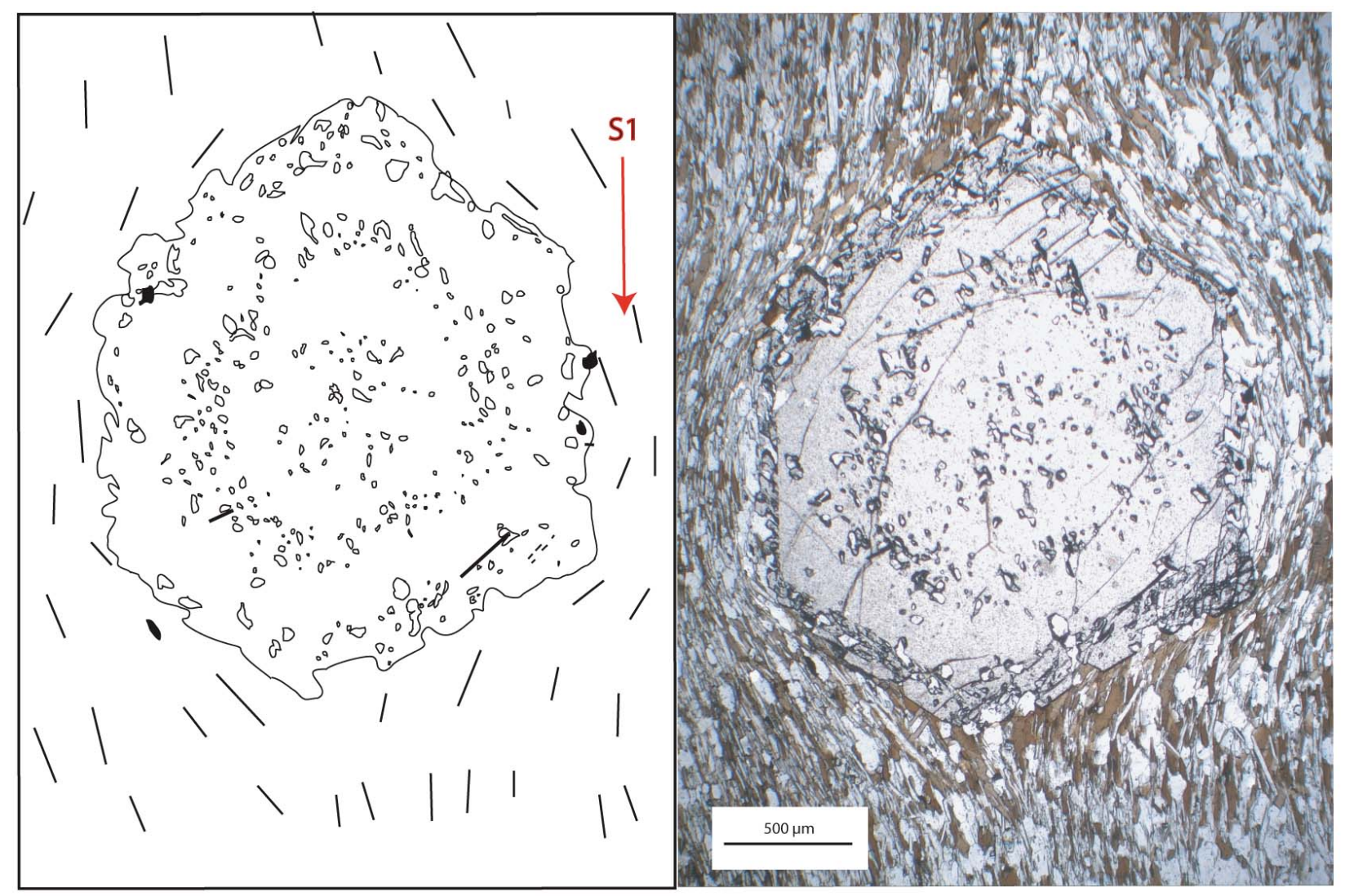

Figure 31 


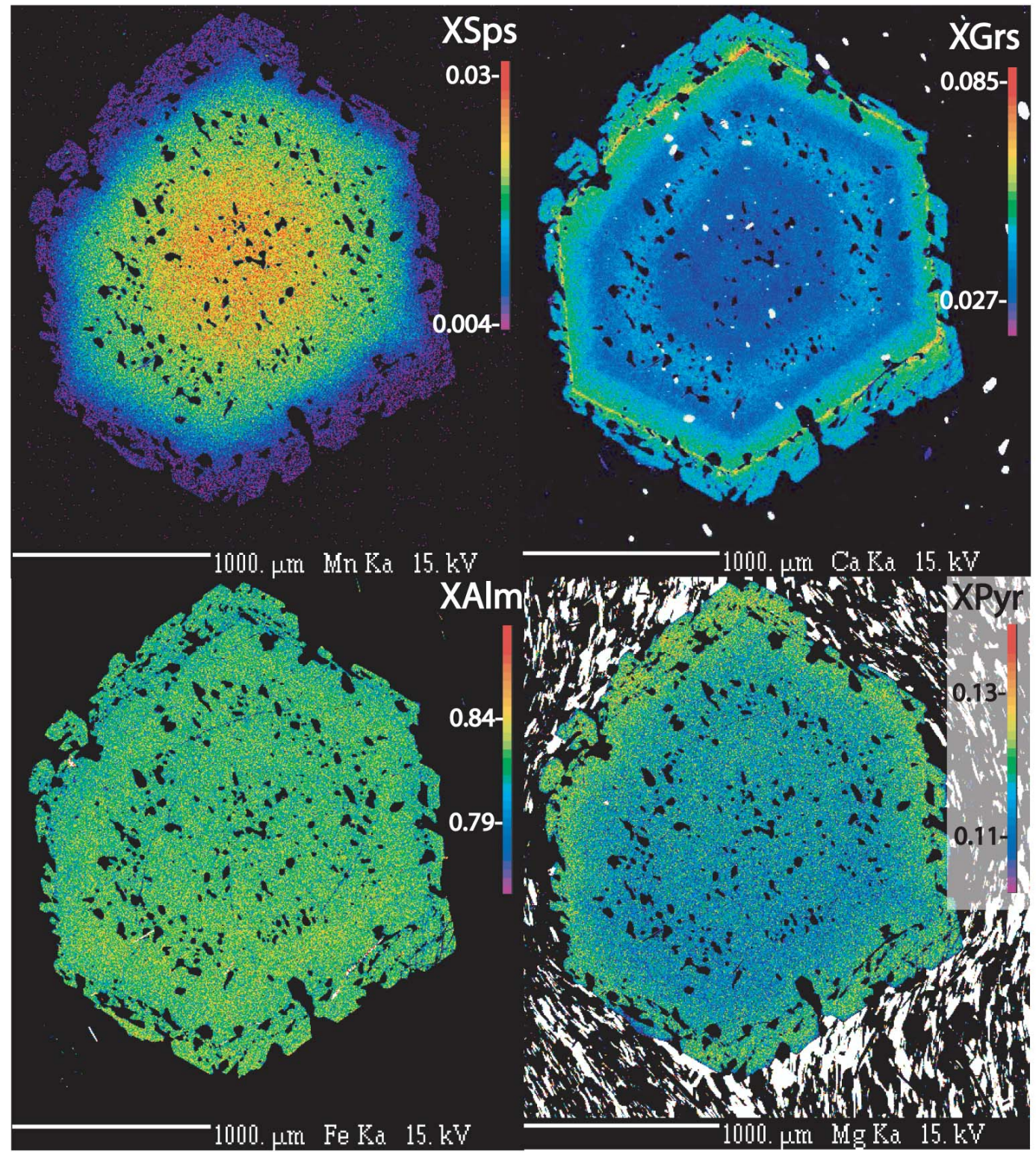

Figure 32 


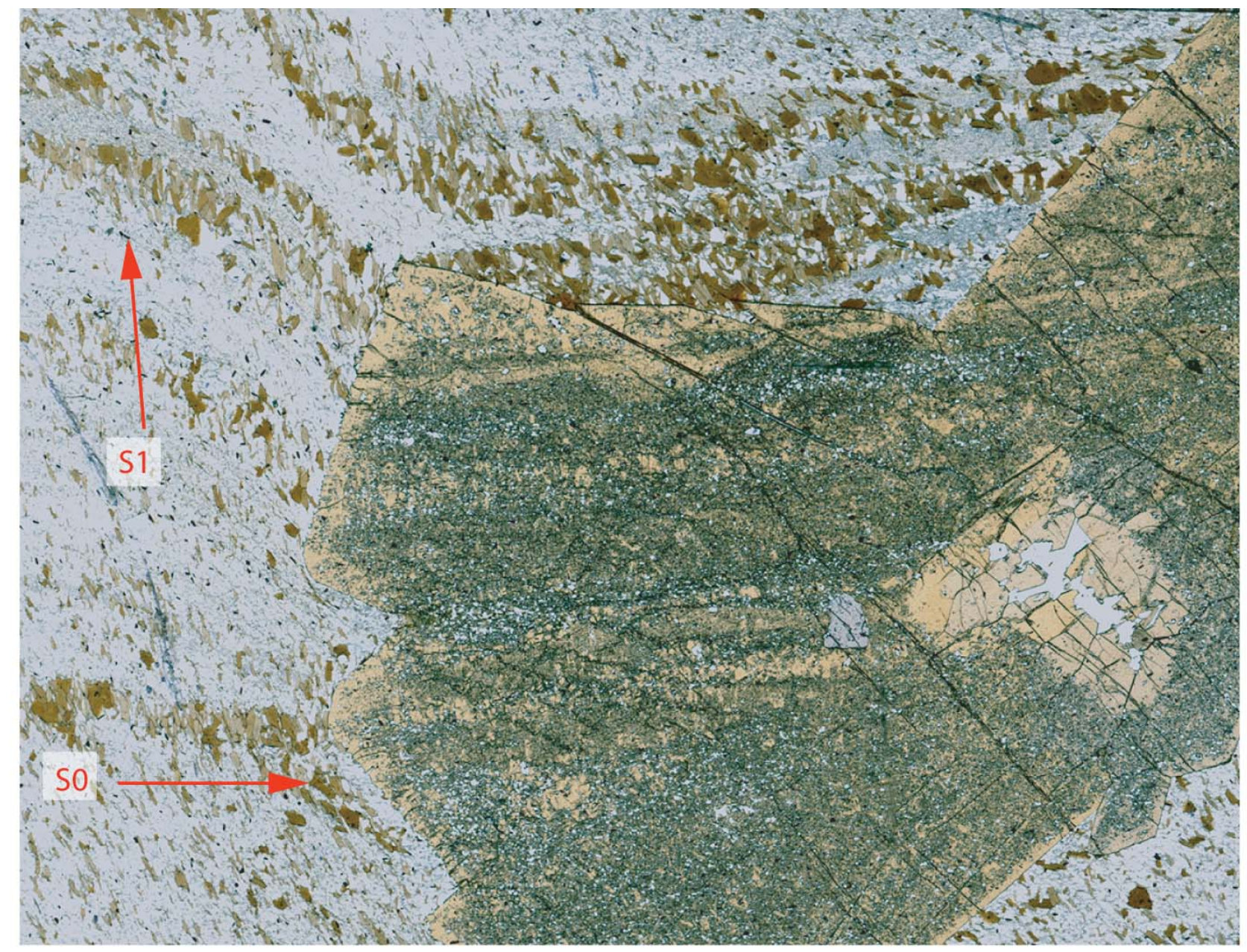

Figure 33 


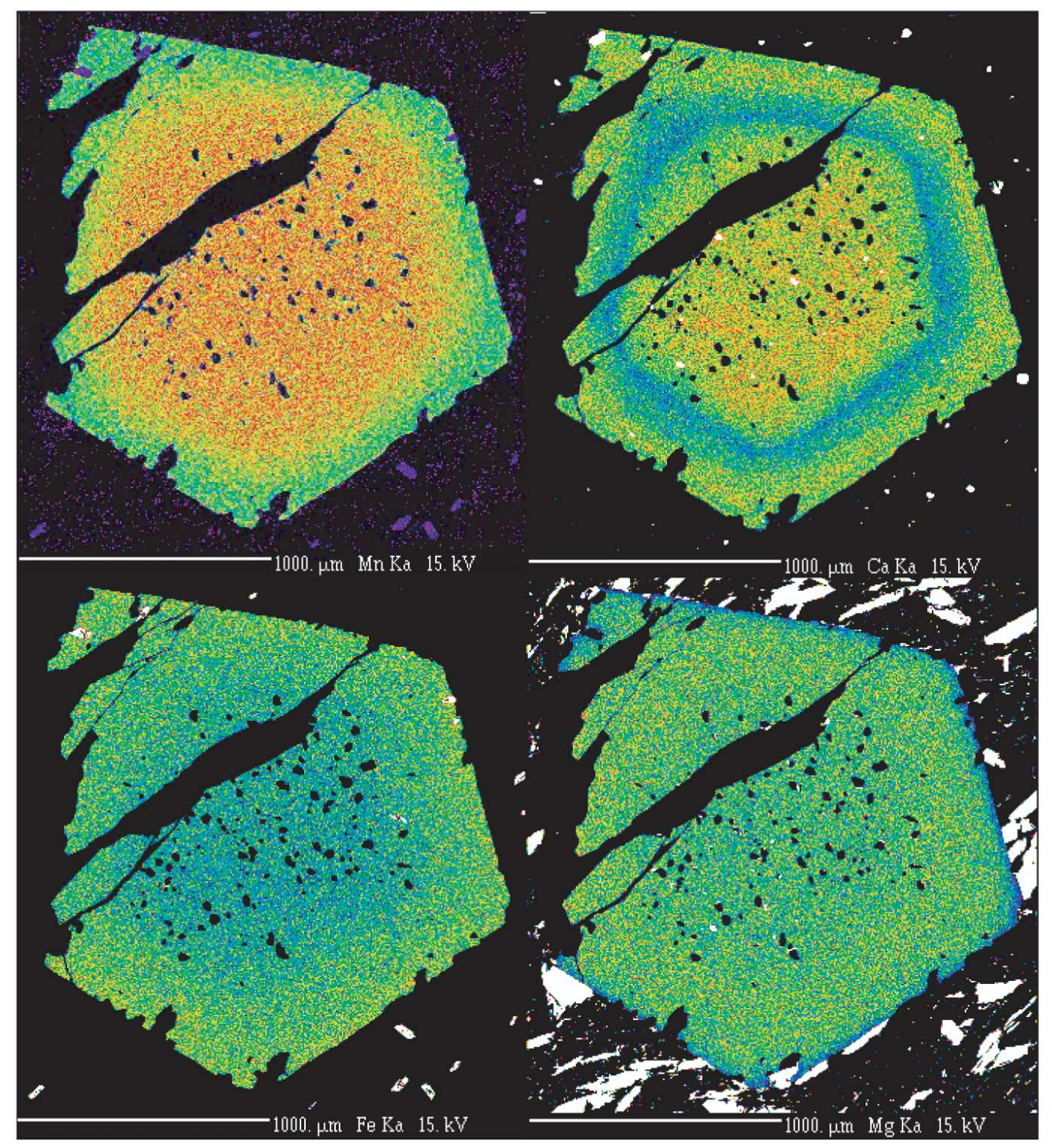

Figure 34 


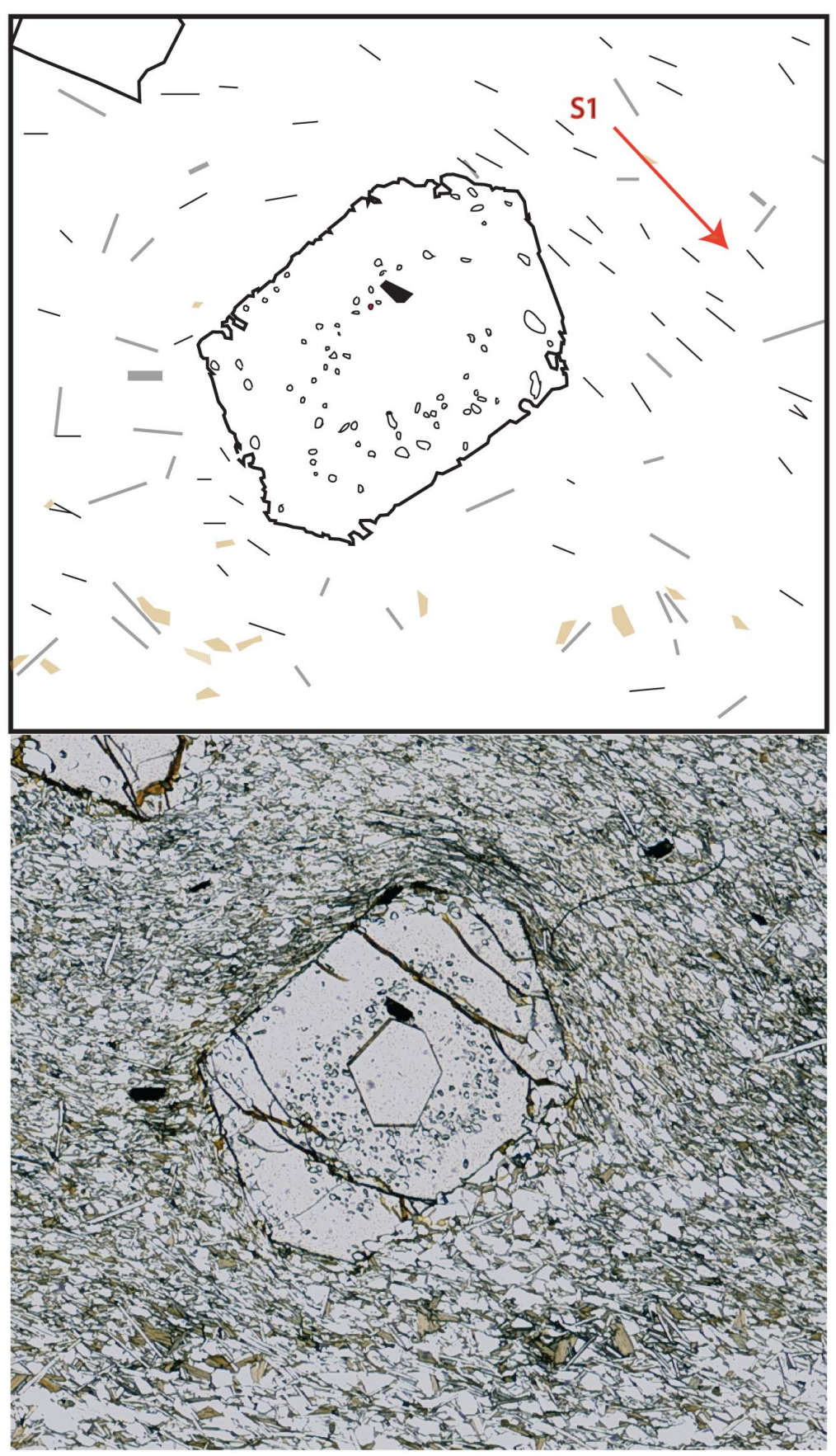

Figure 35 


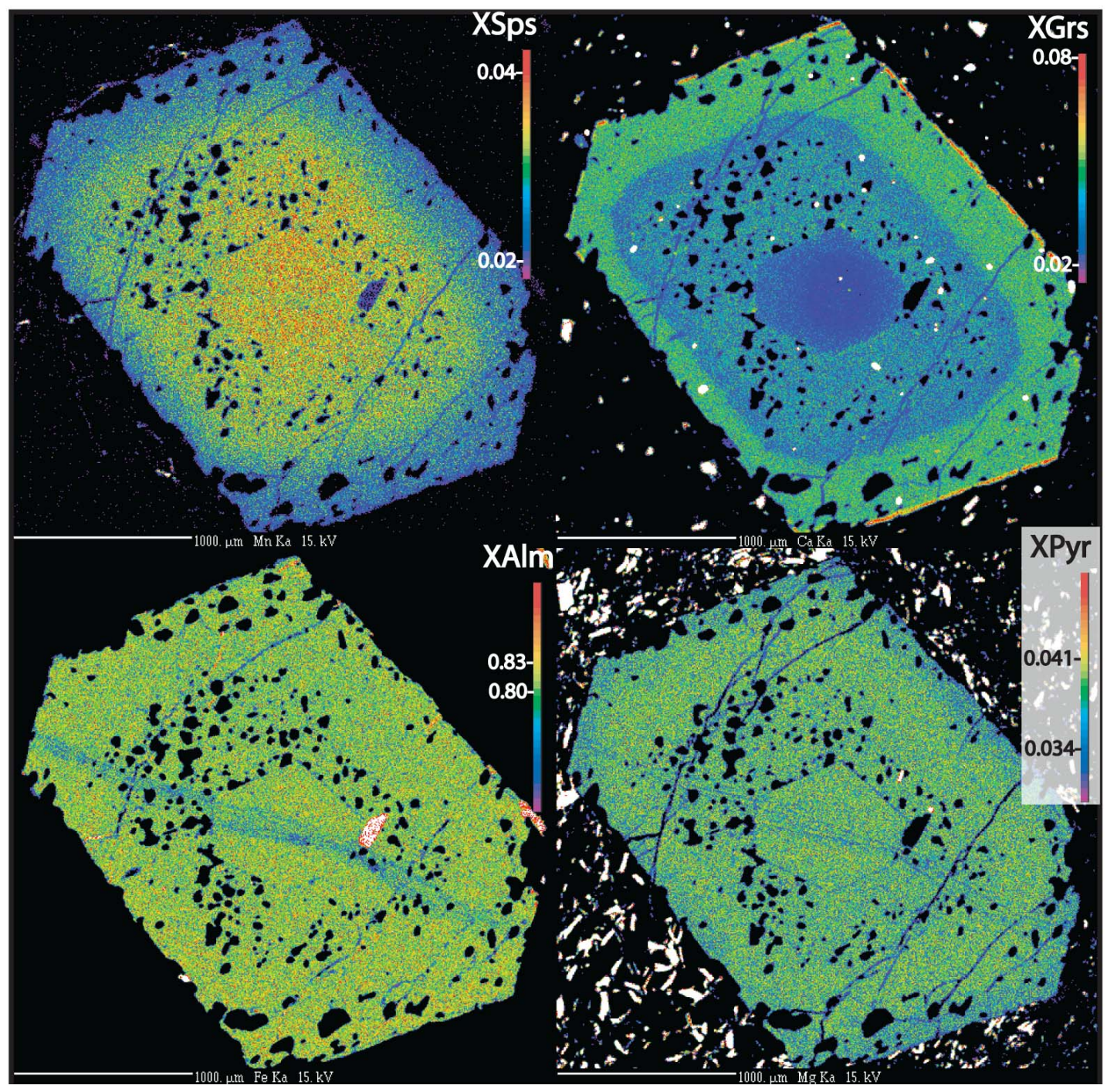

Figure 36 


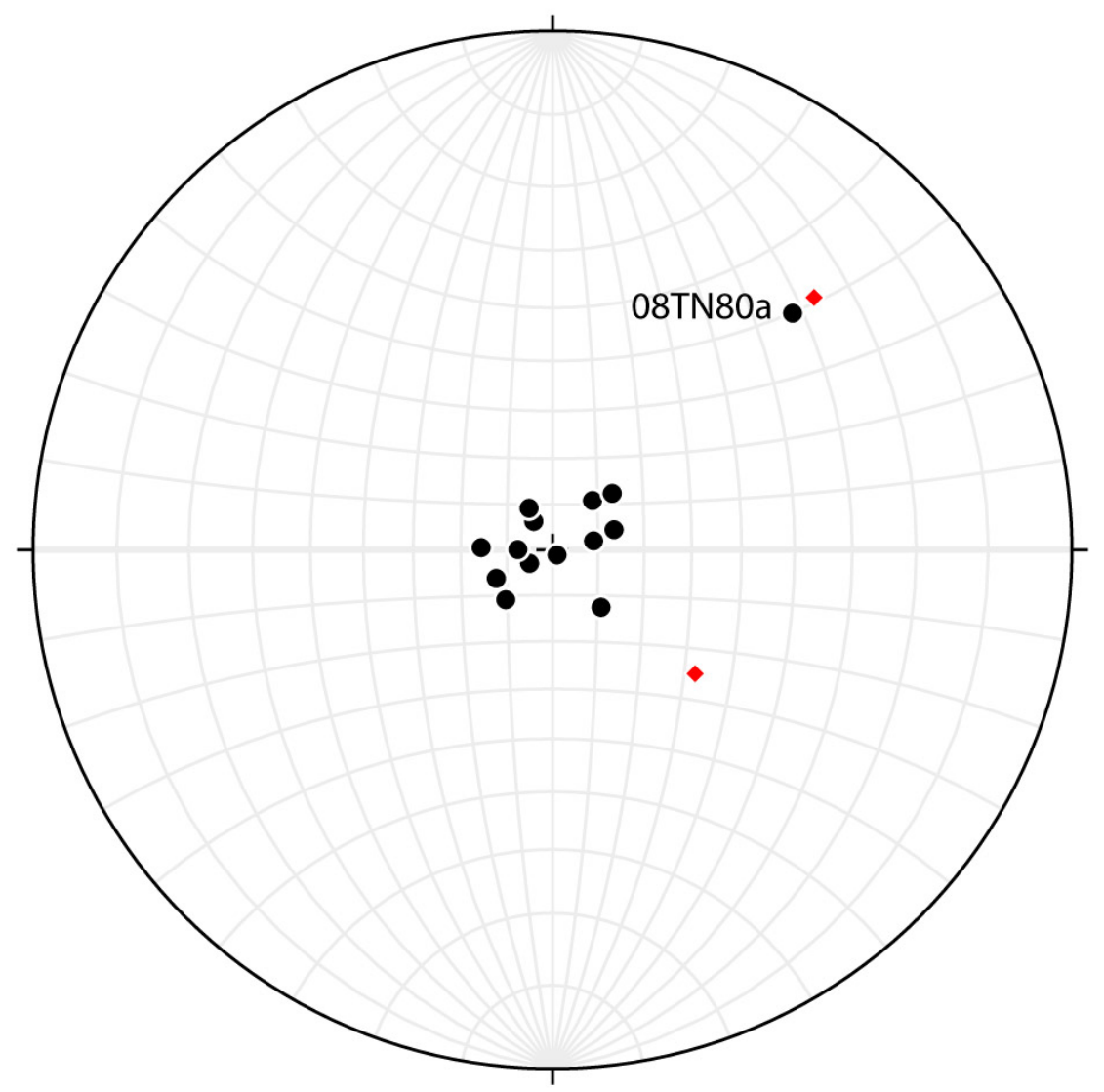

Figure 37 

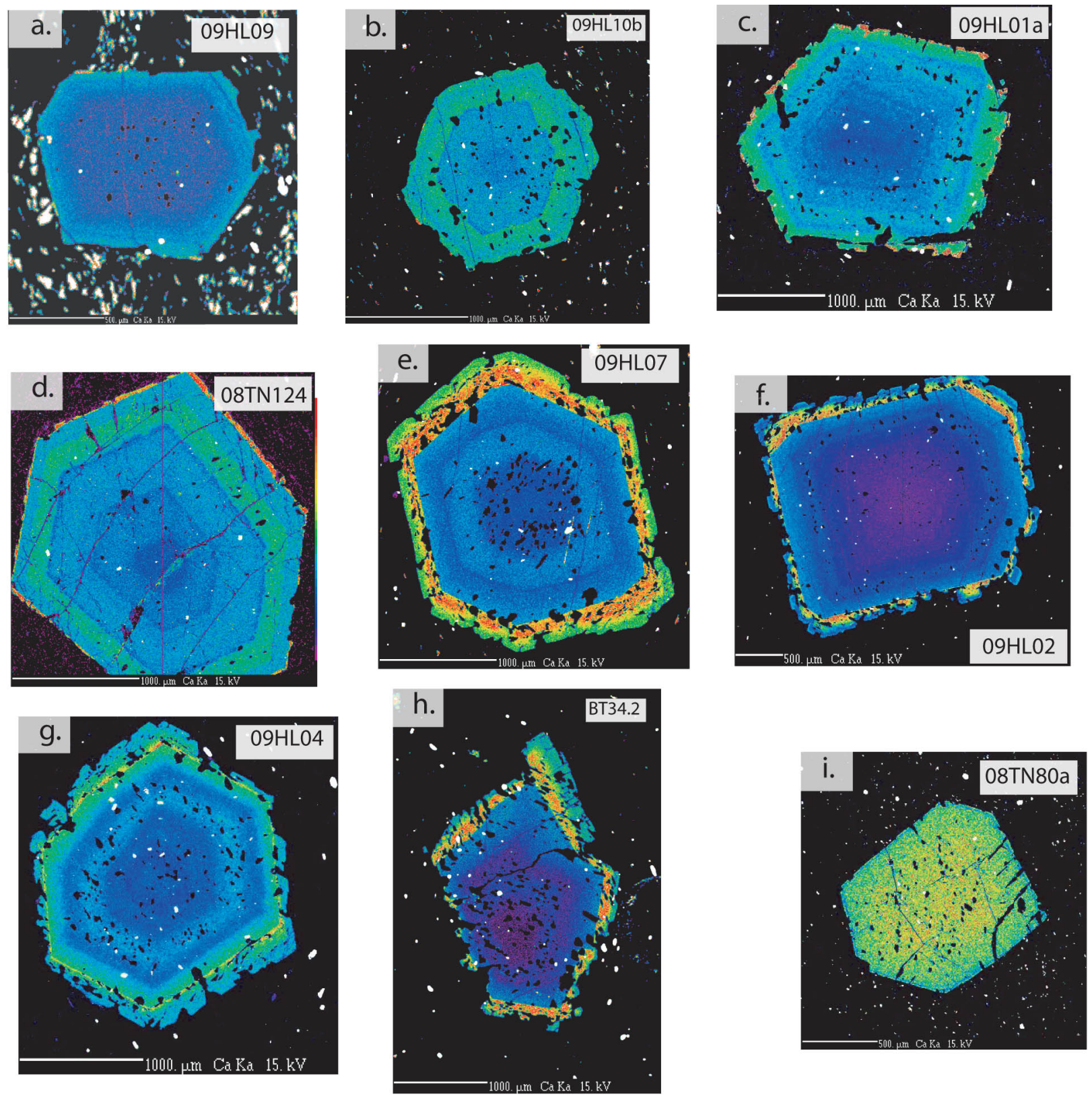

Figure38 

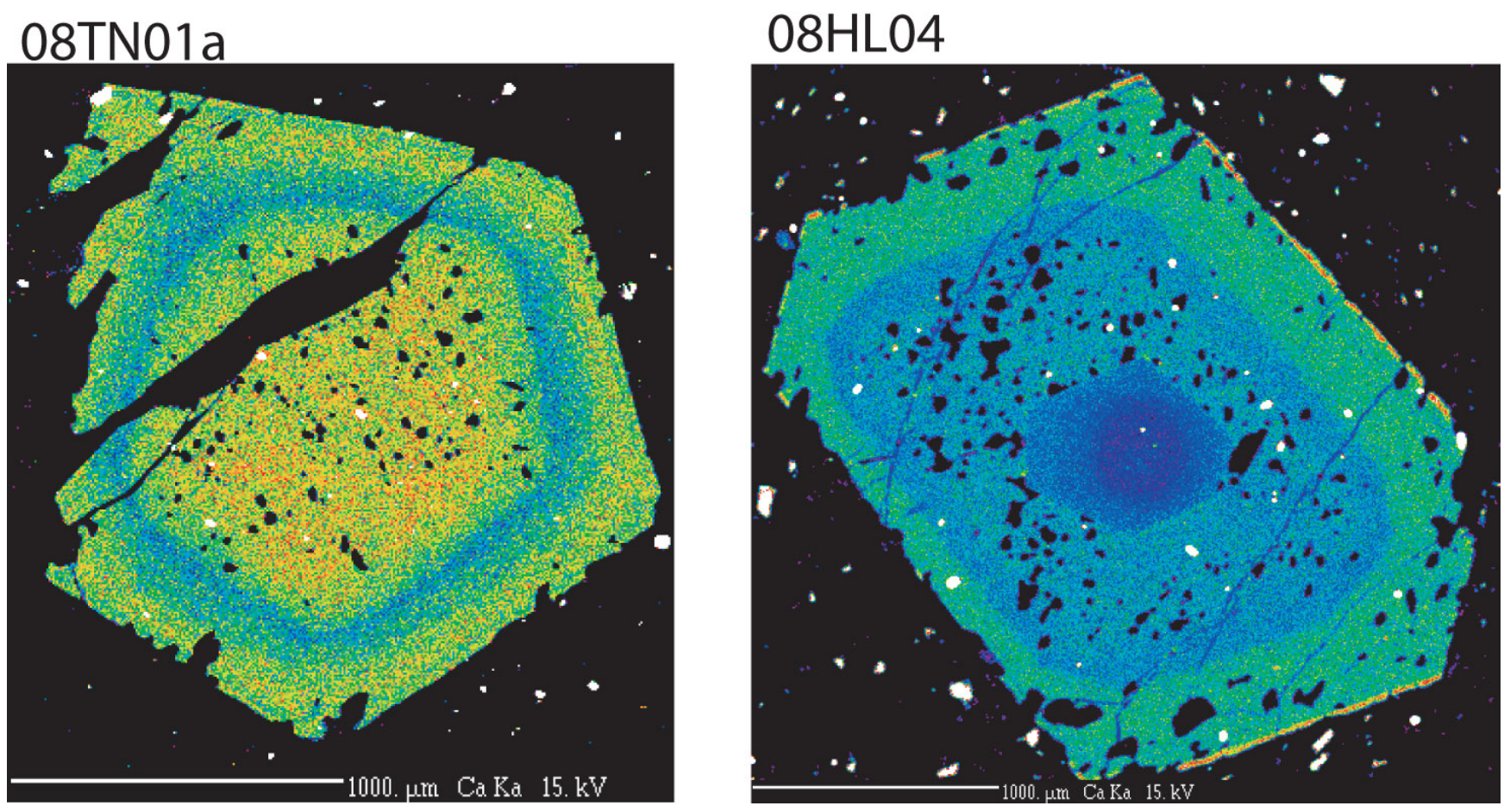

Figure $38 b$ 


\begin{tabular}{|l|c|c|c|c|}
\cline { 2 - 5 } \multicolumn{1}{c|}{} & $\begin{array}{c}\text { Metamorphic } \\
\text { Zone }\end{array}$ & $\begin{array}{c}\text { Elemental } \\
\text { Spot }\end{array}$ & $\begin{array}{c}\text { Ages (Ma) } \\
\text { Lu-Hf }\end{array}$ & S \\
\hline Snow Peak & & & & \\
\hline 08 TN-80a & Garnet & G B M P1 & $1085 \pm 2.4$ & S2 \\
\hline 09 HL-09 & Garnet & G B M P1 Cl & $1314 \pm 2.3$ & S1 \\
\hline 09 HL-10b & Staurolite & G P1 M B Cl & $1198 \pm 79$ & S1 \\
\hline 08 TN-124b & Staurolite & G B M P1 Cl & $1255 \pm 28$ & S1 \\
\hline 09 HL-01a & Staurolite & G St M B Cl & & S1 \\
\hline 09 HL-07 & Staurolite & G St B M P1 & & S1 \\
\hline 08 BM-216 & Ky/St & G St B M P1 & & S1 \\
\hline 09 HL-02a & Ky/St & G St M B & & S1 \\
\hline BT34.2 & Ky/St-Chl out & G St P1 M B & & S1 \\
\hline 09 HL-04b & Ky/St-Chl out & G St M B & $1206.6 \pm 8.4$ & \\
\hline
\end{tabular}

\begin{tabular}{|l|c|c|c|c|}
\hline \multicolumn{1}{|l|}{ Clarkia } & \multicolumn{3}{|l|}{} \\
\hline 08 TN-01a & Staurolite & G St M B P1 & $1064 \pm 10$ & S1 \\
\hline 08HL-04 & Ky/Sil & G B M P1 & $\begin{array}{c}\text { Rim: } 1102 \pm 43 \\
\text { Core: } 1347 \pm 10 \\
\text { Mixed: } 1306 \pm 18\end{array}$ & S1 \\
\hline
\end{tabular}

Table 1 


\begin{tabular}{|c|c|c|c|c|c|c|c|c|c|c|}
\hline \multirow[b]{3}{*}{ M1 } & \multicolumn{2}{|c|}{ Garnet Zone } & \multicolumn{4}{|c|}{ Staurolite Zone } & \multicolumn{4}{|c|}{ Kyanite/Staurolite Zone } \\
\hline & 08TN80a & 09 HL09 & 09HL10b & 08TN124 & 09HL01a & 09HL07 & 08BM216 & 09HL02a & BT34.2 & 09HL04b \\
\hline & N/A & $\begin{array}{c}\text { Majority of grt } \\
\text { growth }\end{array}$ & $\begin{array}{l}\text { Majority of grt } \\
\text { growth }\end{array}$ & $\begin{array}{l}\sim 93 \% \text { grt } \\
\text { growth }\end{array}$ & $\begin{array}{l}\text { Majority of grt } \\
\text { growth }\end{array}$ & $\begin{array}{l}\sim 56 \% \text { grt } \\
\text { growth }\end{array}$ & $\begin{array}{l}\sim 80 \% \text { grt } \\
\text { growth }\end{array}$ & $\begin{array}{l}\sim 69 \% \text { grt } \\
\text { growth }\end{array}$ & $\begin{array}{l}\sim 62 \% \text { grt } \\
\text { growth }\end{array}$ & $\begin{array}{l}\sim 66 \% \text { grt } \\
\text { growth }\end{array}$ \\
\hline D1 & N/A & S1 & S1 & S1 & s1 & s1 & S1 & S1 & S1 & S1 \\
\hline M2 & $\begin{array}{l}\text { All grt } \\
\text { growth }\end{array}$ & $\begin{array}{l}\text { minimal grt } \\
\text { growth }\end{array}$ & $\begin{array}{l}\text { minimal grt } \\
\text { growth }\end{array}$ & $\begin{array}{l}\sim 7 \% \text { grt } \\
\text { growth }\end{array}$ & $\begin{array}{l}\text { minimal grt } \\
\text { growth }\end{array}$ & $\begin{array}{l}\sim 44 \% \text { grt } \\
\text { growth }\end{array}$ & $\begin{array}{l}\sim 20 \% \text { grt } \\
\text { growth }\end{array}$ & $\begin{array}{l}\sim 31 \% \text { grt } \\
\text { growht }\end{array}$ & $\begin{array}{l}\sim 38 \% \text { grt } \\
\text { growth }\end{array}$ & $\begin{array}{l}\sim 34 \% \text { grt } \\
\text { growth }\end{array}$ \\
\hline D2 & $\mathrm{S} 2$ & $\begin{array}{c}\mathrm{S} 2= \\
\text { crenulation } \\
\text { cleavage }\end{array}$ & $\begin{array}{c}\mathrm{S} 2= \\
\text { crenulation } \\
\text { cleavage }\end{array}$ & $\begin{array}{c}\mathrm{S} 2= \\
\text { crenulation } \\
\text { cleavage }\end{array}$ & $\begin{array}{c}\mathrm{S} 2= \\
\text { crenulation } \\
\text { cleavage \& } \\
\text { strain } \\
\text { shadows }\end{array}$ & $\begin{array}{c}\mathrm{S} 2= \\
\text { crenulation } \\
\text { cleavage }\end{array}$ & $\begin{array}{l}\mathrm{S} 2=\text { strain } \\
\text { shadows }\end{array}$ & $\begin{array}{l}\text { S2 }=\text { strain } \\
\text { shadows }\end{array}$ & $\begin{array}{c}\mathrm{S} 2= \\
\text { crenulation } \\
\text { cleavage }\end{array}$ & $\begin{array}{c}\mathrm{S} 2= \\
\text { crenulation } \\
\text { cleavage }\end{array}$ \\
\hline
\end{tabular}

Table 2 
Figure 1. Geological map of the region where the study area is located in northern Idaho. The Snow Peak area where most of the samples were collected is outlined in black and is the main study area as seen in Fig. 2. The area where extra samples were collected to use for comparison near Clarkia, as seen in Fig. 3, is also outlined in black. This map was modified after Lewis et al. (2007) and is based on original mapping by Anna Hietanen (1956).

Figure 2. This is a geologic map of the study area near Snow Peak displaying the samples collected for this study listed in Table 1. Also mapped are the different metamorphic zones separated by M2 isograds. This map was a modified from Lewis (2007) and Neshiem (2009).

Figure 3. Geologic Map of the Clarkia area where three samples to be used for comparison were collected. Modified after Lewis et. al. (2007) and Neshiem (2009); isograds are from Hietanen, 1984.

Figure 4. An example of a pseudomorph taken from sample 09HL02 located in the the Kyanite + Staurolite zone consisting mostly of coarse, randomly arranged muscovite grains. It is thought this was originally staurolite due to the similar shape it has, and also there is M2 staurolite that nucleated just above the pseudomorph. The matrix consists mainly of biotite, muscovite, and quartz that wraps around the M2 minerals indicating that growth of this crystal must have been pre/syn-kinematic.

Figure 5. This is a photo taken from sample 08TN80a in ppl. Note how the original quartz rich and argillaceous bedding layers are still distinguishable (S0). The matrix fabric S2 defined by the parallel alignment of matrix minerals and graphite trails is oblique to S0. Garnet porphyroblasts cross-cuts the matrix so garnet growth must have been post kinematic.

Figure 6. Schematic figure of a garnet in sample 08TN80a. The dominate foliation, S2, is defined by the parallel alignment of matrix minerals. Original bedding is still present in this sample and is labeled S0. A better photograph depicting S0 in this sample can be seen in Fig. 5. Garnet growth cross-cuts the matrix and has little effect on matrix foliation indicating growth was syn-post kinematic. Biotite crystals have no preferred orientation, indicating growth was post kinematic.

Figure 7. Semi-quantitative garnet maps from sample 08TN80a showing distribution of composition. Warmer colors are higher concentrations, and cooler colors are lower concentrations. The resulting maps are as follows: (a) $\mathrm{Mn}$, (b) $\mathrm{Ca}$, (c) Fe, (d) $\mathrm{Mg}$. Notice how there are few signs of multiple episodes or changing metamorphic conditions except 
for changes at the rim where there is a distinct low $\mathrm{Mn}$, low $\mathrm{Ca}$, high $\mathrm{Fe}$, low $\mathrm{Mg}$ zone. Note in figure $7 \mathrm{~d}$ that the inclusions inside of the garnet are aligned in a preferred orientation parallel to the matrix foliation.

Figure 8. This figure shows the crenulation foliation in 09HL09, S2, in red that can be seen best with the naked eye in reflected daylight. S1/S0 is also labled and is defined by compositional layering and the parallel alignement of matirx minerals.

Figure 9. A schematic figure of a garnet in sample 09HL09. The dominant matrix foliation for this sample is $\mathrm{S} 1 / \mathrm{S} 0$. S1/S0 is defined by compositional layering and by the alignment of inclusions in the garnet porphyroblast. S2 is a crenulation cleavage present throughout the entire sample better seen in Fig. 8. Inclusions inside the garnet are aligned with S1 indication that growth occurred during the development of S1 during the M1 event.

Figure 10. Garnet maps from sample 09HL09 showing distribution of Mn, Ca, Fe, and $\mathrm{Mg}$. The warmer colors indicate higher concentrations and the cooler colors indicate lower concentrations. Fig. 10a is the Mn map, and shows the general trend of $\mathrm{Mn}$ composition in garnets. Fig $10 \mathrm{~b}$ is the Ca map that has 3 zones. There are lower concentrations in the core, followed by a slight increase nearing the rim, and then a distinct high $\mathrm{Ca}$ rim at the outermost edge highlighted by arrows. Fig. 10c and 10d represent $\mathrm{Fe}$ and $\mathrm{Mg}$ and displays uniform composition throughout. The $\mathrm{Mg}$ map, however, does show a unique feature at the top left and bottom right corners where there is a dramatic increase in the cracks the arrows are pointing to.

Figure 11. A photomicrograph of 09HL10b showing the sericite pseudomorph (lower left) and the matrix displaced around it. The earlier labeled S1 foliation has been preserved as quartz rich layers inside of the pseudomorph. Although S2 crenulation deformation is not obvious in this figure, it is labeled based on alignment of ilmenite and fold hinges found throughout the sample.

Figure 12. Schematic cartoon and photomicrograph of 09HL10b. S1 is the main matrix foliation. Notice how the quartz inclusions inside the garnet porphyroblast are mostly aligned with S1. Also note that some biotite crystals are aligned with S1 and some (shades of light brown in schematic cartoon) are randomly oriented suggesting growth was syn- to post-kinematic.

Figure 13. Garnet maps of sample 09HL10b showing relative concentrations of $\mathrm{Mn}, \mathrm{Ca}$, $\mathrm{Fe}$, and $\mathrm{Mg}$ concentrations. Warmer colors indicate higher concentrations and cooler colors indicate lower concentrations. 13a is the Mn map, and shows the typical trend of 
Mn composition in garnets. 13b, the Ca map, has multiple zones. There are lower concentrations in the core, followed by a slight increase that gradually decreases toward the rim where there are patches of high $\mathrm{Ca}$ at the outermost edge of the rim pointed out by white arrows. $13 \mathrm{c}$ and $13 \mathrm{~d}$ represent $\mathrm{Fe}$ and $\mathrm{Mg}$ and display mostly uniform composition throughout.

Figure $14 \mathrm{a}, \mathrm{b}$. This is a schematic cartoon of a photomicrograph taken from sample 08TN124b. The matrix foliation is S1 also parallel to compositional zoning in the sample. S2 is not obvious from this photo, but the strain shadow surrounding the garnet and highlighted in grey in Fig. 14a is sheared, suggesting a component of simple shear in this area.

Fig. 14c. Sample 08TN125 collected near 08TN124 showing the Si parallel to the dominate foliation S1.

Figure 15. Garnet maps from sample 08TN124b showing distribution of $\mathrm{Mn}, \mathrm{Ca}, \mathrm{Fe}$, and $\mathrm{Mg} .15 \mathrm{a}$ is the Mn map which shows a usual trend for garnets with higher concentrations in the core and lower concentrations at the rim with no sharp zones. An interesting feature is how the Mn concentrations are lower near the fractures in the garnet. $5 \mathrm{~b}$ is the Ca map which has at least 7 concentric zones. The general trend is from lower concentrations in the core to a high concentration of $\mathrm{Ca}$ at the rim. Figs. $15 \mathrm{c}, \mathrm{d}$ are of Fe and $\mathrm{Mg}$ and show relative uniform concentration throughout.

Figure 16. A schematic cartoon of a photomicrograph taken from sample 09HL01. The matrix is displaced around the garnet suggesting that growth was pre-syn kinematic. The dominant foliation is labeled S1. The pressure shadow is sheared around the garnet highlighted in gray. This is the attributed to the development of S2.

Figure 17. This is a ppl and xpl photomicrograph of a partial staurolite pseudomorph seen in sample 09HL01a. The sericite adjacent to the staurolite porphyroblast associated with retrograde metamorphism is more apparent in xpl. Notice the surrounding muscovite is coarse grained and randomly oriented.

Figure 18. Garnet maps from sample 09HL01 showing relative distribution of $\mathrm{Mn}, \mathrm{Ca}$, $\mathrm{Fe}$, and $\mathrm{Mg}$. Warmer colors are higher concentrations and cooler colors are lower concentrations. 15a is the Mn map and shows a typical bell curve graph with high concentration in the core and low concentrations at the rim. 15b is the $\mathrm{Ca}$ map and shows multiple concentric zones of high and low concentrations. The general trend is from lower concentrations in the center to higher concentrations at the rim. There is a zone of drastically higher Ca concentrations at the outermost edge of the rim. 15c, d show the $\mathrm{Mg}$ 
and $\mathrm{Fe}$ concentrations and both are relatively uniform throughout the garnet. The Fe decreases at the edge of the rim which is probably due to the drastic increase in $\mathrm{Ca}$.

Figure 19. A schematic cartoon highlighting fabrics of the photomicrograph taken from sample 09HL07. An early fabric, S0, has been preserved as the alignment of quartz and ilmenite inclusions in the garnet's core and is also parallel to compositional zoning in the sample. The dominant matrix foliation for this sample is $\mathrm{S} 1$.

Figure 20. This is a photomicrograph taken from sample 09HL07 highlighting the 2 different foliations present. S0, the compositional layering, is shown in this figure as alternating biotite rich and muscovite rich layers, and is also aligned with ilmenite inclusions inside of garnet and staurolite porphyroblasts. S1 is the main matrix foliation.

Figure 21. Garnet maps from sample 09HL07 showing relative distribution of $\mathrm{Mn}, \mathrm{Ca}$, Fe, and Mg. 21a is the Mn map and shows the typical trend of Mn composition in garnets. There is a distinct zone where the concentration drops suddenly near the rim also marked by a concentric zone of quartz inclusions. $22 \mathrm{~b}$ is the Ca map and shows dramatic zoning from core to rim. The core has the lowest concentration, and then gets higher, lower, then higher again before there is a dramatic increase at the rim also marked by the zone of quartz inclusions, and then decreases slightly towards the outermost edge of the rim. The Fe and Mg maps are almost identical and show fairly uniform concentrations throughout the garnet except where the Ca concentration increases, there is a slight decrease in both $(21 \mathrm{c}, \mathrm{d})$. This probably due to the increase of $\mathrm{Ca}$ ions.

Figure 22. This is a schematic cartoon and a photomicrograph of sample 08BM216. An earlier foliation has been preserved as aligned inclusions inside of the garnet porphyroblasts and is labeled $\mathrm{Si}$. The main foliation of this sample, $\mathrm{S} 1$, makes up the matrix foliation. There are distinct pressure shadows that have been sheared adjacent to the garnets highlighted in grey in the top photo. This shear-strain shadow is attributed to the M2/D2 event and evidence for S2.

Figure 23. Photomicrograph of a staurolite porphyroblast in sample 08BM216. Notice the dendritic rims growing out around quartz in the matrix. There are a few distinct zones of inclusions. The core of the staurolite twin is clustered with quartz inclusions that are aligned in a different orientation than the matrix. Then there is an inclusion free zone nearing the rim before the rim grows out in a dendritic pattern around the quartz inclusions in the matrix.

Figure 24. A photomicrograph of kyanite in sample 08BM216. It grew inside of a coarse-grained muscovite pseudomorph that caused it to have unusual growth textures. 
Figure 25. False colored images of elements $\mathrm{Mn}, \mathrm{Ca}, \mathrm{Fe}$, and $\mathrm{Mg}$ in sample 08BM216 produced by ImageJ. Figure a. shows the Mn map, and shows a general trend typical of Mn composition in garnets. $\mathrm{B}$ is the Ca map and shows two distinct zones of relatively low concentrations in the core all the way to the rim where there is a zone of much higher $\mathrm{Ca}$ concentration. C. and D. are the Fe and $\mathrm{Mg}$ maps that show fairly uniform compositions, except at the rim both decrease slightly.

Figure 26. This is a schematic cartoon and a photomicrograph of sample 09HL02 located in the kyanite/staurolite zone. The matrix foliation is labeled S1. The pressure shadows around the garnet are sheared. That is attributed to the effects of the M2/D2 event. There is a coarse-grained muscovite pseudomorph directly above the garnet. There is no parent mineral left, but it is thought to be staurolite due to the shape and that there is an M2 staurolite nucleated above. (See Fig.4)

Figure 27: Garnet maps of sample 09HL02a showing relative concentrations of $\mathrm{Mn}, \mathrm{Ca}$, $\mathrm{Fe}$, and $\mathrm{Mg}$. Warmer colors are higher concentrations and cooler colors are lower concentrations. Fig. 27a is the Mn map showing a general trend for Mn concentration in garnets. There is a distinct zone of lower Mn concentration at the rim marked also by an inclusion rich zone. Fig. $27 \mathrm{~b}$ shows a general trend of low concentrations in the core radiating out to higher concentrations toward the inclusion rich rim. There are many concentric zones of slightly higher and lower concentrations. At the rim there is a dramatic increase and then an equally dramatic decrease at the outermost edge of the rim. Fig. $27 \mathrm{c}, \mathrm{d}$ is the Fe and $\mathrm{Mg}$ maps that show relatively uniform concentrations throughout except at the rim where the abrupt increase in $\mathrm{Ca}$ begins.

Figure 28: A schematic cartoon of a photomicrograph taken from sample BT34.2. The matrix foliation is labeled S1. S1 is also preserved inside of the garnet porphyroblasts. The compositional layering, S0, is oblique to S1. There are S2 crenulation cleavages in sample BT34.2, but not obvious in this figure. This sample was reworked from S1 to S2 but was not completely transposed before metamorphism ceased.

Figure 29. This is a photomicrograph taken from sample BT34.2. It shows all three foliations present in this sample. S0 is the compositional layering that has been highly deformed. S1 is the dominant matrix foliation. S2 has overprinted S1, leaving behind a crenulation cleavage.

Figure 30. Garnet maps from sample BT34.2 showing relative concentrations of $\mathrm{Mn}, \mathrm{Ca}$, $\mathrm{Fe}$, and $\mathrm{Mg}$. 30a shows the typical trend for $\mathrm{Mn}$ in a garnet. There is a boundary towards the rim where the concentration drops. $30 \mathrm{~b}$ shows the Ca concentration. There are four 
zones in the core starting with the lowest concentrations, followed by an increase, a decrease, and then another increase before the boundary where $\mathrm{Ca}$ increases drastically and finally decreases at the outermost edge of the rim. 30c, d show fairly uniform Fe and $\mathrm{Mg}$ concentrations.

Figure 31. A schematic cartoon and a photomicrograph of sample 09HL04. The dominant matrix fabric is labeled S1. There may be an internal foliation preserved inside of the garnet, but it is hard to notice in this photomicrograph. It is more apparent in Figure 32.

Figure 32. Garnet maps sample 09HL04b showing relative concentrations of $\mathrm{Mn}, \mathrm{Ca}$, $\mathrm{Mg}$, and Fe. 32a is the Mn map that shows typical distribution for a garnet. There is a boundary where there is an abrupt drop in Mn towards the rim. 32b is the Ca map and it shows many zones. It starts with the lowest concentration in the core, then increases, decreases, and increases again before an extreme increase in Ca toward the rim and then finally gradually decreases before the outer most edge of the rim. $32 \mathrm{c}$ is the Fe map, and it shows fairly even distribution. $32 \mathrm{~d}$ is the $\mathrm{Mg}$ map and it has higher concentrations starting at the same boundary as $\mathrm{Ca}$. Note the internal foliation preserved inside the garnet subparallel to the matrix foliation.

Figure 33: A photomicrograph taken of sample 08TN01a. The matrix foliation is labeled $\mathrm{S} 1$ and is nearly perpendicular to compositional layering, S0. S0 has been preserved as inclusion trails inside of the staurolite porphyroblast.

Figure 34: Garnet maps from sample 08TN01showing relative concentrations of $\mathrm{Mn}, \mathrm{Ca}$, $\mathrm{Fe}$, and $\mathrm{Mg}$. Warmer colors indicate higher concentrations and cooler colors lower. 34a shows Mn concentration typical for garnet growth in pelites. $34 \mathrm{~b}$ shows the Ca content for garnet. The core has a high concentration followed by a ring of lower concentration, and the back to higher at the rim. There is no evidence for two growth events in this garnet like in the other samples. 34c shows the Fe content, which has slightly lower concentrations in the core than the rim. $34 \mathrm{~d}$ shows the $\mathrm{Mg}$ content, which is mostly uniform except for the outer most edge where there is a distinct zone of lower concentration.

Figure 35: A photomicrograph and a schematic sketch of sample 08HL04. The matrix foliation is labeled S1. There is no evidence of S2 in this photo, but in micaceous layers throughout the sample, a slight crenulation cleavage can be seen.

Figure 36. Garnet maps from sample 08HL04 showing relative concentrations of $\mathrm{Mn}, \mathrm{Ca}$, $\mathrm{Fe}$, and Mg. 36a shows the Mn concentration typical for garnet growth in pelites. 36b shows the $\mathrm{Ca}$ content. There are four zones. The core has the lowest concentrations, 
followed by a slight increase, then another increase, and then the extreme rise in $\mathrm{Ca}$ concentration at the rim. 36c, d show the Fe and $\mathrm{Mg}$ concentrations and they are relatively uniform.

Figure 37. Stereonet showing lower hemispheric stereographic projections using the poles from planes function. The black circles are Snow Peak samples and the red diamonds are Clarkia samples. The Snow Peak samples that cluster in the center have been assigned $\mathrm{S} 1$ as the dominant matrix foliation. Sample 08TN80a plots away from most samples in the northwest quadrant and has a dominant foliation labeled S2. 08TN01 is the Clarkia sample that plotted right next to 08TN80a.

Figure 38. A series of garnet maps showing Ca content. (a-h) These garnet maps are set up in order from the lowest grade samples in the top left hand corner to the highest grade samples in the bottom center. Notice how the lower grade samples do have not high $\mathrm{Ca}$ rims indicative of the M2 event. Fig. $38 \mathrm{i}$ is the only sample that is entirely M2.

Figure 38b. The garnet maps showing relative Ca content for the two Clarkia samples.

Table 1. Table listing the samples in order of increasing metamorphic grade collected from the Snow Peak study area and two from the Clarkia area. Also listed are the Lu-Hf garnet ages obtained and the dominant matrix foliation identified.

Table 2. Table listing the affects from the earlier M1/D1 event and the later M2/D2 event. 